\title{
MINERALIZAÇÃO IN VITRO DE MATRIZES DE COLÁGENO ANIÔNICO DERIVADAS DE TECIDOS BIOLÓGICOS
}

Thelma Matuura de Batista

Tese apresentada ao Instituto de Química de São Carlos, da Universidade de São Paulo para obtenção do título de Doutor em Ciências (Química Analítica).

Orientadora: Prof ${ }^{\mathrm{a}}$. Dr. Ana Maria de Guzzi Plepis

São Carlos 


\section{Dedicatória}

Aos meus pais, Antonio Carlos e Catarina, pelo apoio e dedicação ao longo de toda minha vida.

As minhas irmãs Georgea, Gláucia, Carina e a minha sobrinha Giovanna que mesmo estando longe me apoiaram. 


\section{Agradecimentos}

À minha orientadora, Profa. Dr. Ana Maria de Guzzi Plepis, pelo apoio à pesquisa e pela confiança em mim depositada.

À Virginia Conceição Amaro Martins, pela amizade, incentivo, otimismo e pelo auxílio na elaboração deste trabalho.

À Cláudia Bernal e à Profa. Dr. Janice Perussi pelas análises de citotoxicidade in vitro.

À Oxetil e à Acecil pela esterilização das matrizes utilizadas nas análises de citotoxicidade in vitro.

Aos amigos de laboratório em especial à Fabiana e Marília pela amizade, paciência e incentivo.

A CAPES pela 6olsa concedida.

Ao pessoal do CAQVI em especial ao Carlos Bento e ao Márcio.

A todo pessoal da biblioteca e da seção de alunos em especial à Sílvia e a Andréia.

$\mathcal{A}$ todos aqueles que, porventura, não tenham sido citados nominalmente, e que tenham, de alguma forma, contribuído para este trabalho. 
"Que os esforços desafiem as impossibilidades. Lembrai-vos de que as grandes proezas da história foram conquistadas do que parecia impossivel".

Charles Chaplin 


\section{SUMÁRIO}

\section{LISTA DE FIGURAS}

LISTA DE TABELAS

LISTA DE ABREVIATURAS

RESUMO

ABSTRACT

1. INTRODUÇÃO

1.1. Biomateriais e engenharia de tecido ósseo

1.2. Tecido ósseo 22

1.3. Hidroxiapatita (HA) 23

1.4. Colágeno 24

1.5. Matrizes de colágeno (MC) 30

1.5.1. Tecidos biológicos como fonte para matrizes de colágeno 31

1.5.1.1. Pele Porcina (PP) 31

1.5.1.2. Pericárdio Bovino 32

1.5.1.3. Serosa Porcina 34

1.6. Mineralização do colágeno 36

2. OBJETIVOS 39 
3.2. Limpeza dos tecidos utilizados. 40

3.3. Preparação de matrizes de colágeno aniônico (hidrolisadas) 41

3.4. Mineralização das matrizes 42

3.5. Caracterização das matrizes 46

3.5.1. Calorimetria Exploratória diferencial (DSC) 46

3.5.2. Termogravimetria (TG) 46

3.5.3. Microscopia Eletrônica de Varredura (MEV) 46

3.5.4. Difração de raios $X(D R X)$ 47

3.5.5. Espectroscopia por energia dispersiva (EDS) 47

3.5.6. Espectroscopia no infravermelho (FTIR) 47

3.5.7. Avaliação do potencial de citotoxicidade in vitro 48

3.5.7.1. Cultura Celular 48

3.5.7.2. Método de difusão em ágar ... 50

4. RESULTADOS E DISCUSSÃO 52

4.1. Mineralização - Ensaio Piloto 52

4.2. Avaliação Macroscópica das matrizes. 55

4.2.1. Pele Porcina (PP) 55

4.2.2. Pericárdio Bovino. 57 


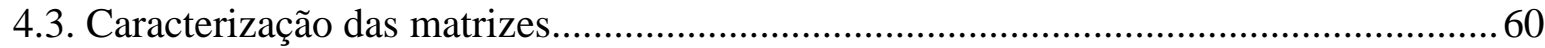

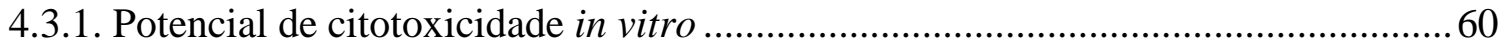

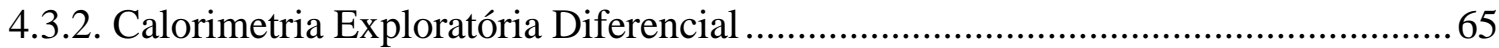

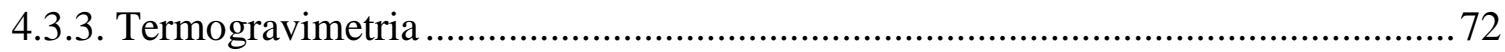

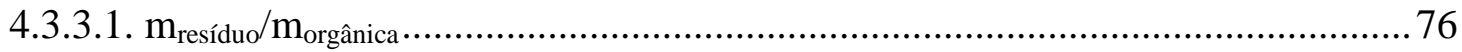

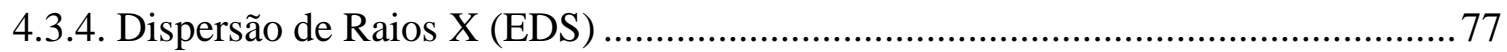

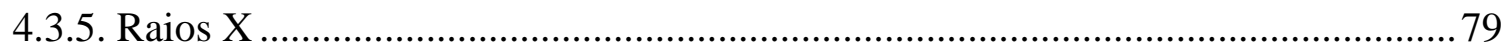

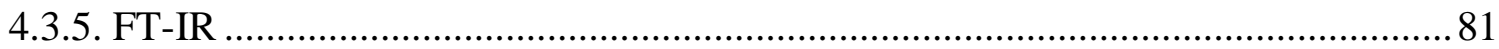

4.3.7. Microscopia Eletrônica de Varredura ........................................................................ 86

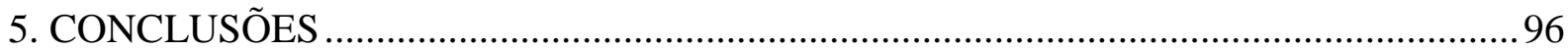

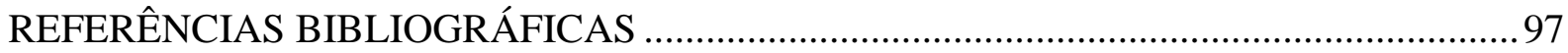

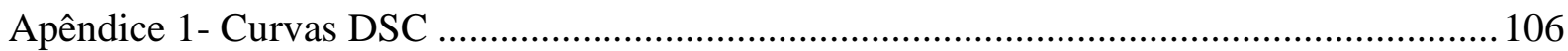

Apêndice 2 - Curvas Termogravimétricas ......................................................................... 109

Apêndice 3 - Espectros no infravermelho............................................................................ 112

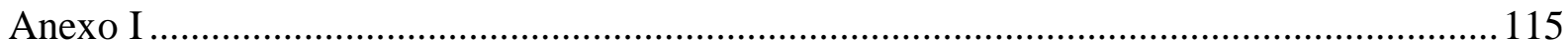




\section{LISTA DE FIGURAS}

Figura 1. Organização hierárquica do osso.

Figura 2. Arranjo atômico da hidroxiapatita. 23

Figura 3. Estrutura da molécula de colágeno. 25

Figura 4. Formação da fibrila de colágeno. 26

Figura 5. Representação da formação intramolecular e intermolecular do colágeno. 27

Figura 6. Esquema de agregação das moléculas de tropocolágeno para a formação da microfibrila.

Figura 7. Hidrólise alcalina dos grupos carboxiamidas dos resíduos de Asn e Gln. 29

Figura 8. Resultante de carga líquida para o tropocolágeno para colágeno nativo (pontilhado) e colágeno aniônico (preto) 29

Figura 9. Pele porcina. 32

Figura 10. Pericárdio bovino. 33

Figura 11. Diagrama da seção transversal do intestino delgado de suínos. 34

Figura 12. Aspecto macroscópico: (A) SIS desidratada e (B) serosa porcina. 35

Figura 13. Fotomicrografia por MEV de SIS (A) e serosa porcina (B). 35

Figura 14. Fluxograma da preparação das matrizes. 42

Figura 15. Cela dupla utilizada para mineralização das matrizes. 44

Figura 16. Método de imersão alternada. 45

Figura 17. Suspensão das células. 49

Figura 18. Câmara de Neubauer. 50 
Figura 19. Meio de cobertura com corante vermelho neutro (A) e matriz sendo colocada na placa de petri (B).

Figura 20. Curvas termogravimétricas do método $1,5 \mathrm{SBF}(-) 5$ dias e (-) 10 dias. 52

Figura 21. Curvas termogravimétricas de PP96SC em triplicata, obtida após a mineralização pelo método II.

Figura 22. Fotomicrografia por MEV de PP96SC, obtida pelo método da cela dupla termostatizada (aumento de 500 vezes).

Figura 23. Curvas termogravimétricas de PP96SC em triplicata obtida após mineralização pelo método III.

Figura 24. Fotomicrografia por MEV de PP96SC, obtida pelo método de imersão (aumento de 500 vezes). 55

Figura 25. Foto digital das matrizes (A) PPn, (B) PP96S e (C) PP96S mineralizada. 56

Figura 26. Foto digital das matrizes pré-tratadas com solvente orgânico: (A) PP96 e (B)

PP96C. 57

Figura 27. Foto digital das matrizes (A) PBn, (B) PB96 e (C) PB96C. 58

Figura 28. Foto digital das matrizes (A) SPn, (B) SP96 e (C) SP96C. 59

Figura 29. Avaliação macroscópica do controle positivo (A) e negativo (B). 60

Figura 30. Foto digital das células HEp-2 no controle positivo (A) e negativo (B). 61

Figura 31. Foto digital das matrizes derivadas de pericárdio bovino PB24 (A), PB24C (B), PB96 (C) e PB96C (D). 62

Figura 32. Foto digital das matrizes derivadas de serosa porcina SP24 (A) e SP24C (B), SP96 (C) e SP96C (D). 62

Figura 33. Foto digital das matrizes derivadas de pele porcina PP24S (A), PP24SC (B), PP96S (C) e PP96SC (D). 
Figura 35. Foto digital da avaliação macroscópica das matrizes derivadas de pele porcina PP24 (A), PP24C (B), PP96 (C) e PP96C (D).

Figura 36. Desnaturação do colágeno. 66

Figura 37. Curva representativa da determinação de Td por DSC.

Figura 38. Curvas DSC dos tecidos com ou sem hidrólise alcalina (96h) e mineralizados, (A) Pele Porcina, (B) Pericárdio Bovino e (C) Serosa Porcina. 68

Figura 39. Variação da Td de acordo com o tempo de hidrólise das matrizes (A) não mineralizadas e (B) mineralizadas; derivadas de PP (-), PB (-) e SP (-).

Figura 40. Curva TG/DTG das matrizes (-) sem tratamento, (-) hidrolisadas por 96h e (-) mineralizadas, - TG; … DTG. .73

Figura 41. Espectro de dispersão de raios X obtido da superfície da matriz PP96C. .78

Figura 42. Difratograma de raios X das matrizes (A) PP96C, (B) PB96C, (C) SP96C......... 80

Figura 43. Difratograma de raios $X$ de HA sintética não cristalina 81

Figura 44. Espectros no FTIR das matrizes PPn (A), PBn (B) e SPn (C). 82

Figura 45. Espectros no FTIR das matrizes PP96C (A), PB96C (B) e SP96C (C). 84

Figura 46. Fotomicrografias das matrizes PP24 (A), PP48(B), PP72 (C) e PP96 (D), aumento de 500 vezes. 86

Figura 47. Fotomicrografias das matrizes PB24 (A), PB48(B), PB72 (C) e PB96 (D), aumento de 500 vezes.

Figura 48. Fotomicrografias das matrizes SP24 (A), SP48(B), SP72 (C) e SP96 (D), aumento de 500 vezes. 88

Figura 49. Fotomicrografia da secção transversal de PP96 (A), PB96(B), aumento de 500 vezes e SP24, aumento de (C) 3500 vezes

Figura 50. Fotomicrografia da matriz PP24C (A), PP48C (B), PP72C (C) e PP96C (D) aumento de $5.000 x$ 
Figura 51. Fotomicrografia da matriz PB24C (A), PB48C (B), PB72C (C) e PB96C (D) aumento de $5.000 \mathrm{x}$

Figura 52. Fotomicrografia da matriz SP24C (A), SP48C (B), SP72C (C) e SP96C (D) aumento de $10.000 \mathrm{x}$

Figura 53. Fotomicrografia da matriz PP24C, aumento de: (A) 20.000x e (B) 40.000X......93

Figura 54. Fotomicrografia do interior da matriz PP96C, aumento de: 200x. 94

Figura 55. Fotomicrografia do interior da matriz PB96C, aumento de 500x .94

Figura 56. Fotomicrografia do interior da matriz SP96C, aumento de 1000x. 95

Figura 57. Curvas DSC para as matrizes derivadas de pele porcina hidrolisadas e mineralizadas: (A)24h, (B) 48h e (C) $72 \mathrm{~h}$. 106

Figura 58. Curvas DSC para as matrizes derivadas de pericárdio bovino hidrolisadas e mineralizadas: (A)24h, (B) 48h e (C) $72 \mathrm{~h}$.

Figura 59. Curvas DSC para as matrizes derivadas de serosa hidrolisadas e mineralizadas: (A) $24 \mathrm{~h},(\mathrm{~B}) 48 \mathrm{~h}$ e (C) $72 \mathrm{~h}$. 108

Figura 60. Curvas termogravimétricas das matrizes derivadas de pele porcina hidrolisadas e mineralizadas: (A) 24h, (B) 48h e (C) 72h. 109

Figura 61. Curvas termogravimétricas das matrizes derivadas de pericárdio bovino hidrolisadas e mineralizadas: (A) 24h, (B) 48h e (C) $72 \mathrm{~h}$. 110

Figura 62. Curvas termogravimétricas das matrizes derivadas de serosa porcina hidrolisadas e mineralizadas: (A) 24h, (B) 48h e (C) $72 \mathrm{~h}$.

Figura 63. Espectros no infravermelho das matrizes derivadas de pele porcina (A) PP24C,

(B) PP48C e (C) PP72C.

Figura 64. Espectros no infravermelho das matrizes derivadas de pericárdio bovino (A) PB24C, (B) PB48C e (C) PB72C.

Figura 65. Espectros no infravermelho das matrizes derivadas de serosa porcina (A) SP24C, (B) SP48C e (C) SP72C. 


\section{LISTA DE TABELAS}

Tabela 1. Relação $\mathrm{Ca} / \mathrm{P}$ de fosfatos de cálcio.

Tabela 2. Matrizes de colágeno aniônico tipo I obtidas após hidrólise alcalina. 41

Tabela 3. Concentração iônica dos sais da solução utilizada 43

Tabela 4. Matrizes de colágeno obtidas após mineralização pelo método de imersão alternada 45

Tabela 5. Valores dos diâmetros dos halos formados no controle positivo e negativo 61

Tabela 6. Temperatura de desnaturação do colágeno presente nos tecidos e nas matrizes ..... 71

Tabela 7. Porcentagens de perda de massa das matrizes obtidas através de TG/DTG 73

Tabela 8. Relação massa inorgânica por massa orgânica das matrizes mineralizadas .77

Tabela 9. Razão Ca/P dos sais depositados nas matrizes mineralizadas e hidrolisadas 78

Tabela 10. Relação $\mathrm{Ca} / \mathrm{P}$ dos principais tipos de fosfato de cálcio 79

Tabela 11. Principais valores de $\mathrm{d}$ para as matrizes mineralizadas 80

Tabela 12. Principais freqüências das bandas para o colágeno presente nas matrizes 83

Tabela 13. Principais frequências das bandas para o colágeno mineralizado 85

Tabela 14 - Composição do meio ISCOVE'S 


\section{LISTA DE ABREVIATURAS}

Asn - Asparagina

DSC - Calorimetria Exploratória Diferencial

DRX - Difração de raios X

EDS - Espectroscopia por Energia Dispersiva

EDTA - Ácido Etilenodiaminotetracético

FTIR - Espectroscopia no Infravermelho por Transformada de Fourier.

Gln - Glutamina

Gly - Glicina

HA - Hidroxiapatita

Hyp - Hidroxiprolina

MC - Matriz de Colágeno

MEV - Microscopia Eletrônica de Varredura

PB - Pericárdio Bovino

PB24 - Pericárdio Bovino Hidrolisado por 24h

PB24C - Pericárdio Bovino Hidrolisado por 24h Mineralizado

PB48 - Pericárdio Bovino Hidrolisado por $48 \mathrm{~h}$

PB48C - Pericárdio Bovino Hidrolisado por 48h Mineralizado 
PB72 - Pericárdio Bovino Hidrolisado por 72h

PB72C - Pericárdio Bovino Hidrolisado por 72h Mineralizado

PB96 - Pericárdio Bovino Hidrolisado por 96h

PB96C - Pericárdio Bovino Hidrolisado por 96h Mineralizado

PBn - Pericárdio Bovino Nativo (não hidrolisado)

PBS - Tampão Fosfato Salino

PP - Pele Porcina

PP24 - Pele Porcina Hidrolisada por 24h

PP24C - Pele Porcina Hidrolisada por 24h Mineralizada

PP24S - Pele Porcina Hidrolisada por 24h sem Pré-Tratamento Orgânico

PP24SC - Pele Porcina Hidrolisada por 96h Sem Pré-Tratamento Orgânico, Mineralizada

PP48 - Pele Porcina Hidrolisada por 48h

PP48C - Pele Porcina Hidrolisada por 48h Mineralizada

PP72 - Pele Porcina Hidrolisada por 72h

PP72C - Pele Porcina Hidrolisada por 72h Mineralizada

PP96 - Pele Porcina Hidrolisada por 96h

PP96C - Pele Porcina Hidrolisada Por 96h Mineralizada

PP96C - Pericárdio Bovino Hidrolisado por 96h Mineralizado 
PP96S - Pele Porcina Hidrolisada por 96h Sem Pré-Tratamento Orgânico

PP96SC - Pele Porcina Hidrolisada por 96h Sem Pré-Tratamento Orgânico, Mineralizada

PPn - Pele Porcina Nativa (não hidrolisada)

Pro - Prolina

SBF - Solução Simuladora de Fluido Corpóreo

SIS - Submucosa Intestinal Porcina

SP - Serosa Porcina

SP24 - Serosa Porcina Hidrolisada por 24h

SP24C - Serosa Porcina Hidrolisada por 24h Mineralizada

SP48 - Serosa Porcina Hidrolisada por 48h

SP48C - Serosa Porcina Hidrolisada por 48h Mineralizada

SP72 - Serosa Porcina Hidrolisada por 72h

SP72C - Serosa Porcina Hidrolisada por 72h Mineralizada

SP96 - Serosa Porcina Hidrolisada por 96h

SP96C - Serosa Porcina Hidrolisada por 96h Mineralizada

SPn - Serosa Porcina Nativa (não hidrolisada)

Td - Temperatura de Desnaturação

TG/DTG - Termogravimetria 


\section{RESUMO}

A reconstrução de defeitos ósseos é um problema que afeta milhões de pessoas, que a medicina tenta resolver. Uma alternativa para a solução deste problema tem sido o desenvolvimento de biomateriais que atuem no processo de reparação óssea. O colágeno é um polímero de origem natural capaz de promover cicatrização e regeneração óssea e juntamente com a hidroxiapatita são os principais componentes encontrados no tecido ósseo. Vários trabalhos têm sido reportados com matrizes mineralizadas de colágeno tipo I em diferentes formas como em géis, membranas e esponjas, mas a mineralização in vitro de matrizes acelulares com maior teor de mineralização obtidas de tecidos biológicos sem a perda da estrutura colagênica não tem sido descrito. Este trabalho teve como objetivo a mineralização in vitro e a caracterização de matrizes de colágeno aniônico obtidas de pele porcina, pericárdio bovino e serosa porcina. Os tecidos foram tratados em temperatura ambiente com solução alcalina por períodos variáveis de 0 à $96 \mathrm{~h}$ e mineralizados pelo processo de imersão alternada. Os materiais obtidos foram caracterizados pela avaliação preliminar da citotoxicidade in vitro, termogravimetria (TG/DTG), calorimetria exploratória diferencial (DSC), microscopia eletrônica de varredura (MEV), dispersão de raios X (EDS), difração de raios X (DRX) e absorção no infravermelho (FTIR). Não foi observada citotoxicidade em nenhuma das matrizes avaliadas, contudo foi necessário um pré-tratamento nas matrizes de pele porcina para remoção de gordura. Os resultados de DSC mostraram a integridade da matriz colagênica após o tratamento alcalino. $\mathrm{O}$ aumento no tempo desse tratamento diminui a temperatura de desnaturação sendo observado um efeito maior nas matrizes de pele porcina seguidas por pericárdio bovino e serosa porcina. A mineralização induz a um aumento na temperatura de desnaturação em todos os casos. As curvas TG apresentaram perdas de massa relacionadas à água presente no material, decomposição da proteína e carbonização do material orgânico e um resíduo após $750{ }^{\circ} \mathrm{C}$ que foi associado ao material inorgânico presente na forma de hidroxiapatita, sendo as matrizes de serosa porcina as de maior teor de mineralização. As matrizes mineralizadas tendem a um aumento na estabilidade térmica do colágeno quando comparadas com as matrizes hidrolisadas. Os espectros FTIR mostraram a presença de íons fosfatos e a interação de íons cálcio com o colágeno. As relações $\mathrm{Ca} / \mathrm{P}$ obtidas por EDS foram aquelas esperadas em comparação com o valor teórico para hidroxiapatita (HA) e resultados de DRX confirmaram a obtenção de HA amorfa como principal produto de mineralização. Pelas fotomicrografias obtidas por MEV pôde-se observar que as fibras de colágeno tornam-se mais desestruturadas quando há um aumento no tempo de hidrólise e que a deposição de sais ocorreu de forma heterogênea, disposta em aglomerados esféricos no formato de agulhas por toda a superfície e interior, exceto para matrizes derivadas de pele porcina que não são mineralizadas internamente devido a sua espessura. Os resultados demonstraram que é possível a mineralização in vitro de matrizes de colágeno tipo I obtidas de diferentes tecidos biológicos em diferentes tempos de hidrólise, produzindo um material com potencial de uso para regeneração óssea. 


\begin{abstract}
The reconstruction of osseous defects is still a problem that affects millions of people and medicine tries to solve it. One alternative to solve these problems has been the development of biomaterials that can be used as inductors in the osseous repair process. Collagen is a natural polymer able to promote healing and bone regeneration, and among hydroxyapatite (HA) is the main component found in bone tissue. Several mineralized collagen scaffolds are described in literature, in the form of gel, membranes and films, however, in vitro mineralization of acellular matrices, obtained from biological tissues without the loss of collagenic structure, has not been reported. The objective of this work was the mineralization and characterization of anionic collagen matrices obtained from porcine skin, bovine pericardium and porcine serosa. Biological tissues were treated at room temperature for 0-96h in alkaline solution and mineralized by alternate soaking method. Materials were characterized by preliminary assay of in vitro cytotoxicity, differential scanning calorimetry (DSC), termogravimetric analysis (TG/DTG), scanning electronic microscopy (SEM), energy dispersive x-ray analysis (EDS), x-ray diffraction (XRD), and Fourier Transform Infrared Spectroscopy (FTIR). No cytotoxicity was observed in any of the evaluated matrices; however, a pre-treatment of porcine skin matrices, for fat removal, was necessary. DSC results showed the integrity of collagen matrices after alkaline treatment. Denaturation temperature is dependent of time of alkaline treatment, and this effect is greater for porcine skin matrix, followed by bovine pericardium and porcine serosa. TG/DTG curves showed weight losses associated with release of water, degradation of protein structure and combustion of residual organic components. Residues were obtained at $750^{\circ} \mathrm{C}$ and associated to hydroxyapatite, being porcine serosa matrix the most mineralized. All mineralized matrices showed an increase in collagen thermal stability when compared to hydrolyzed matrices. FTIR spectra showed the presence of phosphate ions and the interaction of calcium ions with collagen. $\mathrm{Ca} / \mathrm{P}$ ratios obtained by EDS were as expected when compared with literature values for HA, and RDX results confirmed amorphous HA as the main mineralization product. MEV analysis showed that collagen fibers were more affected for longer hydrolysis times, and that salt deposition was heterogeneous, with crystals grouped in spherical agglomerates in a needle-like shape throughout surface and inner, except for porcine skin derived matrices that were not internally mineralized due their width. Obtained results demonstrated that in vitro mineralization of type I collagen matrices, using different sources of biological tissues and hydrolysis time was possible, producing a material with potential to be used in bone regeneration.
\end{abstract}




\section{INTRODUÇÃO}

A perda do tecido ósseo, resultante de doenças ou traumas causados por acidentes é um dos mais importantes e preocupantes problemas da área ortopédica, atingindo um número muito significativo de pessoas em todo o mundo.

Entre os métodos tradicionais para reconstrução dos defeitos ósseos estão a utilização de enxertos autólogos (provenientes do mesmo indivíduo), enxertos homólogos (provenientes de indivíduos da mesma espécie) e heterólogos (provenientes de espécies diferentes).

O enxerto autólogo tem sido considerado o melhor substituto, pois contém na sua estrutura células osteogênicas viáveis e fatores de crescimento adequados à osteogênese (SALGADO; COUTINHO; RUI, 2004), o que faz com que a osteointegração seja rápida. Embora este seja o melhor tratamento, sua utilização é limitada devido à morbidade do sítio doador, que aumenta com a quantidade de osso retirado. Hematoma, infecção e dor crônica são complicações comuns no local da retirada do osso autógeno (KNESER et al., 2006).

Os enxertos homólogos não apresentam as complicações relacionadas com a área doadora, como ocorre com o enxerto autólogo. Contudo, têm a desvantagem da resposta inflamatória que desencadeiam e do alto risco da transmissão de doenças infecto-contagiosas associadas às respostas imunológicas, responsáveis por altos índices de insucesso (ROSE; OREFFO, 2002).

Os enxertos heterólogos, especialmente os de origem bovina, vem sendo usados, pois são de fácil obtenção e disponibilidade, porém oferecem riscos de contaminação e/ou rejeição. 
Com o intuito de substituir estes enxertos, biomateriais são utilizados no processo de reparação óssea incluindo os naturais como colágeno, quitosana e os sintéticos, tais como metais, cerâmicas e polímeros.

\subsection{Biomateriais e engenharia de tecido ósseo}

Biomateriais podem ser definidos como quaisquer substâncias ou combinação de substâncias que podem ser utilizados por um período de tempo para melhorar, aumentar ou substituir, parcial ou inteiramente, qualquer tecido órgão ou função (PARK; BRONZINO, 2003).

Os biomateriais podem ser classificados em dois grupos de acordo com a natureza química: naturais, que incluem o colágeno, elastina, seda, tecidos biológicos, ou sintéticos que incluem as cerâmicas, os polímeros sintéticos, metais e compósitos.

De um modo geral os biomateriais devem apresentar as seguintes características (PARK; BRONZINO, 2003):

- $\quad$ ser biocompatível;

- não ser tóxico ou carcinogênico;

- ter propriedades químicas projetadas para o trabalho de reconstrução;

- estabilidade mecânica apropriada ao uso;

- $\quad$ peso e densidade adequados;

- estimular reações biológicas favoráveis aos processos de remodelagem. 
O melhor entendimento das interações biomateriais: tecido:células e das respostas celulares aos implantes tem acarretado em um amplo desenvolvimento dos biomateriais. Esses novos biomateriais não visam apenas o preenchimento de espaço, mas também estimular uma resposta biológica quando implantados. Dentre esses se enquadram:

- os materiais inteligentes que são aqueles que usam a analogia com materiais biológicos sendo capazes de modificar e adaptar sua estrutura, morfologia e outras propriedades para substituir ou melhorar alguma função biológica, quando física e/ou quimicamente estimulados (FURTH; ATALA; DYKE, 2007);

- os biomiméticos que são aqueles que mimetizam as propriedades naturais, tais como estrutura e função dos tecidos ou órgãos que irão substituir (SHIN; JO; MIKOS, 2003);

- as matrizes extracelulares (MEC) que são aqueles materiais destinados à engenharia de tecidos visando substituir, manter ou melhorar uma função de um órgão ou tecido (KIM; MOONEY, 1998).

Para a engenharia de tecido ósseo se propõe que a matriz deva induzir a formação do osso e tecidos circunvizinhos ou que atue como portadora para células ósseas implantadas ou outros agentes. A matriz deve conter características particulares como (JONES; LEE; HENCH, 2006):

- Atuar como modelo para o crescimento ósseo in vitro e in vivo em três dimensões;

- propriedades mecânicas e físicas apropriadas para aplicação;

- tamanhos médios de poros de 200-400 $\mu$ m; 
- $\quad$ ser passível de esterilização sem a perda de suas propriedades;

- não ter efeito prejudicial ao tecido circunvizinho;

- não promover crescimento de tecido mole na interface osso-implante;

- boa justaposição óssea;

- ser absorvida na mesma velocidade em que o osso é reparado, com produtos de degradação não-tóxicos que podem ser facilmente excretados pelo organismo;

- crescimento ósseo máximo através de osteoindução e/ou osteocondução, promovendo crescimento ósseo interno;

Dentre as várias matrizes que vêm sendo estudadas, as naturais, tais como o colágeno através de compósitos com fosfatos de cálcio, tem se destacado. Os compostos contendo hidroxiapatita (HA) e colágeno têm potencial para mimetizar e substituir o tecido ósseo (WAHL; CZERNUSKA, 2006), pois a combinação destes dois componentes apresentou osteogênese acelerada (XIE; BAUMANN; McCABE, 2004).

Estudos com compósitos de matrizes de colágeno aniônico com hidroxiapatita mostraram uma baixa irritabilidade tecidual, permitindo a evolução reparativa do tecido ósseo. A avaliação biológica em ratos mostrou que após sessenta dias de implante o compósito encontrava-se incorporado ao processo de ossificação com as cavidades ósseas quase que totalmente preenchidas por tecido ósseo (MARTINS et al., 1998).

O estudo de nanofibras do compósito colágeno/HA mostrou que este biomaterial tem potencial para a mineralização por osteoblastos sendo um biomaterial promissor para a regeneração de tecidos ósseos (VENUGOPAL et al., 2008). 


\subsection{Tecido ósseo}

O tecido ósseo é constituído por fibras de colágeno reforçado por partículas minerais de poucos nanômetros. Da massa total do tecido ósseo cerca de $70 \%$ estão sob a forma de hidroxiapatita (HA) depositadas sobre as fibras colagênicas (Figura 1) e a relação $\mathrm{Ca} / \mathrm{P}$ pode variar entre 1,50 a 1,67 (HABRAKEN; WOLKE; JANSEN, 2007). Os 30\% referentes à parte orgânica são quase que exclusivamente compostos por uma única proteína, o colágeno tipo I, que participa de forma importante no processo de mineralização óssea.

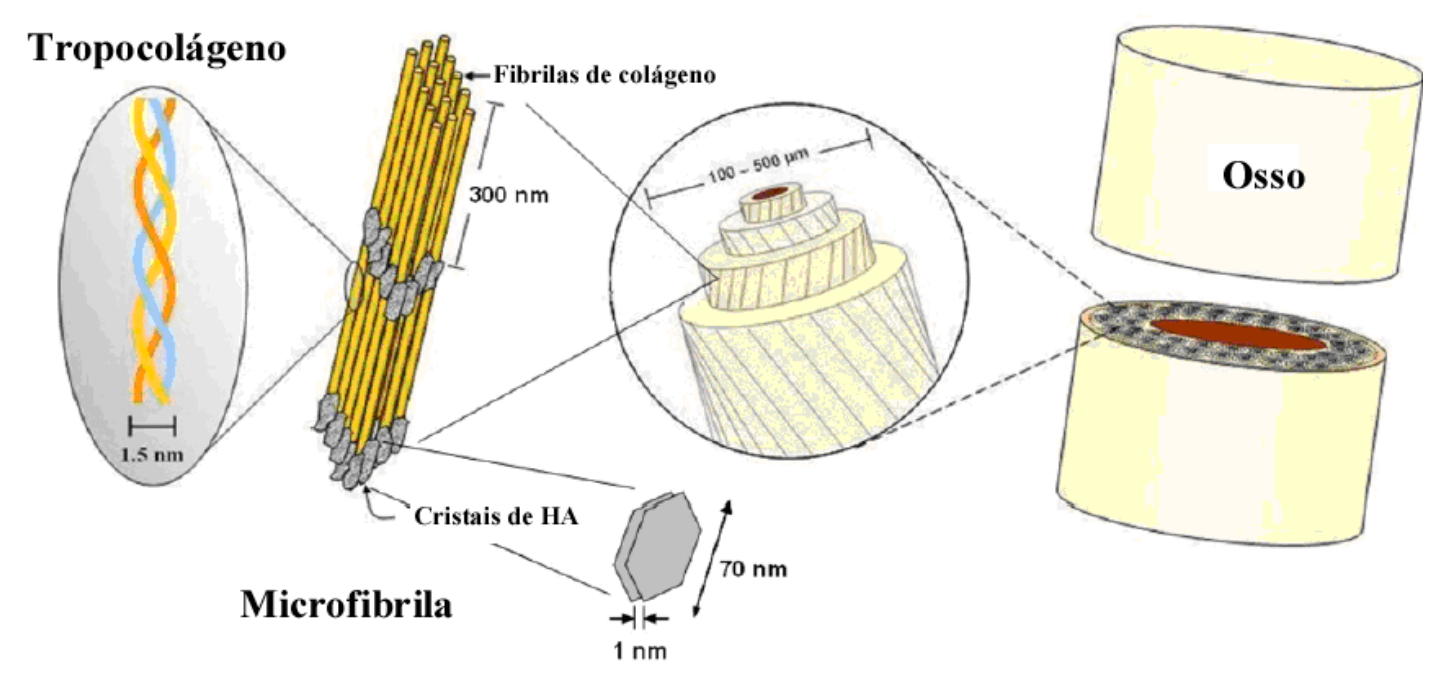

Figura 1. Organização hierárquica do osso. (Adaptada de MEYERS et al., 2008).

Durante a maturação óssea a estrutura cristalina do mineral pode sofrer um rearranjo contínuo sendo possível encontrar intermediários que apresentam estruturas cristalinas de compostos que se assemelham a brushita ou monohidrogeno fosfato de cálcio diidratado, fosfato octacálcico e fosfato tricálcico (KAWACHI, 2002) que têm como relações $\mathrm{Ca} / \mathrm{P}$ mostrados na Tabela 1. 
Tabela 1. Relação Ca/P de fosfatos de cálcio.

\begin{tabular}{|c|c|c|}
\hline Fosfato de cálcio & Fórmula química & Razão Ca/P \\
\hline Fosfato octacálcico & $\mathrm{Ca}_{8} \mathrm{H}_{2}\left(\mathrm{PO}_{4}\right)_{6} .5 \mathrm{H}_{2} \mathrm{O}$ & 1,33 \\
\hline Brushita ou DCPD & $\mathrm{CaHPO}_{4} \cdot 2 \mathrm{H}_{2} \mathrm{O}$ & 1,00 \\
\hline Fosfato tricálcico $(\mathrm{TCP})$ & $\mathrm{Ca}_{3}\left(\mathrm{PO}_{4}\right)_{2}$ & 1,50 \\
\hline
\end{tabular}

\subsection{Hidroxiapatita (HA)}

Durante a década de 20 reconheceu-se que o mineral presente nos ossos e dentes era muito similar em sua estrutura ao mineral hidroxiapatita $\left(\mathrm{Ca}_{10}\left(\mathrm{PO}_{4}\right)_{6}(\mathrm{OH})_{2}\right)(\mathrm{BOSKEY}$, 1998) (Fig. 2).

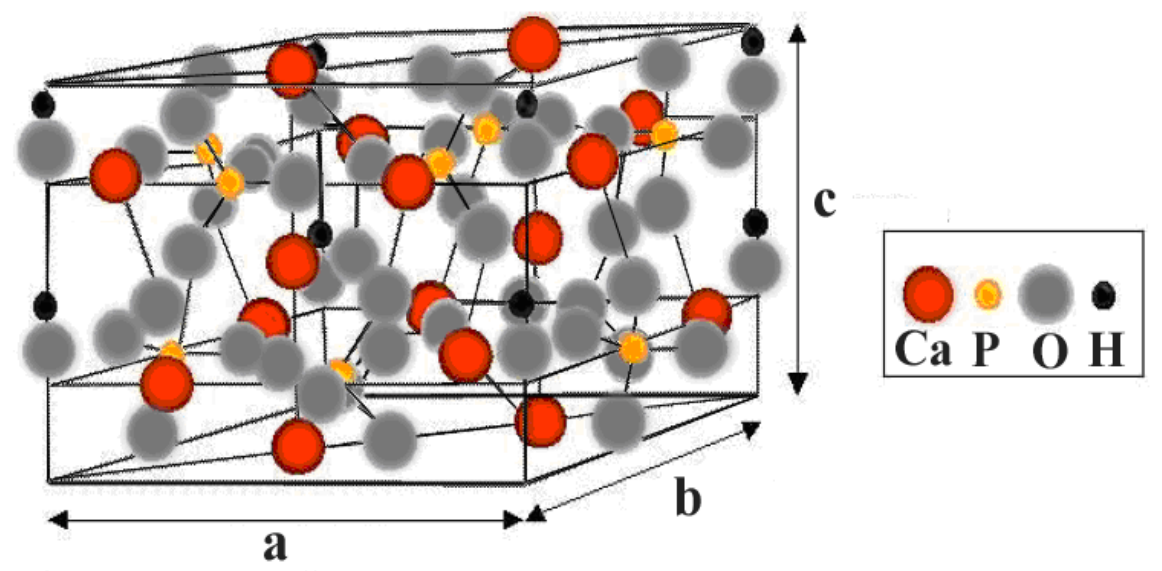

Figura 2. Arranjo atômico da hidroxiapatita (SILVA, 2008).

Por ter composição química semelhante à fase mineral dos ossos e possuir características como biocompatibilidade, bioatividade e osteocondutividade (MURUGAN; RAMAKRISHNA, 2005), a hidroxiapatita sintética tem sido considerada o material ideal como um implante ósseo em uma variedade de situações e mostrou promover o crescimento de células mesenquimais e diferenciação osteogênica (ZHAO et al, 2006). 
A HA (sintética ou natural) é um dos poucos materiais bioativos usados em aplicações dentais, ortopédicas e maxilo-faciais. A HA tem aplicações como revestimento de biocerâmicas e preenchedores ósseos. Os revestimentos de hidroxiapatita muitas vezes são aplicados aos implantes metálicos (mais comumente titânio / aços inoxidáveis e de ligas de titânio) para alterar as propriedades superficiais. Para preencher defeitos ósseos, a HA pode ser utilizada em várias formas como em pó, blocos ou esferas porosas.

De modo geral a HA é um material frágil e sua resistência mecânica é pobre, não é bioabsorvível e tem uma baixa taxa de substituição, resultando no afrouxamento ou quebra de implantes de HA in vivo, não podendo ser utilizada como dispositivo para substituir grandes defeitos ósseos.

Para melhorar essas características, matrizes de HA com colágeno têm sido desenvolvidas já que a adição desta proteína produz materiais com boas qualidades como por exemplo o aumento da resistência mecânica.

\subsection{Colágeno}

O colágeno é a proteína fibrosa mais abundante no corpo humano, representando aproximadamente $30 \%$ das proteínas do corpo. Tem a função de manter a integridade estrutural do tecido e conferir resistência mecânica a diversos tecidos e órgãos. Mais de $90 \%$ das proteínas extracelulares no tendão e ossos e mais de $50 \%$ na pele são constituídas por colágeno.

Atualmente, são identificados 29 tipos de colágeno (SÖDERHÄLL et al., 2007), os quais se diferenciam na composição de aminoácidos, nos domínios de cada molécula e nos diferentes arranjos estruturais. 
O colágeno tipo I é o mais conhecido química e estruturalmente. É facilmente encontrado na pele, tendão, vasos sanguíneos, intestinos e ossos.

A macromolécula de colágeno (Fig. 3) é formada por uma unidade monomérica denominada de tropocolágeno que é formado por duas cadeias idênticas $\left(\alpha_{1}\right)$, possuindo cerca de 1055 resíduos de aminoácidos cada e uma cadeia diferente $\left(\alpha_{2}\right)$, possuindo cerca de 1029 resíduos. Dando origem a uma hélice tripla com 300nm de comprimento e 1,5nm diâmetro.

As extremidades não helicoidais são denominadas de telopeptídeos N- e Cterminais, que possuem respectivamente 16 e 25 resíduos de aminoácidos (CHAPMAN et al., 1990).

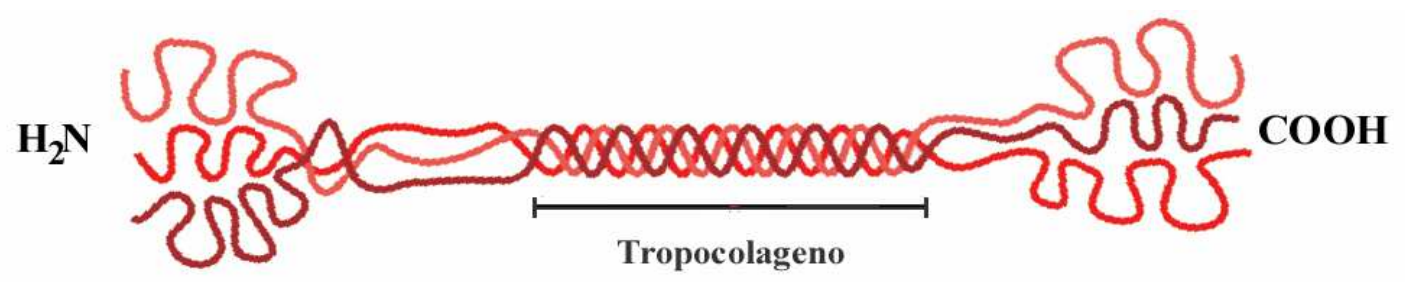

Figura 3. Estrutura da molécula de colágeno.

A seqüência desses resíduos de aminoácidos é regular, apresentando-se na forma de unidades repetitivas ou tripletes do tipo: (-Gly-X-Y-), em que cada terceiro resíduo de aminoácido é glicina (Gly). Na posição X existem diferentes aminoácidos; no entanto, a prolina (Pro) é típica nesta posição. Na posição Y, existem aminoácidos diferentes, mas aproximadamente cada sétima posição de Y é ocupada por hidroxiprolina (Hyp), sendo que a seqüência Gly-Pro-Hyp representa cerca de $10 \%$ da molécula.

Prolina e hidroxiprolina são aminoácidos cíclicos e rígidos. A sua presença no esqueleto da molécula impede um movimento rotativo e, portanto, contribui para a estabilidade da hélice tripla. A Gly é a menor molécula de aminoácido e sua presença entre os 
resíduos permite uma maior eficiência da torção da cadeia em uma hélice (KENNEDY; WESS, 2003).

Nos tecidos biológicos, o colágeno organiza-se em estruturas fibrilares que são estabilizadas por ligações de hidrogênio, interações eletrostáticas e hidrofóbicas. Esta organização fibrilar tem origem na microfibrila. Através das interações entre cinco moléculas de tropocolágeno, tem-se a formação das microfibrilas, menor unidade estrutural do tecido conjuntivo.

A Figura 4 mostra a formação da fibrila do colágeno.

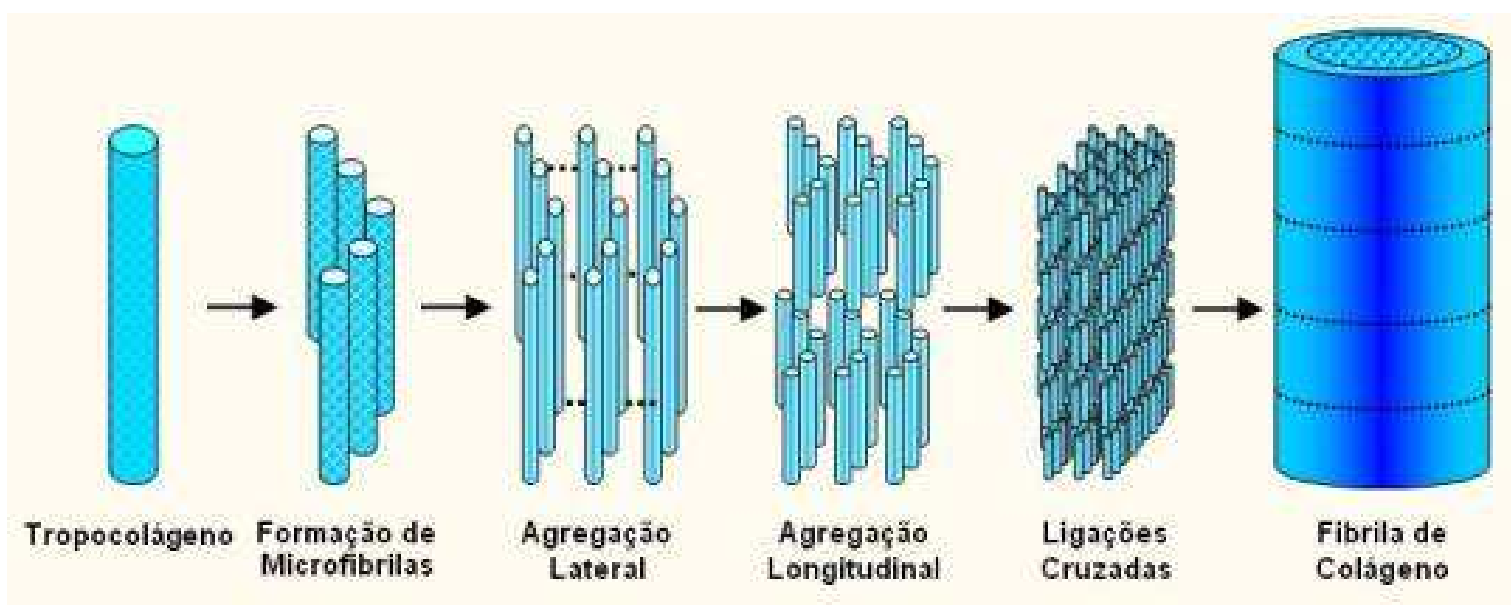

Figura 4. Formação da fibrila de colágeno.

Formadas as microfibrilas, inicia-se o processo de agregação denominado de fibrilogênese, para formar fibrilas insolúveis, as quais são mantidas por ligações cruzadas intra (entre a mesma unidade de tropocolágeno) e intermoleculares (entre as unidades de tropocolágeno) e também por ligações eletrostáticas que lhes conferem estabilidade (NIMNI; HARKNESS, 1988; VEIS, 1982). A Figura 5 mostra a representação das ligações intra e intermoleculares no tropocolágeno. 


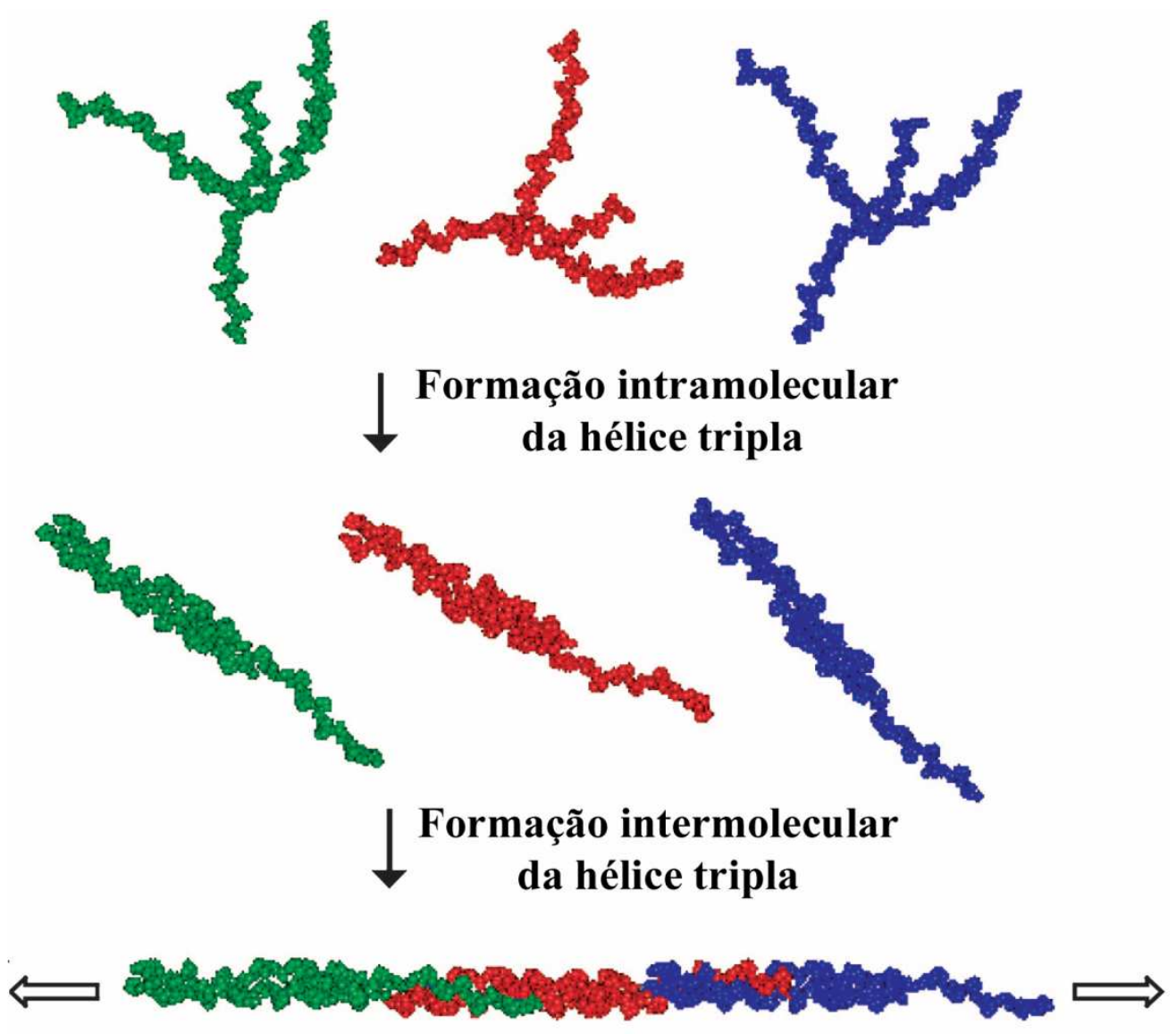

Figura 5. Representação da formação intramolecular e intermolecular do colágeno (KOTCH; RAINES, 2006).

O modelo mais aceito para a organização do tropocolágeno é o quarto alternado pentafibrilar proposto por Smith (1968). Neste modelo, as moléculas de tropocolágeno estão deslocadas um quarto de seu comprimento, ou seja, cerca de $67 \mathrm{~nm}$ em relação à molécula adjacente, apresentando também uma região de espaçamento vazio entre duas moléculas alinhadas longitudinalmente (“gap”), seguidas de uma região de sobreposição (“overlap”) destas moléculas (Fig. 6). O conjunto "gap:overlap" é o período D da estrutura fibrilar do colágeno tipo I. 


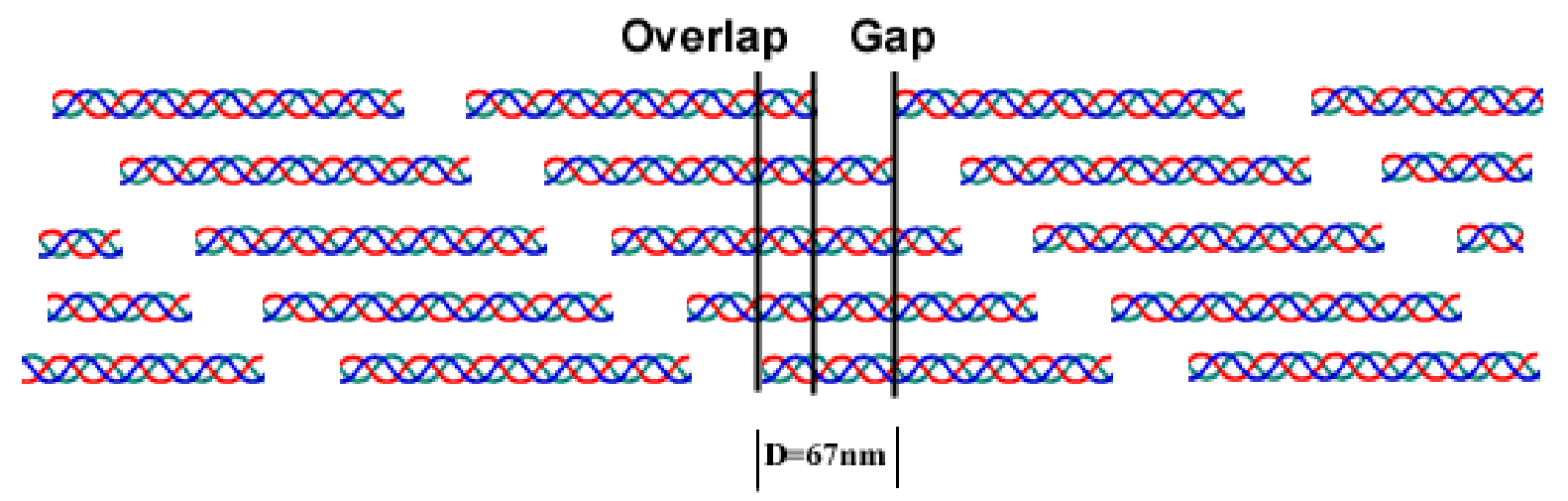

Figura 6. Esquema de agregação das moléculas de tropocolágeno para a formação da microfibrila.

As fibras insolúveis têm uma alta capacidade de tensão elástica, tendo ainda a função de orientar tecidos em desenvolvimento, que torna o colágeno altamente compatível na utilização como biomaterial (MAYNE, BURGESON, 1987; HUC, 1985).

Para o colágeno tipo I a formação de fibras ocorre em $\mathrm{pH} 7,0$, sendo este o $\mathrm{pH}$ onde se tem a máxima interação eletrostática entre as moléculas de tropocolágeno, fazendo com que a resultante de cargas na molécula seja zero (colágeno nativo). A resultante das cargas no colágeno pode ser modificada resultando em uma matriz colagênica carregada positiva ou negativamente. Como por exemplo, as reações podem ser de esterificação (REID, GORHAM, LACKIE, 1993) e succinilação (ZHANG et al., 2007).

Uma outra modificação possível do colágeno é a hidrólise alcalina (Fig. 7) dos grupos carboxiamidas dos resíduos de aminoácidos asparagina (Asn) e glutamina (Gln)

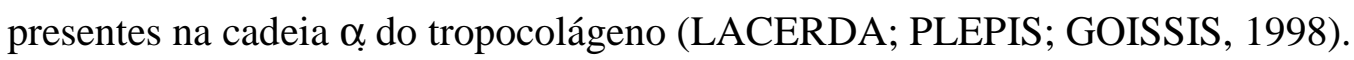




\section{Grupo carboxiamida}

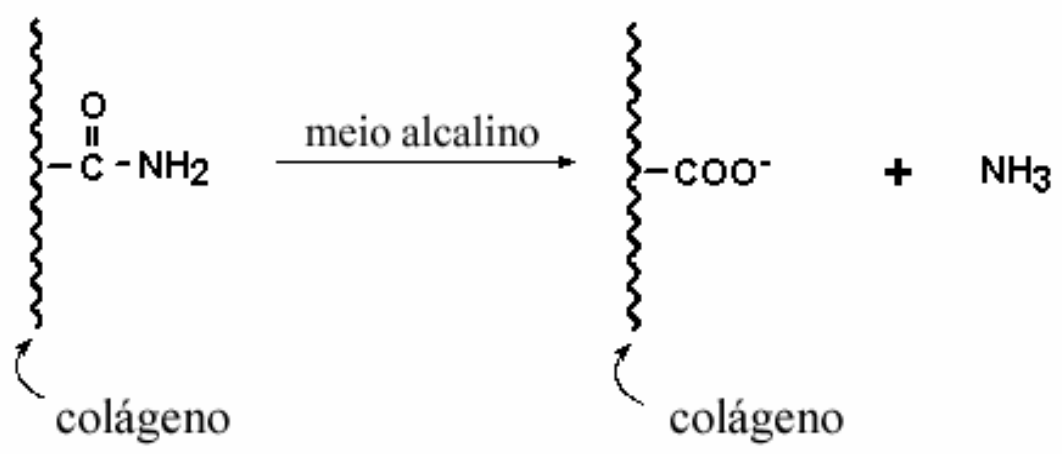

Figura 7. Hidrólise alcalina dos grupos carboxiamidas dos resíduos de Asn e Gln.

A hidrólise total dos grupos Asn e Gln tem como resultado, a adição de 130 cargas negativas, superpostas em regiões de carga negativa preexistentes na molécula nativa (BET et al., 2003). Devido à alteração de cargas, há a formação de um centro de carga assimétrico localizada na região central do tropocolágeno (Fig 8). Esta característica é importante para o desenvolvimento de materiais dielétricos a qual pode aumentar as propriedades piezoelétricas existentes no colágeno nativo (PLEPIS, GOISSIS, DAS-GUPTA, 1996).

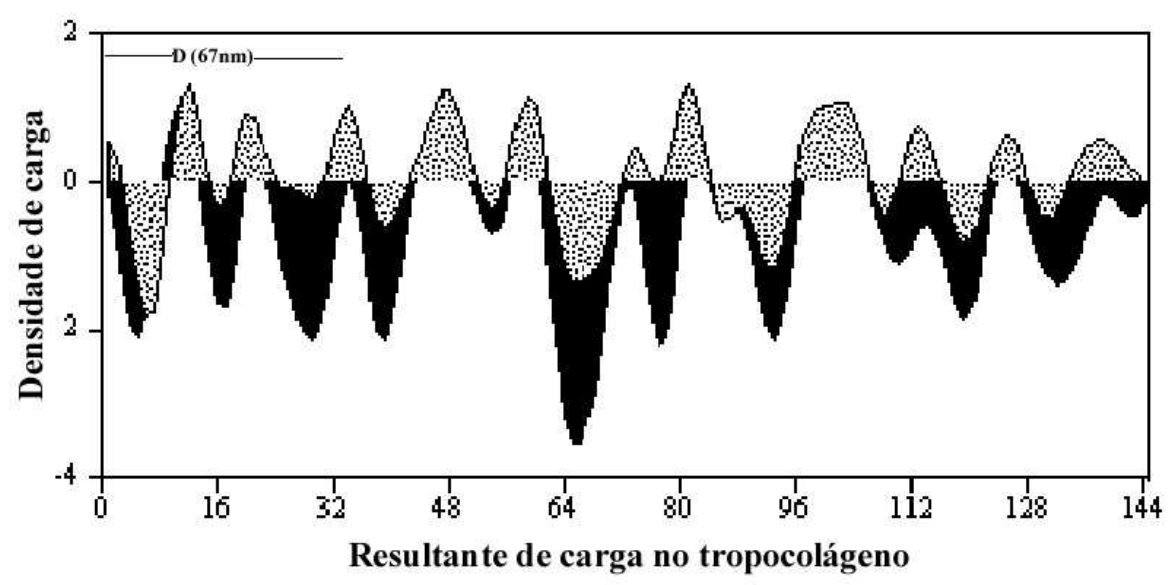

Figura 8. Resultante de carga líquida para o tropocolágeno para colágeno nativo (pontilhado) e colágeno aniônico (preto) (BET, 2000). 
As matrizes de colágeno aniônico preparadas a partir de pericárdio bovino mostraram um aumento na adesão e proliferação celular (BET et al., 2003) e ausência de resposta inflamatória (ROSA et al., 2003).

\subsection{Matrizes de colágeno (MC)}

Nas últimas décadas, o uso de MC para reparação tecidual tem demonstrado que estas podem induzir a remodelagem construtiva de tecidos danificados (LEE, C.; SINGLA; LEE, Y., 2001; ROCHA et al., 2006), e que podem ser modificadas por processos químicos ou físicos resultando em matrizes carregadas positiva ou negativamente tornando as propriedades mecânicas e fisiológicas mais adequadas para as aplicações desejáveis. Elas atuam como sítios para ancoragem de células, servem como base para o crescimento e o desenvolvimento do novo tecido. Estas matrizes podem ser utilizadas em diversas formas como esponjas, filmes, géis e matrizes acelulares sem a perda de sua estrutura tecidual, que podem ser obtidas pela remoção dos componentes celulares presentes em tecidos biológicos. Com a ausência de células há pouca inflamação não levando a rejeição do tecido implantado.

Estas matrizes apresentam algumas propriedades como (LEE, C.; SINGLA; LEE, Y., 2001):

- Biocompatibilidade;

- Bioatividade;

- Biodegradabilidade;

- Capacidade de sustentação celular.

Devido aos excelentes resultados obtidos em uma variedade de aplicações biomédicas (FENG et al., 2006, CAIONE et al., 2006, BAHARUDDIN et al., 2002), o 
desenvolvimento de matrizes acelulares, que são derivadas de tecidos biológicos submetidos a tratamento para remoção de células e componentes celulares, mas que conservam a estrutura nativa, chamou a atenção em diversos estudos. Entre estes tecidos estão a pele, o pericárdio, a serosa, o tendão e as matrizes ósseas desmineralizadas que podem ser obtidas de fontes diferentes como bovina, suína e avestruz.

Como exemplo de aplicações das MC tem-se sua utilização como substituintes de válvulas cardíacas (MIRNAJAFI et al., 2005), pele (METCALFE; FERGUSON, 2007) e ossos (CUNHA et al., 2008).

\subsubsection{Tecidos biológicos como fonte para matrizes de colágeno}

\subsubsection{Pele Porcina (PP)}

Anatomicamente a pele mais similar a pele humana é a porcina comparando-se com outros animais. A epiderme do porco tem espessura que varia de 30 a $140 \mu \mathrm{m}$, estando assim, dentro de um intervalo semelhante ao do homem que varia de 50 a $120 \mu \mathrm{m}$ e, além disso, a razão derme/epiderme da pele porcina varia 10:1 para 13:1 sendo estas medidas comparáveis a da pele humana (VARDAXIS et al., 1997).

PP (Fig. 9) começou a ser utilizada na década de 60 (BROMBERG; SONG; MOHN, 1965) e é atualmente uma das fontes heterólogas mais utilizadas, devido a grande quantidade de colágeno (95 \%), a sua disponibilidade, seu baixo custo e sua estrutura histológica ser similar a da pele humana (RUSZCZAK, 2003). 


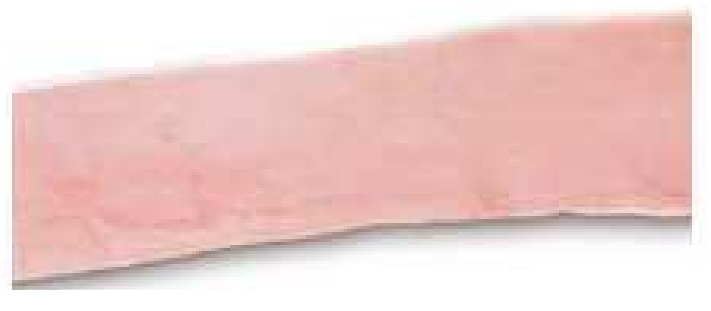

Figura 9. Pele porcina.

Devido a estas características citadas, os enxertos heterólogos de pele porcina têm sido utilizados no tratamento de feridas cutâneas (HOYAMA et al., 2005), no tratamento em incontinência urinária (BARRINGTON et al., 2002), na reparação de fístula rectovaginal (MOORE et al., 2004) e na reconstrução de defeitos abdominais crônicos (SHAIKH et al., 2007). Também são utilizados em queimaduras como revestimentos biológicos atuando como substituintes temporários enquanto ocorre a cicatrização espontânea do tecido (CHIU; BURD, 2005; FENG et al., 2006). Permacol® é um biomaterial comercial derivado de derme porcina pela remoção de células por processos químicos e enzimáticos e também tem sido largamente utilizado no tratamento de queimaduras (MACLEOD et al.; 2005).

\subsubsection{Pericárdio Bovino}

O pericárdio bovino (PB) é uma membrana fibro-elástica que envolve o coração (Fig. 10) e é um dos tecidos que vem sendo utilizados no desenvolvimento de biomateriais. É um material biológico de baixo custo e de fácil manipulação. A grande vantagem da utilização de PB é o seu alto teor de colágeno, cerca de 97\% (GIGLIOTI, 2005), o qual possui uma grande quantidade de grupos reativos que possibilitam alterações químicas do tecido. A modificação química ou fixação, do tecido biológico aumenta sua resistência à degradação enzimática e diminui a sua antigenicidade (NIMMI et al, 1988). 


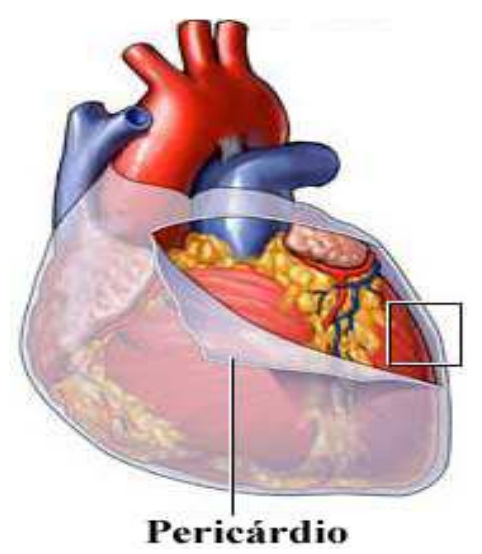

Figura 10. Pericárdio bovino.

PB tem sido utilizado extensivamente como biomaterial na confecção de bioprótese, durante décadas, especialmente para a reparação de lesões cardíacas (OLMOS et al., 1997) após tratamento com diferentes métodos de reticulação (SUNG et al., 1999, SACKS et al., 2007). As próteses vasculares confeccionadas com PB possuem um bom desempenho hidrodinâmico e baixa trombogenicidade (MAIZATO, 2003).

Além disso, este tecido tem sido utilizado no tratamento de valvulopatias, aneurismas e dissecções arteriais, tratamento de hérnias (GAERTNER; BONSACK; DELANEY, 2007), para o revestimento de implantes orbitais após a enucleação (GAYRE et al., 2001), em enxerto dural (BAHARUDDIN et al., 2002) e no tratamento e reparo de ligamento e deficiências do tendão (ROSSOUW; VILLIERS, 2005).

Com a finalidade de reconstituir o diafragma de cão, foi utilizado pericárdio bovino conservado em solução de glutaraldeído. Os autores verificaram boa vedação do defeito, sendo histologicamente observada presença de uma camada de tecido conjuntivo sobre o implante (GALLO et al.,1982).

Os trabalhos realizados com pericárdio bovino mostraram que este material apresenta baixa antigenicidade e toxicidade, possui grande resistência à tração, ausência de 
irritação, e sua permanência no interior dos tecidos provoca uma leve reação inflamatória por tempo limitado (BRAILE et al., 1982).

Alguns estudos também mostram que PB pode ser utilizado no processo de reparação óssea. Rocha et al. mostraram que as matrizes derivadas de PB hidrolisadas são osteocondutivas promovendo rápida recuperação do defeito ósseo (ROCHA et al., 2006).

\subsubsection{Serosa Porcina}

O intestino delgado de suínos é composto de 4 camadas, como mostrado na Figura 11.

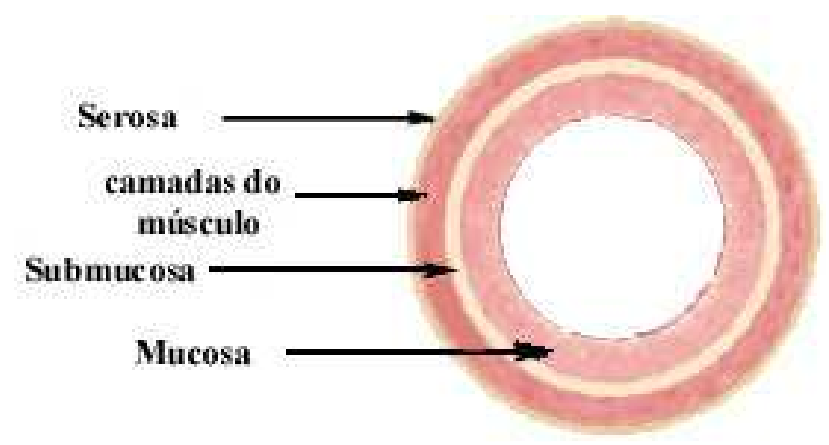

Figura 11. Diagrama da seção transversal do intestino delgado de suínos.

Para a obtenção da Submucosa Intestinal Porcina (SIS) é feita a remoção das demais camadas do intestino (serosa, camadas do músculo e mucosa), sendo obtido um tubo translúcido de aproximadamente $80 \mu \mathrm{m}$ de espessura constituído principalmente de colágeno (cerca de 90\%) e algumas células do tecido conjuntivo (LINDBERG; BADYLAK, 2001). E a serosa obtida pela remoção das demais camadas internas do intestino delgado é lavada exaustivamente.

Devido à biocompatibilidade, composição, propriedades biomecânicas, taxa de degradação in vivo, interação de matriz-célula e a capacidade para suporte na remodelagem construtiva, a SIS vêm sendo estudada como bioenxerto para reparos de diversas estruturas, 
tais como esôfago, intestino delgado, bexiga, ureteres, ossos, tendões e parede abdominal (LEE; CHANG; DUNN, 2008, SOCCOL et al., 2006).

Muitos trabalhos utilizando a SIS como matriz de colágeno têm sido desenvolvidos, mas em literatura pouco tem sido descrito utilizando a serosa porcina que é a camada mais externa do intestino delgado de suínos.

Tanto macro quanto microscopicamente, a SIS é muito semelhante a SP utilizada neste trabalho (Fig. 12 e 13).
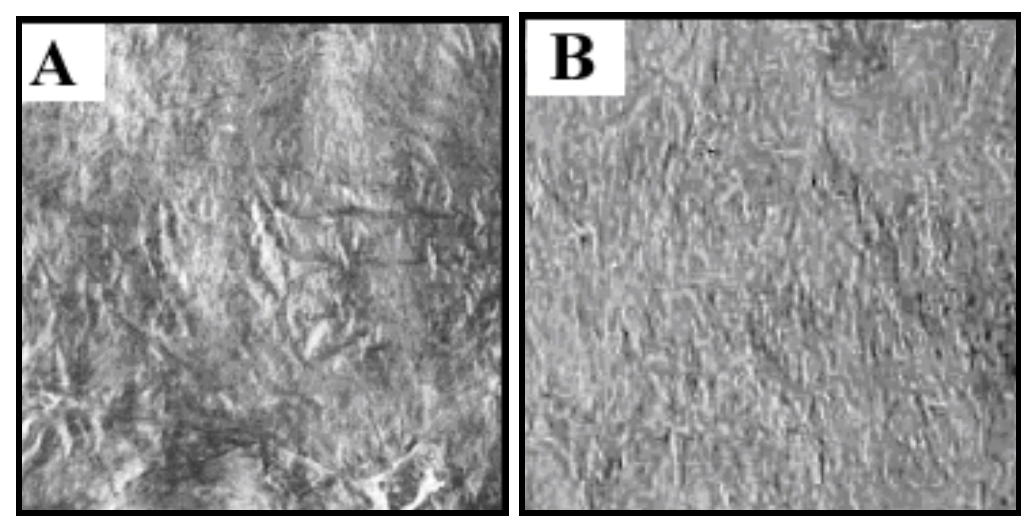

Figura 12. Aspecto macroscópico: (A) SIS desidratada (BADLAK et al; 1999) e (B) serosa porcina.
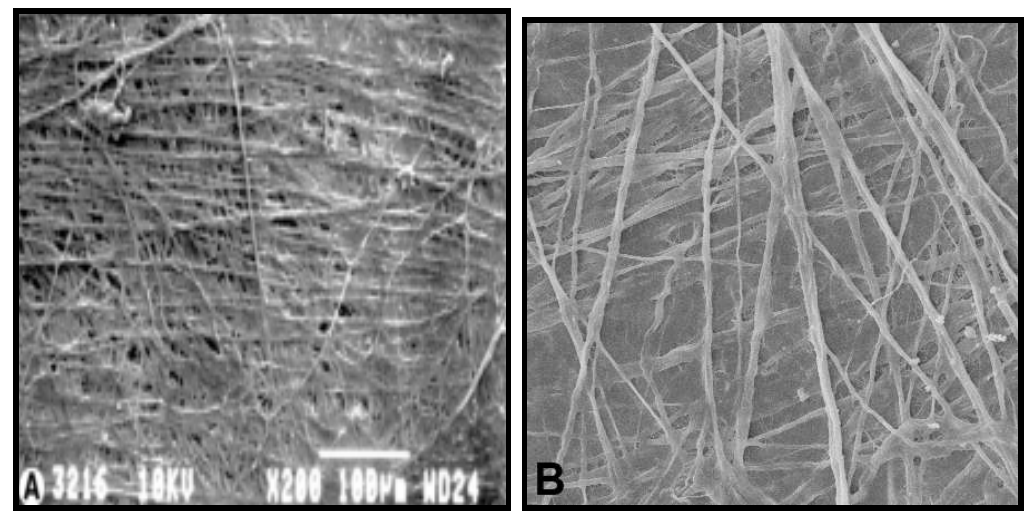

Figura 13. Fotomicrografia por MEV de SIS (A) (BROWN-ETRIS; CUTSHALL; HILES, 2002) e serosa porcina (B).

Girardi (2005) utilizou a membrana de serosa porcina hidrolisada por $24 \mathrm{~h}$ e mostrou que esta matriz é uma boa opção no reparo de lesões cutâneas em ratos, pois é um 
material de baixo custo, tem um excelente manuseio além de atender às principais exigências mencionadas em literatura para qualquer curativo biológico oclusivo.

Desta forma, a serosa porcina torna-se um material para o desenvolvimento de biomateriais que possam ser utilizados na regeneração de tecidos.

\subsection{Mineralização do colágeno}

Tendo em vista a composição do tecido ósseo, a mineralização do colágeno in vitro torna-se de grande interesse para o entendimento dos mecanismos da mineralização in vivo bem como para a síntese de materiais a serem utilizados na regeneração óssea.

Relatos mostram o desenvolvimento de um osso artificial com composição e nanoestrutura química similar a do osso natural. Este material composto por HA e colágeno foi sintetizado sob condições biomiméticas e demonstrou que o eixo-c dos nanocristais de HA está regularmente alinhado juntamente com as fibras de colágeno (KIKUCHI et al., 2004).

A nucleação controlada e o crescimento de cristais, in vitro, têm demonstrado que a nucleação ocorre nas superfícies que tenham grupos aniônicos concentrando cátions e criando locais de supersaturação seguidos por orientação e nucleação dos cristais. (HARTGERINK; BENIASH; STUPP, 2001).

O estudo da mineralização de tendão de coelho utilizando o método de imersão alternada mostrou que nanocristais de fosfato de cálcio foram formados na superfície e na região interna do tendão. Os cristais foram formados nas fibras do colágeno com os eixos-c dos cristais alinhados paralelamente com as fibras de colágeno, sugerindo que os íons cálcio interagem com a superfície do tendão, mais provavelmente com os grupos carboxílicos do colágeno e subseqüente formação de núcleos dos centros cristalinos (YAMAGUSHI et. al., 2003). Além disso, a mineralização pelo método de imersão alternada de filmes colágeno 
aniônico derivado de serosa bovina apresentou uma mineralização 1,24 vezes mais rápida que na superfície de filmes de colágeno nativo (GÓES et al., 2007).

Um dos métodos utilizados de mineralização do colágeno tem sido o uso de solução simuladora de fluido corpóreo $(\mathrm{SBF})$ durante certo período de tempo a fim de induzir a mineralização (LICKORISH et al.; 2004; GIRIJA; YOKOGAWA; NAGATA, 2002). A morfologia dos minerais depositados no colágeno apresentou-se na forma de esferas.

O estudo in situ por microscopia de fase contraste do crescimento biomimético de HA na superfície de membrana de colágeno tipo I imersa em SBF, mostrou a formação dos cristais preferencialmente na superfície de colágeno e que grupos carregados da membrana de colágeno são de grande importância no crescimento desses cristais (ZHANG et al., 2004).

Gel de colágeno obtido de tendão de ratos foi mineralizado por imersão em soluções de cálcio e fosfato. Observou-se, por FTIR a interação entre os íons cálcio e os íons carboxilatos do colágeno e por MEV a formação de aglomerados globulares de fosfato de cálcio com cristalinidade similar àqueles da fase inorgânica do osso (BERTRAN; ALLEGRETTI; BERTAZZO, 2007).

Estudo utilizando matriz de colágeno tipo I mineralizada comprovou que o material tem boa biocompatibilidade, a reabsorção e remodelação foram muito semelhantes ao do enxerto ósseo autólogo, quando implantados no fêmur (YOKOYAMA et al., 2005).

O estudo de colágeno aniônico como suporte à reconstrução de tecido ósseo mostrou que este material é capaz de induzir a deposição de sais de fosfato de cálcio, sugerindo assim que mudanças dielétricas na matriz colagênica podem ter sido os indutores do processo de mineralização do colágeno in vitro, como um sistema semelhante ao estágio de mineralização do osso (GOISSIS; MAGINADOR; MARTINS, 2003). 
Membranas de colágeno aniônico, foram capazes de sustentar o crescimento de osteoblasto por cerca de 8 semanas e a formação de tecido ósseo no interior dessas membranas, sugerindo que as mesmas estimulam a formação de matriz óssea por parte dos osteoblastos (CUNHA, SANTOS, ARNALDO; GENARI, 2005).

Vários trabalhos têm sido reportados com matrizes mineralizadas de colágeno tipo I em diferentes formas como em géis, membranas e esponjas, mas a mineralização in vitro de matrizes acelulares como pericárdio bovino, pele e serosa porcina não têm sido descrito. 


\section{OBJETIVOS}

$\mathrm{Na}$ área de engenharia de tecido ósseo há uma alta demanda por materiais com potencialidade de uso em regeneração óssea. A combinação de colágeno tipo I com fosfatos de cálcio como a hidroxiapatita (HA) gera um material com composição e estrutura próximas à da matriz óssea. Assim este trabalho tem como objetivos:

- Preparação de matrizes de colágeno acelulares através da hidrólise alcalina dos grupos carboxiamidas dos resíduos de asparagina e glutamina presentes na cadeia $\alpha$ do tropocolágeno, com diferentes tempos de hidrólise utilizando como fontes pericárdio bovino, pele e serosa porcina;

- Mineralização in vitro das matrizes hidrolisadas;

- Quantificação da mineralização por termogravimetria.

- Teste de citotoxicidade das matrizes. 


\section{PROCEDIMENTO EXPERIMENTAL}

\subsection{Materiais}

Os tecidos biológicos utilizados foram:

- pele porcina (PPn), retirada da região ventral. O material foi obtido em açougue;

- serosa porcina (SPn) retirada da parte externa do intestino de suínos, a parte interna é retirada e descartada. Este material foi obtido em açougue, sendo normalmente usado para a fabricação de revestimentos para lingüiças.

- pericárdio bovino $(\mathrm{PBn})$ - fornecido pela Braile Biomédica, SA, São José do Rio Preto (SP). O material é usado para confecção de válvulas cardíacas, sendo obtido em frigorífico, imediatamente após o abate dos animais (machos), que têm idades variando entre 30-60 meses.

\subsection{Limpeza dos tecidos utilizados}

SPn e PBn foram lavados com solução salina $0,9 \%(\mathrm{NaCl})$ e água destilada. PPn foi limpa mecanicamente com uma faca para retirada do excesso de gordura, lavada em solução salina $0,9 \%(\mathrm{NaCl})$ e água destilada.

Devido ao excesso de gordura, foi necessário um tratamento prévio para PPn, que foi colocada em uma mistura clorofórmio/metanol (2/1 v/v) em temperatura ambiente por $2 \mathrm{~h}$ e após este período a pele foi lavada exaustivamente com tampão fosfato salino (PBS), pH 7,4 por $6 \mathrm{~h}$ (PRASERTSUNG et al., 2007). 


\subsection{Preparação de matrizes de colágeno aniônico (hidrolisadas)}

Após a limpeza PPn, SPn e PBn foram imersas em uma solução alcalina (hidrólise) por períodos de 0, 24, 48, 72 e 96 h. Esta solução contém sais (sulfatos e cloretos) e hidróxidos de metais alcalinos e alcalinos terrosos, conforme procedimento usual do laboratório (LACERDA; PLEPIS; GOISSIS 1998). Após estes períodos de tempo as matrizes foram colocadas em outra solução contendo sulfatos e cloretos dos íons $\mathrm{Na}^{+}, \mathrm{K}^{+} \mathrm{e} \mathrm{Ca}^{2+}$. O excesso de sais foi removido por lavagens em 3\% de solução de ácido bórico, água desionizada, seguida por EDTA 0,3\% de solução de pH11, e água desionizada.

Após o procedimento de hidrólise, as matrizes foram mantidas em solução de $\mathrm{H}_{3} \mathrm{PO}_{4} 0,01 \mathrm{~mol} \mathrm{~L}^{-1}$ por $24 \mathrm{~h}$ para intumescimento e foram liofilizadas em um equipamento da EDWARDS modelo FREEZE DRYER Modulyo e estocadas a $25^{\circ} \mathrm{C}$.

A matriz de pele porcina hidrolisada por $96 \mathrm{~h}$ sem pré-tratamento orgânico foi nomeada PP96S. As matrizes obtidas após o tratamento orgânico foram nomeadas como mostrado na Tabela 2.

Tabela 2. Matrizes de colágeno aniônico tipo I obtidas após hidrólise alcalina

\begin{tabular}{c|c|c|c|c|c}
\hline \multirow{2}{*}{ Matrizes } & \multicolumn{5}{|c}{ Tempo de Hidrólise (h) } \\
\cline { 2 - 6 } & 0 & 24 & 48 & 72 & 96 \\
\hline Pele Porcina & PPn & PP24 & PP48 & PP72 & PP96 \\
\hline Pericárdio Bovino & PBn & PB24 & PB48 & PB72 & PB96 \\
\hline Serosa Porcina & SPn & SP24 & SP48 & SP72 & SP96 \\
\hline
\end{tabular}


O fluxograma apresentado na Figura 14 resume a preparação das matrizes:

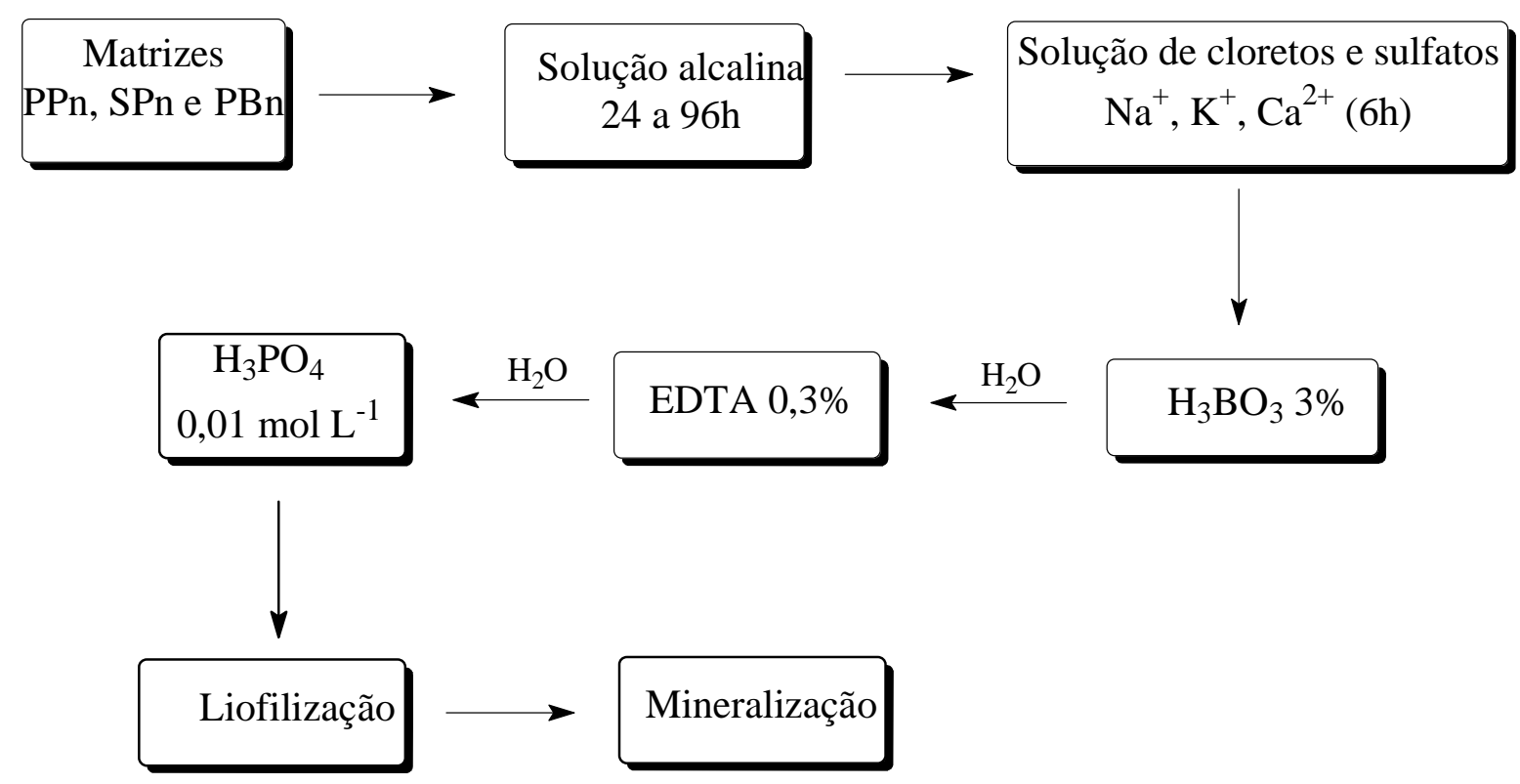

Figura 14. Fluxograma da preparação das matrizes.

\subsection{Mineralização das matrizes}

Foram testados três métodos de mineralização a fim de se obter um procedimento mais reprodutível e com uma quantidade de sal mais elevada. Os testes foram feitos com a matriz PP96S e após obtenção do resíduo inorgânico por termogravimetria pôde-se escolher o método mais adequado a ser utilizado para as demais matrizes.

\section{Método I (1,5 SBF)}

Este método é bastante utilizado em estudos de mineralização in vitro e desta forma foi o primeiro a ser testado. O método consiste da imersão da matriz de colágeno em uma solução simuladora de fluido biológico (SBF) descrita em literatura (KOKUBO et al, 2006). As concentrações iônicas dos sais da solução utilizada estão na Tabela 3. 
Tabela 3. Concentração iônica dos sais da solução utilizada (KOKUBO et al, 2006)

\begin{tabular}{|c|c|c|}
\hline Íons & $\mathrm{SBF}(\mathrm{mmol} \mathrm{L}$ & $1,5 \mathrm{SBF}\left(\mathrm{mmol} \mathrm{L}^{-1}\right)$ \\
\hline $\mathrm{Na}^{+}$ & 142,00 & 213,00 \\
\hline $\mathrm{K}^{+}$ & 5,00 & 7,50 \\
\hline $\mathrm{Ca}^{2+}$ & 2,50 & 3,80 \\
\hline $\mathrm{Mg}^{2+}$ & 1,50 & 2,30 \\
\hline $\mathrm{HCO}^{3-}$ & 4,20 & 6,30 \\
\hline $\mathrm{Cl}^{-}$ & 148,80 & 223,00 \\
\hline $\mathrm{HPO}_{4}{ }^{2-}$ & 1,00 & 1,50 \\
\hline $\mathrm{SO}_{4}{ }^{2-}$ & 0,50 & 0,75 \\
\hline
\end{tabular}

Os sais utilizados foram $\mathrm{Na}_{2} \mathrm{HPO}_{4}, \mathrm{KHCO}_{3}, \mathrm{KCl}, \mathrm{NaHCO}_{3}, \mathrm{NaCl}, \mathrm{MgSO}_{4} 7 \mathrm{H}_{2} \mathrm{O}$, $\mathrm{MgCl}_{2} 6 \mathrm{H}_{2} \mathrm{O}$ e $\mathrm{CaCl}_{2} 2 \mathrm{H}_{2} \mathrm{O}$ e foram dissolvidos em água desionizada. $\mathrm{O} \mathrm{pH}$ da solução foi ajustado para 7,2 com uma solução $\mathrm{HCl} 0,01 \mathrm{~mol} \mathrm{~L}^{-1}$ e Tris $0,05 \mathrm{~mol} \mathrm{~L}^{-1}$. A taxa de nucleação e crescimento de HA pode ser acelerada pelo uso de 1,5 SBF, que possui uma concentração iônica 1,5 vezes maior que para SBF (TANAHASHI et al.; 1994). Neste trabalho foi utilizada apenas a solução de 1,5 SBF já que o objetivo era conseguir uma maior mineralização.

A matriz PP96S foi cortada em dois pedaços semelhantes e foi colocada na solução 1,5 SBF por 5 e 10 dias a $37^{\circ} \mathrm{C}$, retiradas da solução e lavadas com água desionizada. Em seguida foram congeladas, liofilizadas e analisadas por termogravimetria.

\section{Método II (Cela dupla termostatizada)}

A cela dupla consiste de uma câmara com duas partes separadas por um orifício no centro, no qual o material a ser mineralizado pode ser fixado, de modo que as soluções de $\mathrm{Ca}^{2+}$ e $\mathrm{PO}_{4}{ }^{3-}$ fiquem separadas pelo material, que permite a difusão dos íons com a conseqüente precipitação de fosfatos de cálcio (Fig.15). 
O estudo de mineralização foi feito em cela dupla termostatizada (BATISTA; MARTINS; PLEPIS, 2007) a $37{ }^{\circ} \mathrm{C}$ e sob agitação, por $24 \mathrm{~h}$, com soluções de $\mathrm{CaCl}_{2}$ 0,1 mol L $\mathrm{e} \mathrm{NaH}_{2} \mathrm{PO}_{4}$ 0,06 mol L ${ }^{-1}$ ambas em pH 7,4. Após a mineralização, PP96SC foi lavada com água desionizada, congelada e liofilizada.

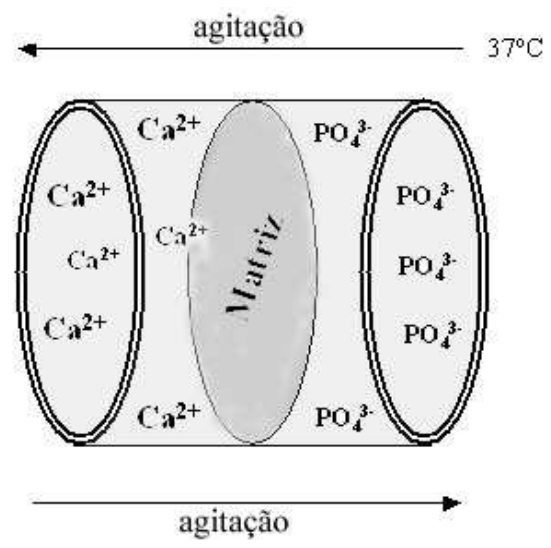

Figura 15. Cela dupla utilizada para mineralização das matrizes.

\section{Método III (Imersão alternada)}

Depois da hidrólise e liofilização as matrizes foram colocadas em soluções para mineralização seguindo os seguintes passos:

1- Imersão em 60 mL de uma solução de $\mathrm{CaCl}_{2}$ 0,2 mol L-1 em tampão Tris $0,05 \mathrm{~mol} \mathrm{~L}^{-1}(\mathrm{pH} 7,4)$ a $37^{\circ} \mathrm{C}$ por 30 minutos ( YAMAGUSHI et. al., 2003).

2- Lavagem com água desionizada;

3- Imersão em solução $\mathrm{Na}_{2} \mathrm{HPO}_{4} \quad 0,12 \mathrm{~mol} \mathrm{~L}^{-1}$ em tampão Tris $0,05 \mathrm{~mol} \mathrm{~L}^{-1}$ (pH 9,0) a $37^{\circ} \mathrm{C}$ por 30 minutos;

4- Lavagem com água desionizada; 
O ciclo de imersão (Fig. 16) foi repetido por 6 vezes para obtenção das matrizes mineralizadas, que foram então lavadas com água desionizada, liofilizadas e analisadas.

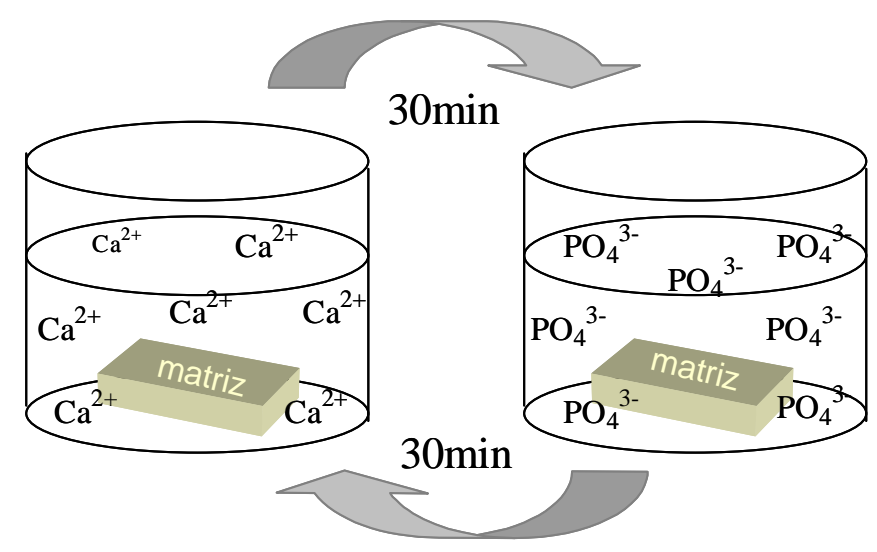

Figura 16. Método de imersão alternada.

Este foi o método escolhido para ser usado para todas as matrizes, pois foi o que obteve uma maior quantidade de resíduo inorgânico e reprodutibilidade.

As matrizes obtidas após a mineralização foram nomeadas como mostrado na Tabela 4.

Tabela 4. Matrizes de colágeno obtidas após mineralização pelo método de imersão alternada

\begin{tabular}{c|c|c|c|c}
\hline \multirow{2}{*}{ Matrizes } & \multicolumn{4}{|c}{ Tempo de hidrólise (h) } \\
\cline { 2 - 5 } & 24 & 48 & 72 & 96 \\
\hline PP mineralizada & PP24C & PP48C & PP72C & PP96C \\
\hline SP mineralizada & SP24C & SP48C & SP72C & SP96C \\
\hline PB mineralizado & PB24C & PB48C & PB72C & PB96C \\
\hline
\end{tabular}




\subsection{Caracterização das matrizes}

\subsubsection{Calorimetria Exploratória diferencial (DSC)}

As curvas DSC foram obtidas em um equipamento TA Instruments, modelo DSC 2010 calibrado com padrão de índio. A razão de aquecimento foi de $10{ }^{\circ} \mathrm{C} \min ^{-1}$, na faixa de aquecimento de 5 a $120{ }^{\circ} \mathrm{C}$, porém foram mostrados apenas na faixa de $30-80^{\circ} \mathrm{C}$ para mostrar

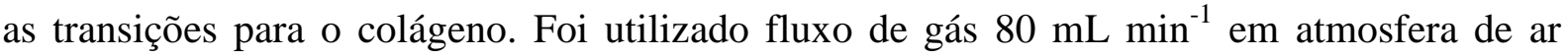
sintético. Foram utilizadas massas de cerca de $10 \mathrm{mg}$, em suportes herméticos de alumínio.

\subsubsection{Termogravimetria (TG)}

As curvas termogravimétricas foram obtidas utilizando amostras de aproximadamente $10 \mathrm{mg}$ em cadinho de alumina, atmosfera de ar sintético com variação de temperatura de 25 a $800{ }^{\circ} \mathrm{C}$, razão de aquecimento de $10{ }^{\circ} \mathrm{C} \mathrm{min}{ }^{-1}$ e fluxo de gás $90 \mathrm{~mL} \mathrm{~min}{ }^{-1}$ em um equipamento TGA 2050 (TA Instruments), calibrado com oxalato de cálcio.

\subsubsection{Microscopia Eletrônica de Varredura (MEV)}

As fotomicrografias foram obtidas em um equipamento LEO 440 (LEO Electron Microscopy Ltda), com um detector Oxford (Oxford Instruments Inc.), utilizando-se feixe de $20 \mathrm{keV}$. As amostras foram recobertas previamente com $20 \mathrm{~nm}$ de liga ouro-paládio em um metalizador Balsers modelo SDC 050. 


\subsubsection{Difração de raios X (DRX)}

Os difratogramas das matrizes mineralizadas, de aproximadamente $1 \mathrm{x} 1 \mathrm{~cm}$, foram obtidos em um difratômetro automático Rigaku-Rotaflex Ru-200B, com radiação monocromática de CuKa $(l=1,5418 \AA)$ com potência de $50 \mathrm{kV}, 100 \mathrm{~mA}$.

\subsubsection{Espectroscopia por energia dispersiva (EDS)}

A técnica permite a determinação da composição qualitativa e semi-quantitativa das amostras, a partir de emissão de raios X característicos. A análise de Energia Dispersiva (EDS) foi realizada em um equipamento EDX LINK ANALYTICAL, (Isis System Series 200), com detetor de SiLi Pentafet, janela ultrafina ATW II (Atmosphere Thin Window), de resolução de $133 \mathrm{eV}$ à 5,9 keV, acoplado a um Microscópio Eletrônico LEO 440 (LEO Electron Microscopy Ltd), com um detector Oxford (Oxford Instruments Inc.). Utilizou-se padrão de Co para calibração, feixe de elétrons de $20 \mathrm{kV}$, distância focal de $25 \mathrm{~mm}$, “dead time" de $30 \%$, corrente de 2,82 A e I "probe" de 950 pA. As análises foram realizadas utilizando-se amostras das matrizes mineralizadas na forma de pastilhas que foram prensadas com 8 toneladas e recobertas com carbono. Para a análise semi-quantitativa foi utilizado o ISIS software 3.1.

\subsubsection{Espectroscopia no infravermelho (FTIR)}

O espectro de absorção na região do infravermelho foi obtido em pastilhas de $\mathrm{KBr}$ em um intervalo entre 400 a $4000 \mathrm{~cm}^{-1}$, com resolução de $4 \mathrm{~cm}^{-1}$ utilizando um espectrofotômetro de FTIR BOMEN MB-120. As matrizes obtidas eram muito rígidas e as partículas de fosfato de cálcio não se desprendiam facilmente, por isso as matrizes foram picotadas para a obtenção das pastilhas. 


\subsubsection{Avaliação do potencial de citotoxicidade in vitro}

Esta análise foi realizada no Grupo de Cultura Celular e Fotossensibilizadores DQFM - IQSC/USP por Cláudia Bernal sob coordenação da Profa Dr. Janice Rodrigues Perussi.

As matrizes derivadas de pericárdio bovino e serosa porcina foram esterilizadas previamente com óxido de etileno pela Oxetil Indústria e Comércio de Produtos Esterilizados Ltda - EPP, Santo Anastácio - SP e as matrizes derivadas de pele porcina, também esterilizadas com óxido de etileno, pela Acecil Central de Esterilização Comércio e Indústria Ltda, Campinas - SP. Foram utilizadas para este teste preliminar as matrizes hidrolisadas por 24 e 96 h e suas respectivas mineralizações, pois as matrizes de 48 e $72 \mathrm{~h}$ seguem a mesma tendência das outras duas matrizes.

Inicialmente foi feito a cultura das linhagens celulares e em seguida o método utilizado para o ensaio de citotoxicidade foi o de difusão em Agar. Neste método a monocamada celular é sobreposta por uma camada de Agar e os materiais a serem testados são colocados sobre esta camada.

\subsubsection{Cultura Celular}

Todas as manipulações com as células foram realizadas em capela de fluxo laminar. As células utilizadas foram:

- Linhagem celular de laringe humana (HEp-2), depositada no ATCC (American Type Culture Collection) sob o código CCL-23, a qual é obtida a partir de um carcinoma de laringe humana, de morfologia epitelial e crescimento aderente a um substrato sólido; 
- Linhagem celular de fibroblastos de rato (McCoy B), depositada no ATCC (American Type Culture Collection) sob o código CRL-1696.

Estas linhagens foram cultivadas separadamente em meio ISCOVE'S (Anexo I) suplementado com $10 \%$ de soro fetal bovino (SFB) e os antibióticos ampicilina e estreptomicina. Este ensaio está de acordo com a norma ASTM F895-84 (2006).

Foram feitos subcultivos das células a cada três dias e as células foram mantidas em estufa de cultura a $37{ }^{\circ} \mathrm{C}$, atmosfera de ar 95\% e 5\% de $\mathrm{CO}_{2}$ (CARVALHO, 2001).

O meio de cultura foi removido por aspiração e em seguida adicionou-se solução de Tripsina - EDTA 0,02\%. Para que as ligações entre as células e a superfície tratada do frasco rompessem e as células se soltassem aguardou-se cerca de cinco minutos. Após este período o conteúdo do frasco foi transferido para um tubo cônico, centrifugou-se a $1000 \mathrm{rpm}$ durante 40 segundos, descartou-se o sobrenadante e ressuspenderam-se as células em meio de cultura (Fig. 17).

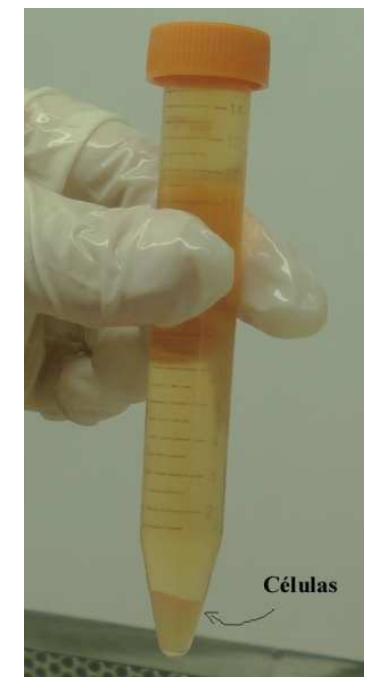

Figura 17. Suspensão das células.

Para a determinação da viabilidade celular utilizou-se o método da contagem em câmara de Neubauer (Fig. 18) e o teste da exclusão do corante (CARVALHO, 2001). Para a 
contagem do número de células retirou-se uma alíquota após a homogeneização. Em seguida, diluiu-se a suspensão de células com meio ISCOVE's com $10 \%$ de soro fetal bovino e as células foram plaqueadas novamente em frascos apropriados.

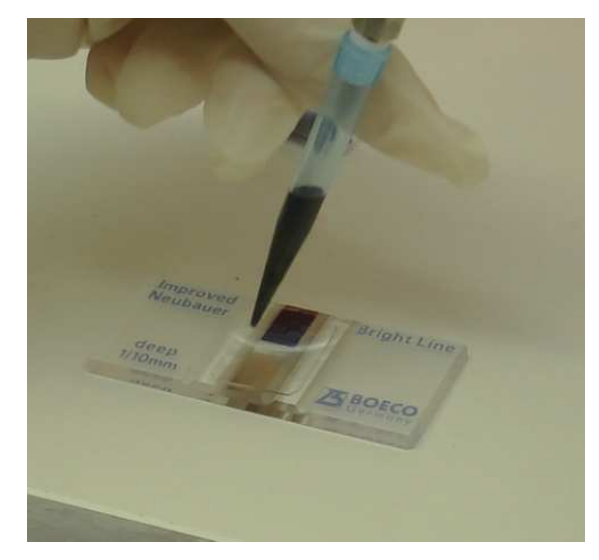

Figura 18. Câmara de Neubauer.

Após a contagem $\left(3,0 \times 10^{5}\right.$ células $\mathrm{mL}^{-1}$, valor mínimo aceitável), as células foram utilizadas nos testes de citotoxicidade utilizando o método de difusão em ágar.

\subsubsection{Método de difusão em ágar}

O teste de citotoxicidade foi feito pelo método de difusão em ágar, utilizando como corante o vermelho neutro (ROGERO et al., 2003) que irá corar somente as células intactas. Neste método a linhagem celular foi incubada durante $48 \mathrm{~h}$ a $37{ }^{\circ} \mathrm{C}$ em placas de Petri em atmosfera de ar com $5 \%$ de $\mathrm{CO}_{2}$.

Após este período, com a monocamada de células já formada, o meio de cultura foi desprezado e adicionado um meio de cobertura sólido composto de partes iguais do meio ISCOVE’S (Sigma) e ágar (Sigma) a 1,8\% contendo 0,01\% de vermelho neutro (JTBaker). No momento do uso, o ágar foi fundido e misturado na mesma proporção com o meio, ambos a uma temperatura de aproximadamente $44{ }^{\circ} \mathrm{C}$. Fragmentos com cerca de $0,5 \mathrm{~cm}^{2}$ de área das 
matrizes foram colocados sobre o ágar antes de sua solidificação completa (Fig. 19B). As placas de Petri foram incubadas novamente em estufa com $5 \% \mathrm{CO}_{2}$ a $37{ }^{\circ} \mathrm{C}$ por $24 \mathrm{~h}$.
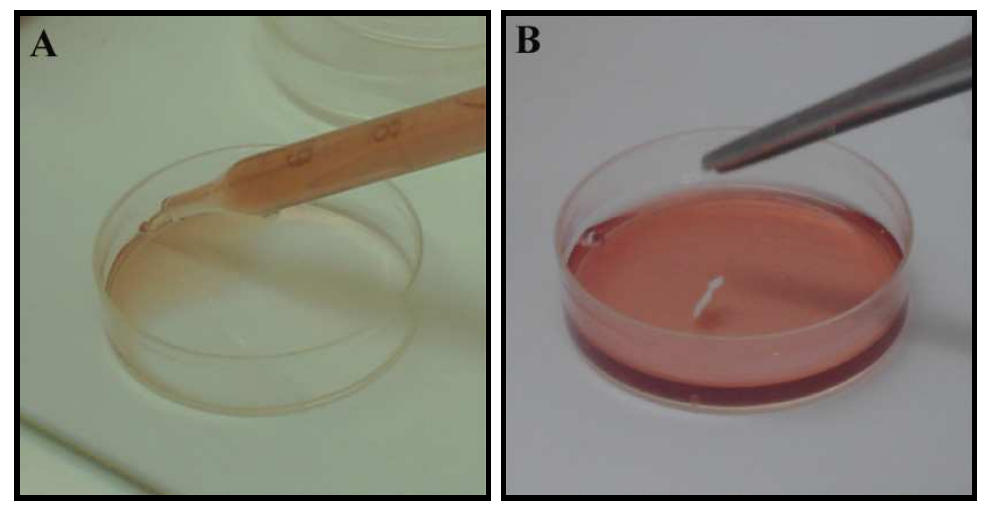

Figura 19. Meio de cobertura com corante vermelho neutro (A) e matriz sendo colocada na placa de petri (B).

Para controle positivo de citotoxidade foram utilizados fragmentos de látex estéreis e como controle negativo fragmentos de papel de filtro de natureza comprovadamente atóxica. As placas foram analisadas macroscopicamente quanto à presença de halo e microscopicamente quanto à integridade celular ao redor da amostra (ROGERO et al., 2003).

As amostras foram avaliadas em triplicata em cada um dos experimentos. 


\section{RESULTADOS E DISCUSSÃO}

\subsection{Mineralização - Ensaio Piloto}

A matriz PP96S foi escolhida para um teste prévio de mineralização usando-se os três métodos propostos: 1,5 SBF (método I), cela dupla termostatizada (método II) e imersão alternada (método III).

O objetivo deste teste prévio foi observar a reprodutibilidade e a porcentagem de mineralização obtida em cada um dos três métodos de mineralização. Os valores de porcentagem de mineralização foram determinados a partir dos resíduos obtidos a $750{ }^{\circ} \mathrm{C}$ nas curvas termogravimétricas (Fig. 20).

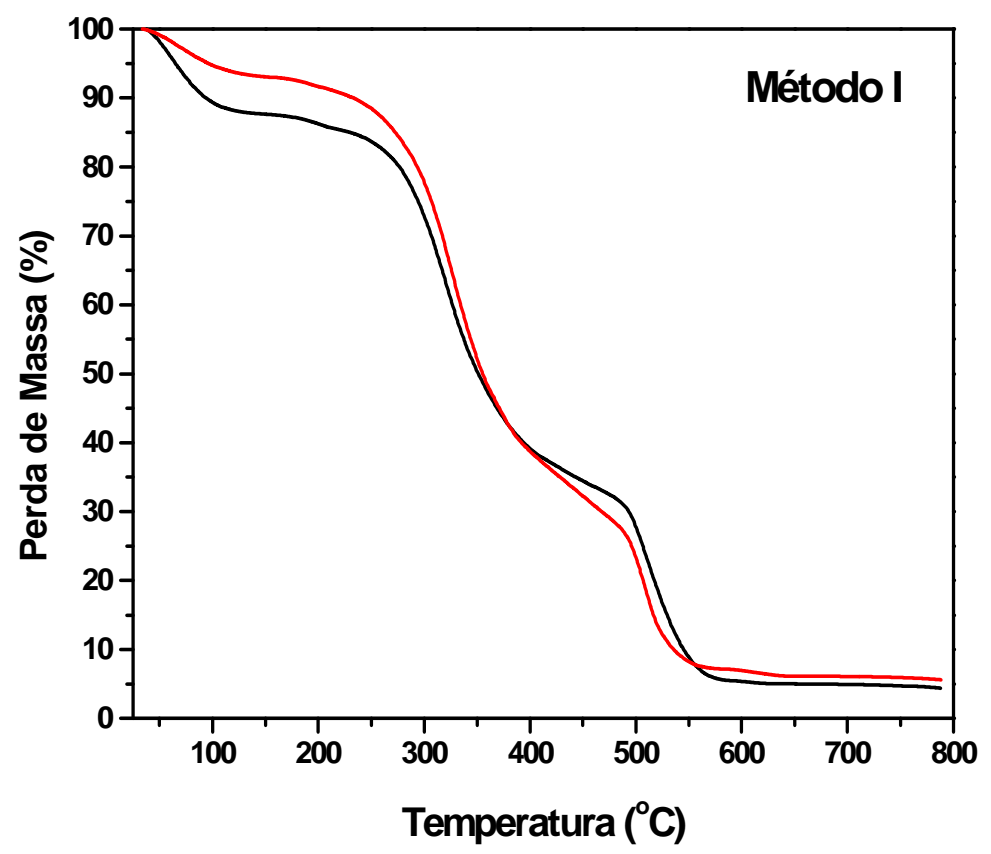

Figura 20. Curvas termogravimétricas do método 1,5 SBF (-) 5 dias e (-) 10 dias. 
Esta metodologia foi descartada por ser muito baixo o conteúdo de material inorgânico depositado e pelo tempo de imersão ser relativamente longo (5 ou 10 dias), quando comparada com os outros dois métodos.

A Figura 21 mostra as curvas termogravimétricas para as matrizes mineralizadas pelo método II que foram feitas em triplicata. Observa-se que não ocorreu repetitividade na obtenção do resíduo tendo-se uma variação de 5 a 30\%, não sendo o método mais adequado a ser usado.

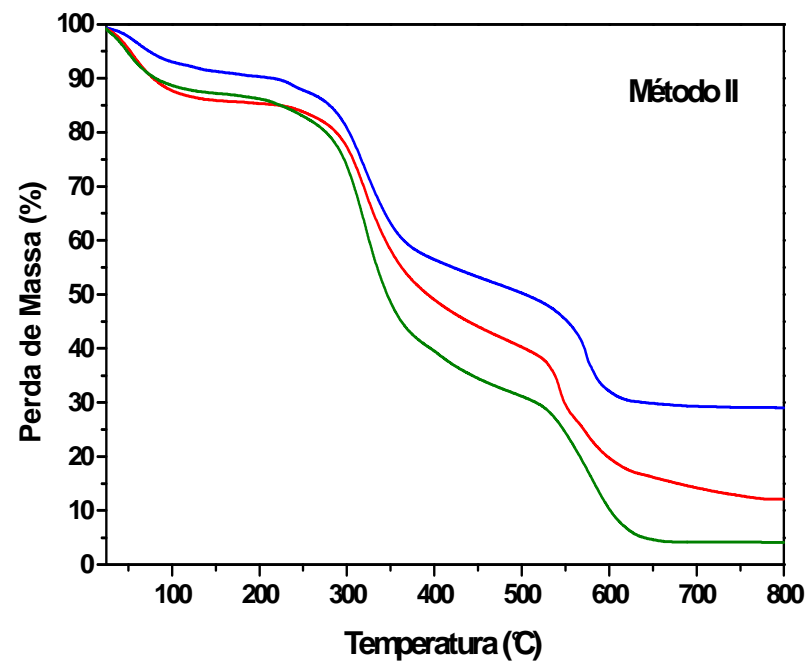

Figura 21. Curvas termogravimétricas de PP96SC em triplicata, obtida após a mineralização pelo método II.

A Fig. 22 mostra a fotomicrografia por MEV da matriz mineralizada onde se vê que a mineralização não ocorre de modo homogêneo, observando-se regiões que não há deposição de sais na superfície (Setas). 


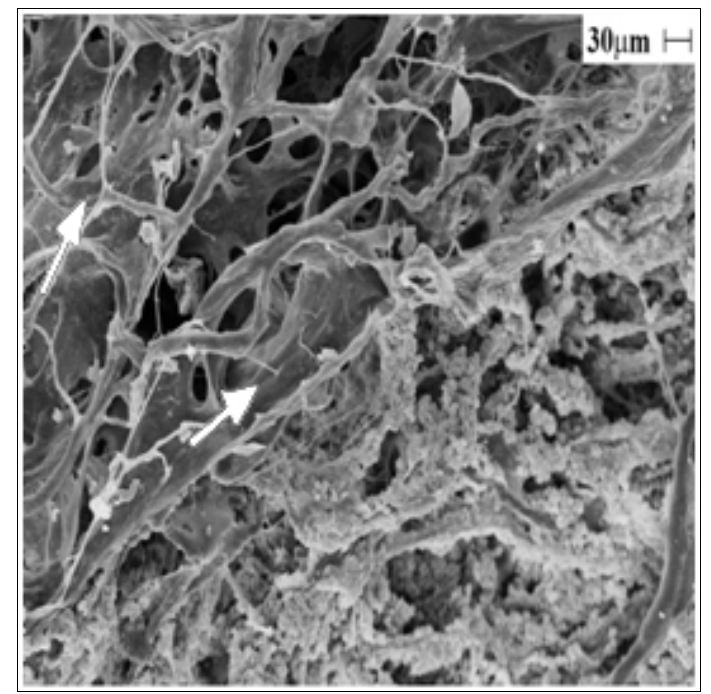

Figura 22. Fotomicrografia por MEV de PP96SC, obtida pelo método da cela dupla termostatizada (aumento de 500 vezes).

O método de mineralização que obteve uma porcentagem de resíduo inorgânico com maior repetitividade e em maior quantidade utilizando a termogravimetria foi o método de imersão alternada (método III), que teve uma variação de aproximadamente 18-20\% (Fig. 23).

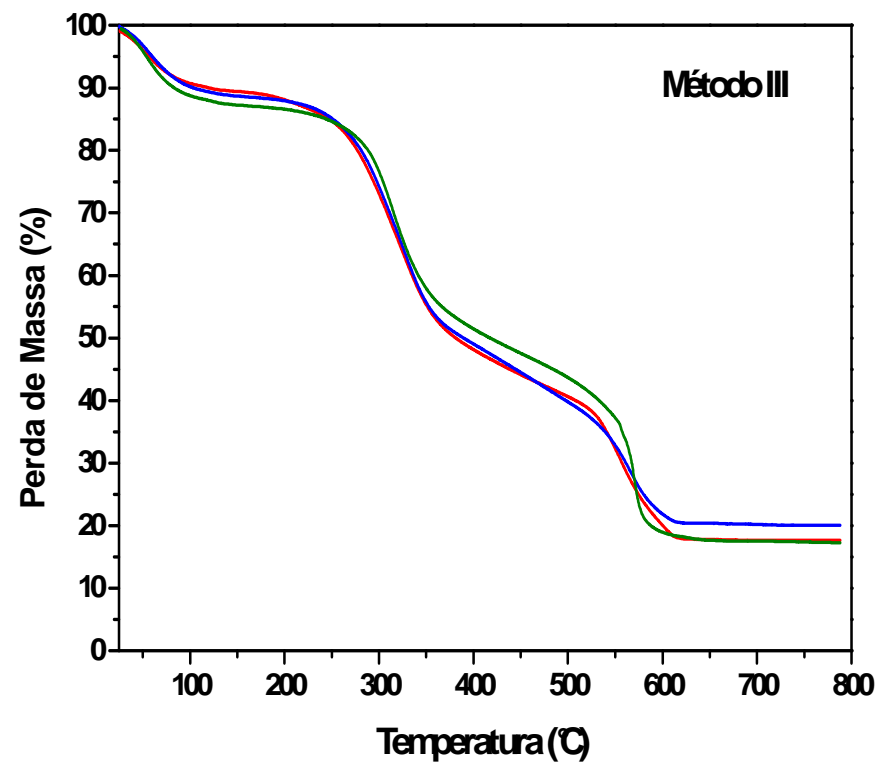

Figura 23. Curvas termogravimétricas de PP96SC em triplicata obtida após mineralização pelo método III. 
A Figura 24 mostra a deposição se sais de fosfato por toda a superfície.

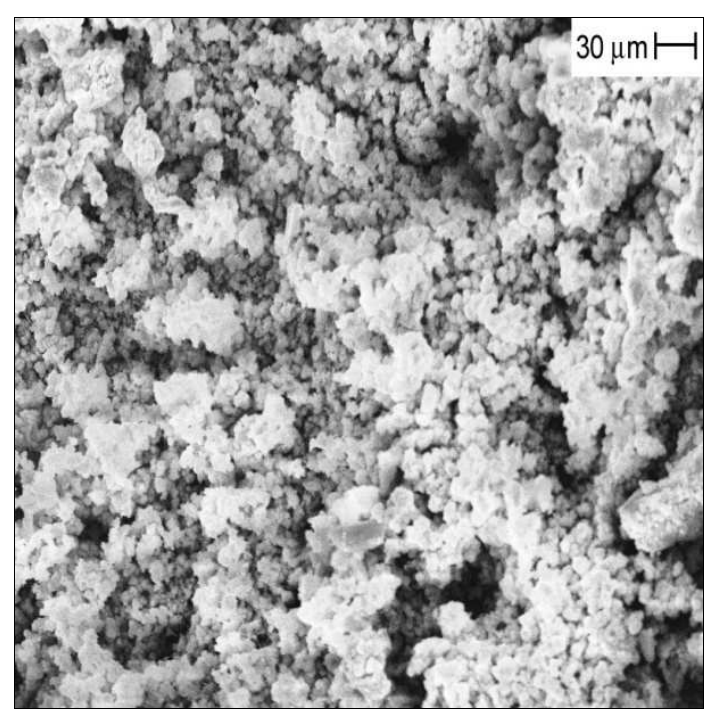

Figura 24. Fotomicrografia por MEV de PP96SC, obtida pelo método de imersão (aumento de 500 vezes).

Assim o método de imersão alternada foi o método escolhido neste trabalho para a mineralização dos tecidos pele porcina, pericárdio bovino e serosa porcina, pois foi o método com maior rendimento de mineralização e o mais reprodutível.

\subsection{Avaliação Macroscópica das matrizes}

Os tecidos hidrolisados possuem espessuras diferentes, sendo que pele porcina é a matriz mais espessa, seguida por pericárdio bovino e serosa porcina. As medidas $(n=25)$ das espessuras foram feitas com um micrômetro (modelo MITUTOYO 0-25 mm) e foram de $4,60 \pm 0,04,1,90 \pm 0,05$ e $0,50 \pm 0,03 \mathrm{~mm}$, respectivamente.

\subsubsection{Pele Porcina (PP)}

Foram utilizados dois tratamentos na pele porcina com e sem a utilização de solvente orgânico. Após a limpeza e liofilização, a matriz PPn apresentou-se rígida e tinha 
uma coloração amarelada (Fig. 25A) devido a presença de gordura na pele. Após limpeza sem o uso de solvente orgânico e hidrólise alcalina, esta matriz ficou mais clara, ou seja, pelo menos parte da gordura presente foi removida neste tratamento (Fig. 25B). Após a mineralização a matriz tornou-se mais rígida e com aspecto esbranquiçado.
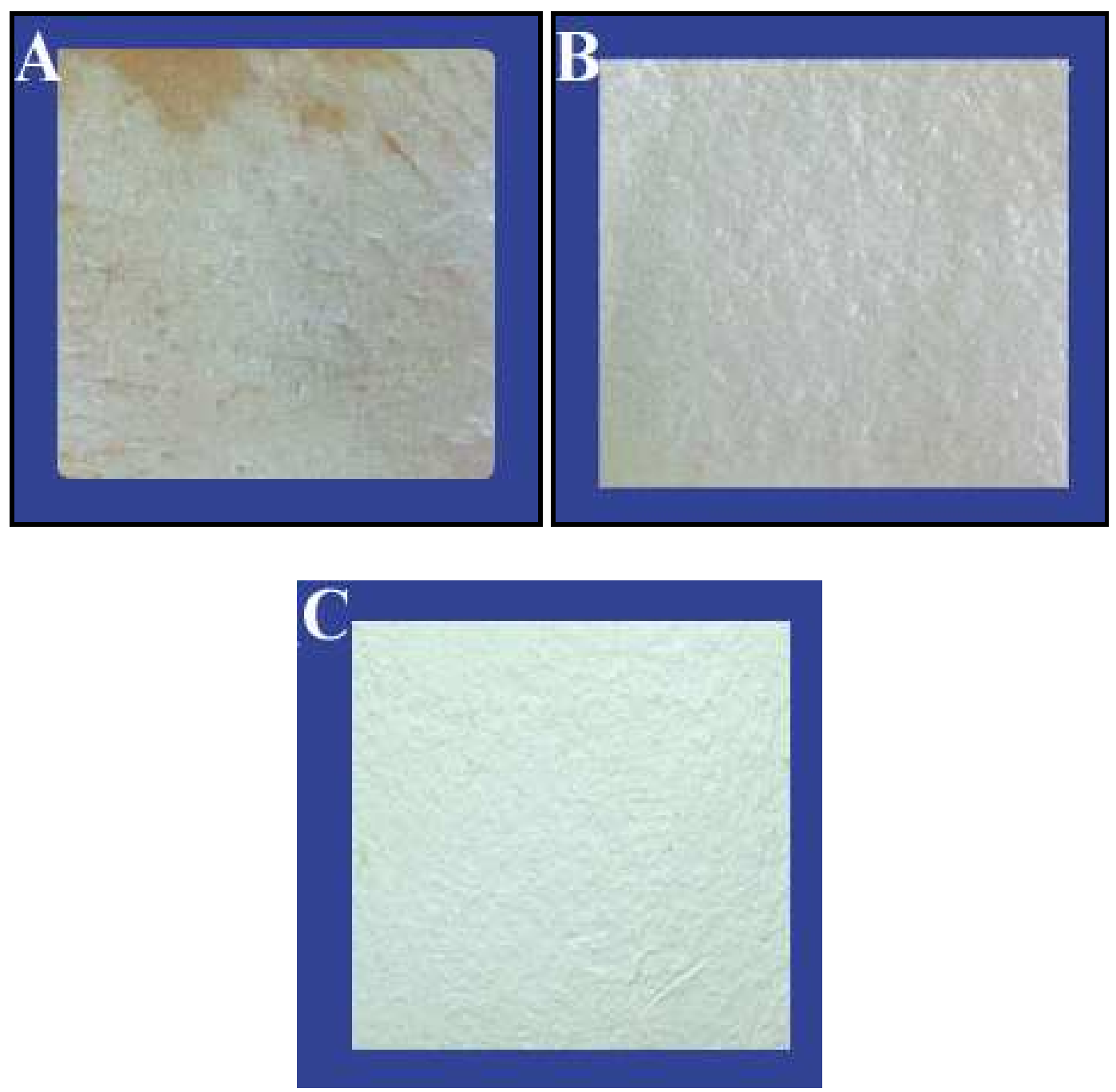

Figura 25. Foto digital das matrizes (A) PPn, (B) PP96S e (C) PP96S mineralizada.

Após tratamento com solvente orgânico a matriz hidrolisada também se apresentou mais clara em relação à nativa. A matriz PP96C apresentou-se mais rígida e com sais brancos (fosfato de cálcio) em toda a superfície (Fig. 26B). 

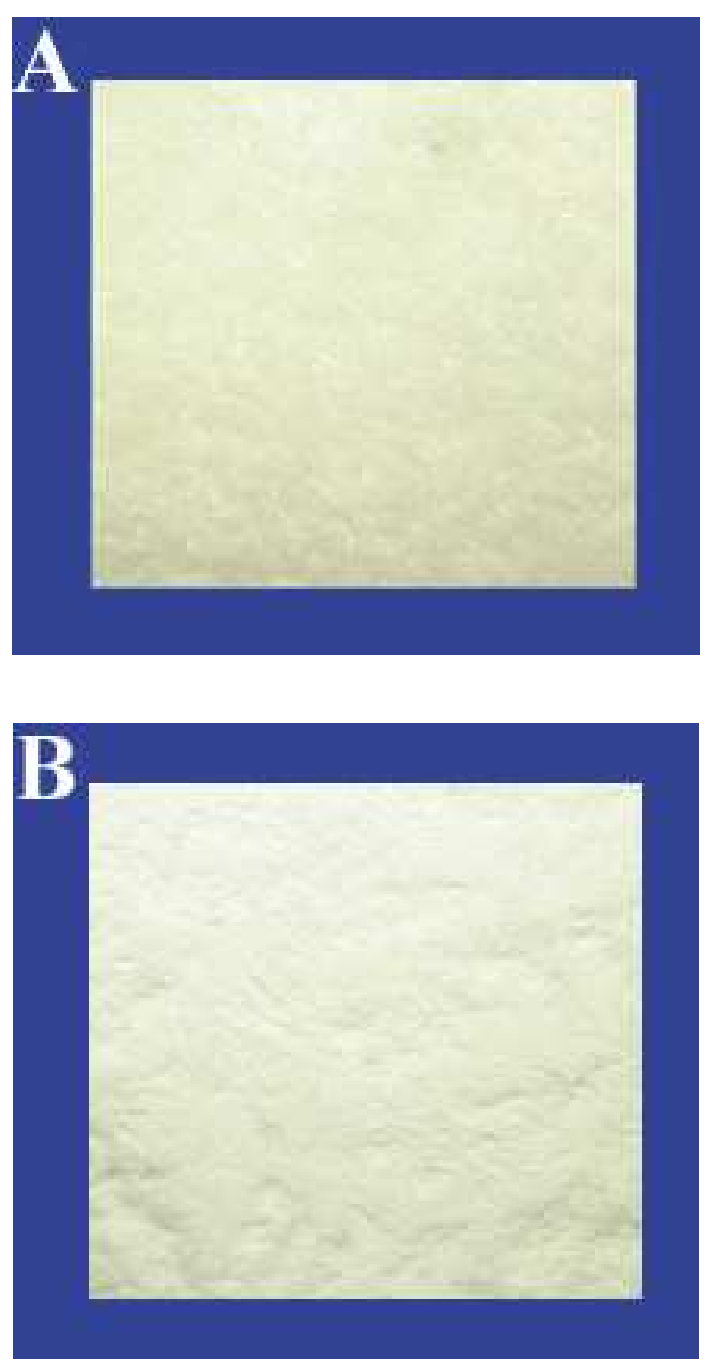

Figura 26. Foto digital das matrizes pré-tratadas com solvente orgânico: (A) PP96 e (B) PP96C.

As matrizes com tempos de hidrólise de 24,48 e $72 \mathrm{~h}$ tiveram o mesmo comportamento, sem diferenças aparentes entre elas.

\subsubsection{Pericárdio Bovino}

Após a limpeza e liofilização PBn tinha um aspecto esbranquiçado. A matriz PB96 tornou-se mais transparente após a hidrólise (Fig. 27B) e após a mineralização apresentou-se esbranquiçada perdendo a transparência quando comparada com a matriz 
apenas hidrolisada. Além disso, PP96C (Fig. 27C) mostrou-se mais rígida que PP96 (Fig. 27B).
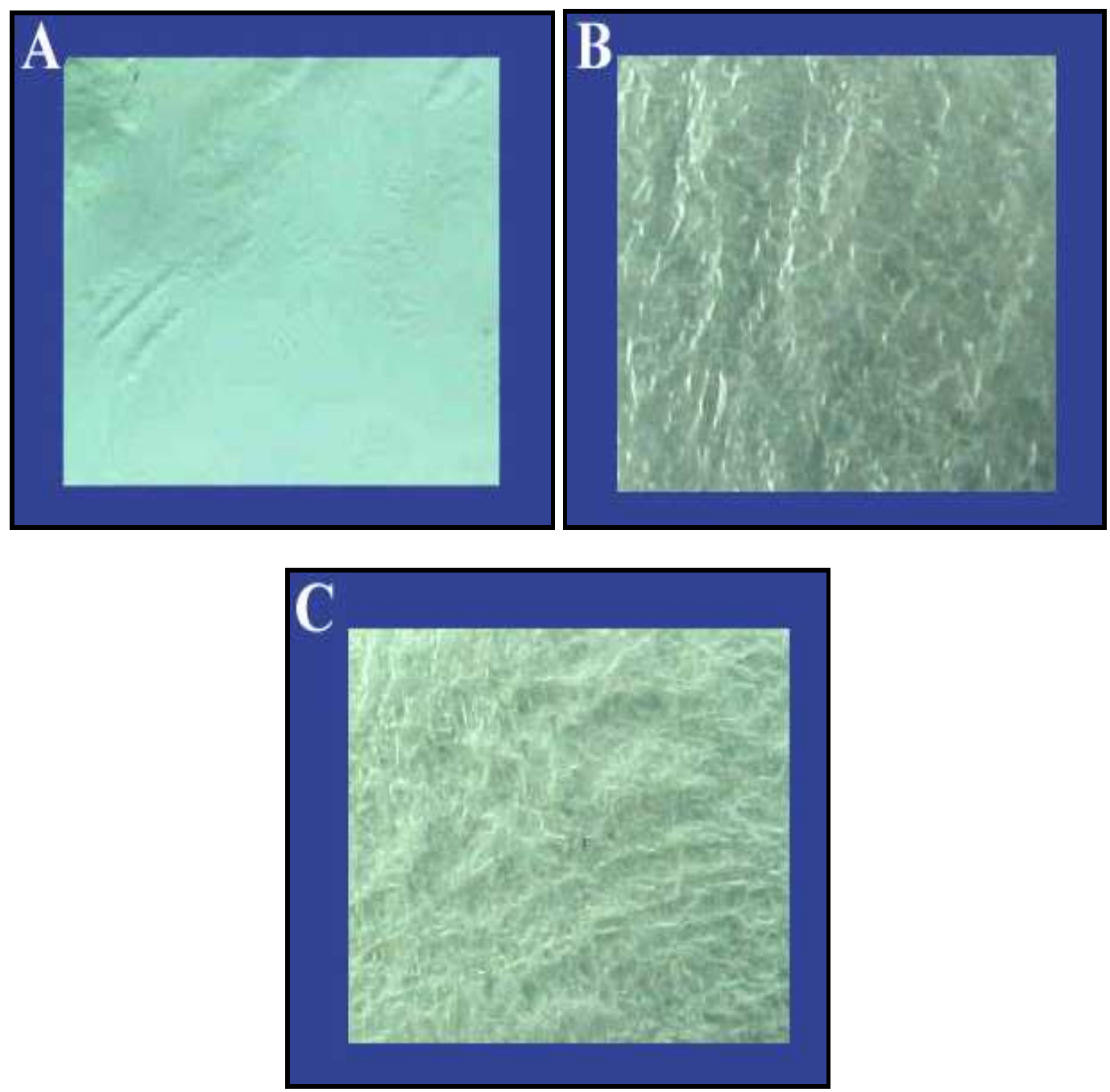

Figura 27. Foto digital das matrizes (A) PBn, (B) PB96 e (C) PB96C.

As demais matrizes hidrolisadas por 24, 48 e $72 \mathrm{~h}$ apresentaram o mesmo aspecto.

\subsubsection{Serosa porcina}

Após a hidrólise alcalina a matriz SP96 apresentou-se mais transparente (Fig. 28B) em comparação com a SPn (Fig.28A). Após mineralização, SP96C tornou-se mais esbranquiçada devido à presença de sais de fosfato de cálcio (Fig. 28C). 

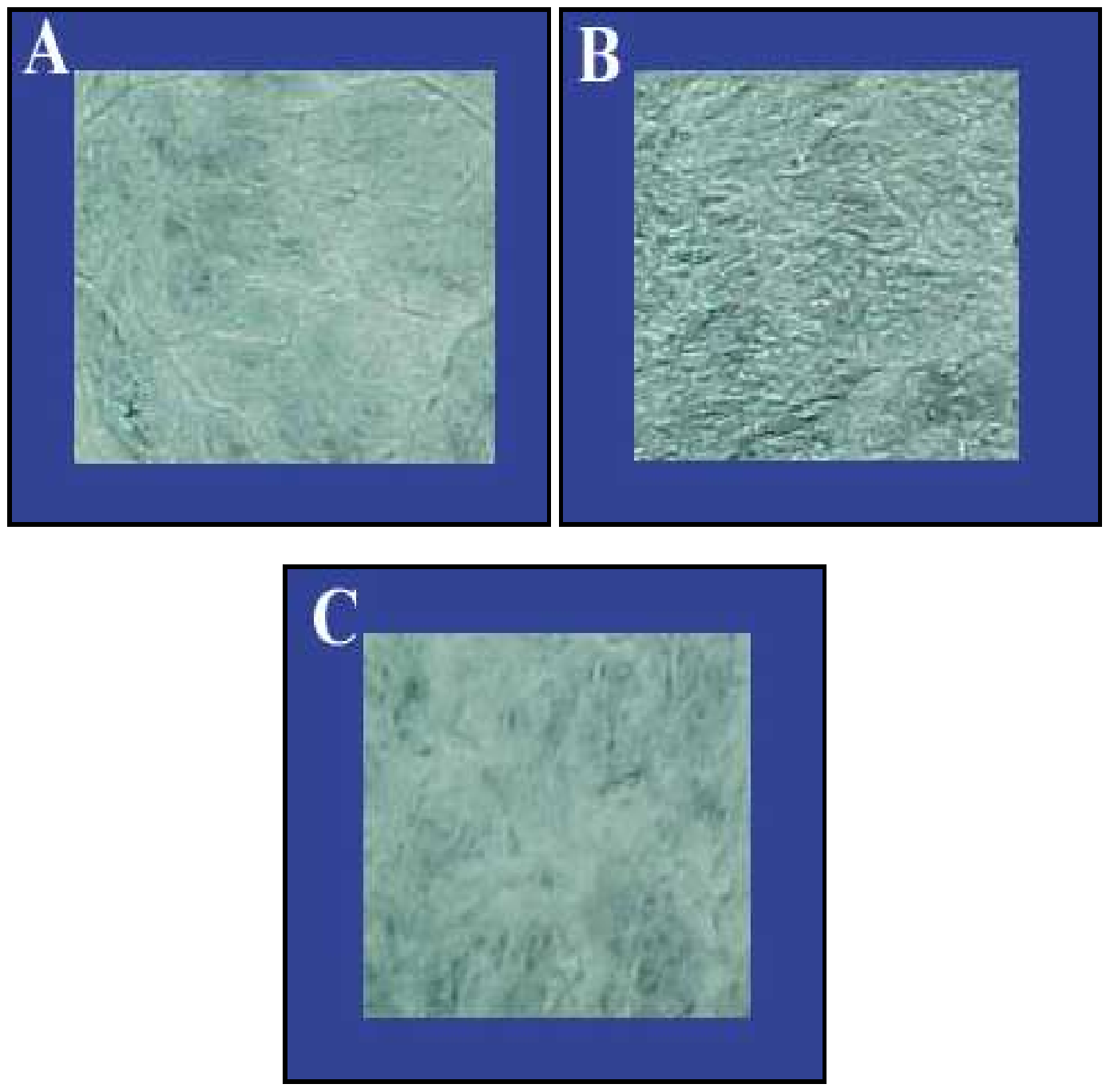

Figura 28. Foto digital das matrizes (A) SPn, (B) SP96 e (C) SP96C.

As demais matrizes hidrolisadas e suas respectivas mineralizações se comportaram da mesma maneira. Comparando-se os três tecidos biológicos utilizados, observa-se que a pele porcina é a mais gordurosa e a mais espessa. Quando hidrolisada é a mais rígida e pericárdio bovino e serosa porcina são mais maleáveis. Observando-se as Figuras 26B, 27B e 28B a pele porcina é a única que não apresenta um aspecto transparente quando submetida à hidrólise alcalina. 


\subsection{Caracterização das matrizes}

\subsubsection{Potencial de citotoxicidade in vitro}

A citotoxicidade é o efeito nocivo ou prejudicial (não desejado) produzido pelo biomaterial. $\mathrm{O}$ teste de citotoxicidade in vitro é usado como uma avaliação inicial e tem como objetivo detectar o potencial de um material ou dispositivo em produzir efeitos letais ou subletais no sistema biológico, utilizando técnicas de cultura de células.

Os resultados para o controle negativo e positivo são mostrados na Figura 29. O controle positivo (látex) é uma substância que apresenta efeito citotóxico de maneira reprodutível e controle negativo (papel atóxico) é o material ou substância que não produza efeito citotóxico.
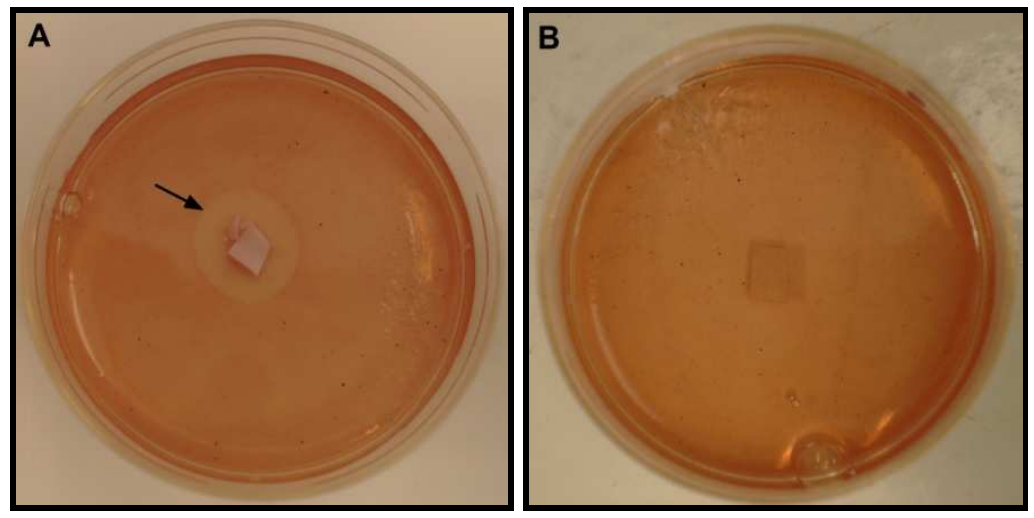

Figura 29. Avaliação macroscópica do controle positivo (A) e negativo (B).

No controle positivo (Fig. 29A) há a presença de um halo (aspecto transparente) ao redor do látex utilizado e para o negativo não se observa formação de halo (Fig. 29B). A avaliação dos resultados do teste de citotoxicidade foi feita pela observação do halo, que é representada pela área não corada pelo corante. Este halo aparece, pois há morte celular e liberação do corante vermelho neutro incorporado nas células. A citotoxicidade foi avaliada 
pela medida com uma régua milimétrica do diâmetro do halo formado (ROGERO et al., 2003). A Tabela 5 mostra os valores dos diâmetros dos halos formados para os controles positivo e negativo.

Tabela 5. Valores dos diâmetros dos halos formados no controle positivo e negativo

\begin{tabular}{c|c}
\hline Amostra & $\begin{array}{c}\text { Diâmetro do halo } \\
(\mathrm{mm})\end{array}$ \\
\hline Controle negativo & $0,0 \pm 0,5$ \\
Controle positivo & $12,0 \pm 0,5$ \\
\hline
\end{tabular}

$\mathrm{Na}$ avaliação microscópica (Figura 30) pode observar-se que no controle negativo há presença de células já para o controle positivo há morte celular com regiões em que não aparecem células (setas).
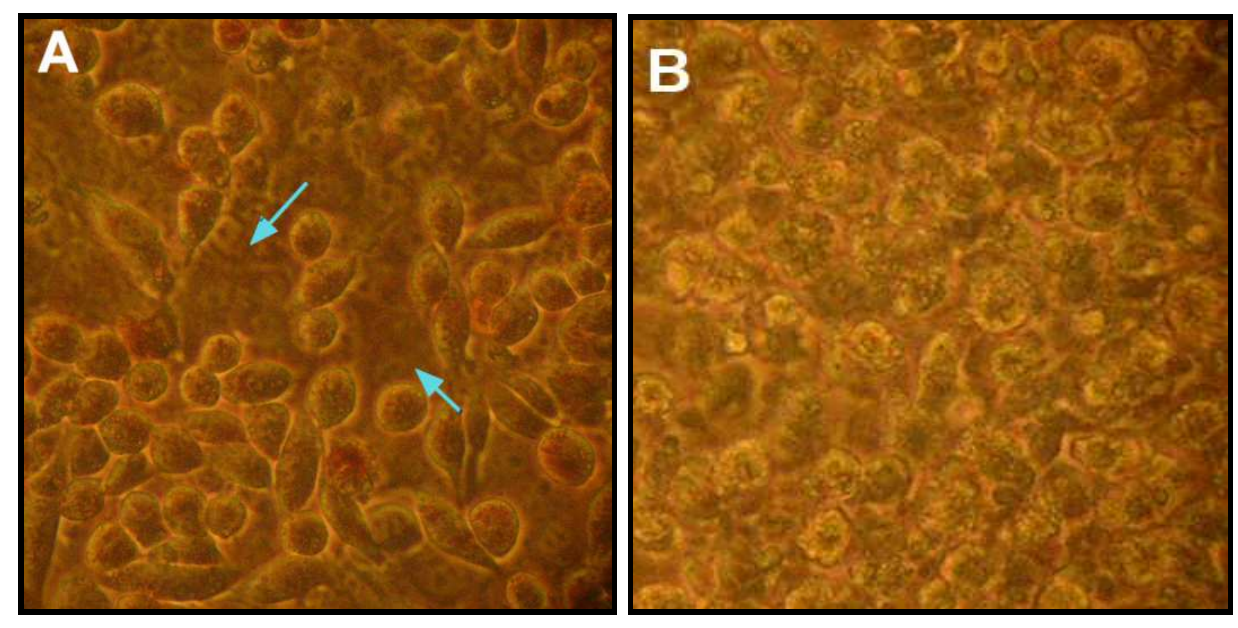

Figura 30. Foto digital das células HEp-2 no controle positivo (A) e negativo (B).

Os testes foram feitos para as matrizes hidrolisadas por 24 e $96 \mathrm{~h}$ e sua respectiva mineralização. As matrizes derivadas de pericárdio bovino e serosa porcina não apresentaram halo ao redor das matrizes não indicando, portanto, nenhum efeito citotóxico (Fig. 31 e 32). 

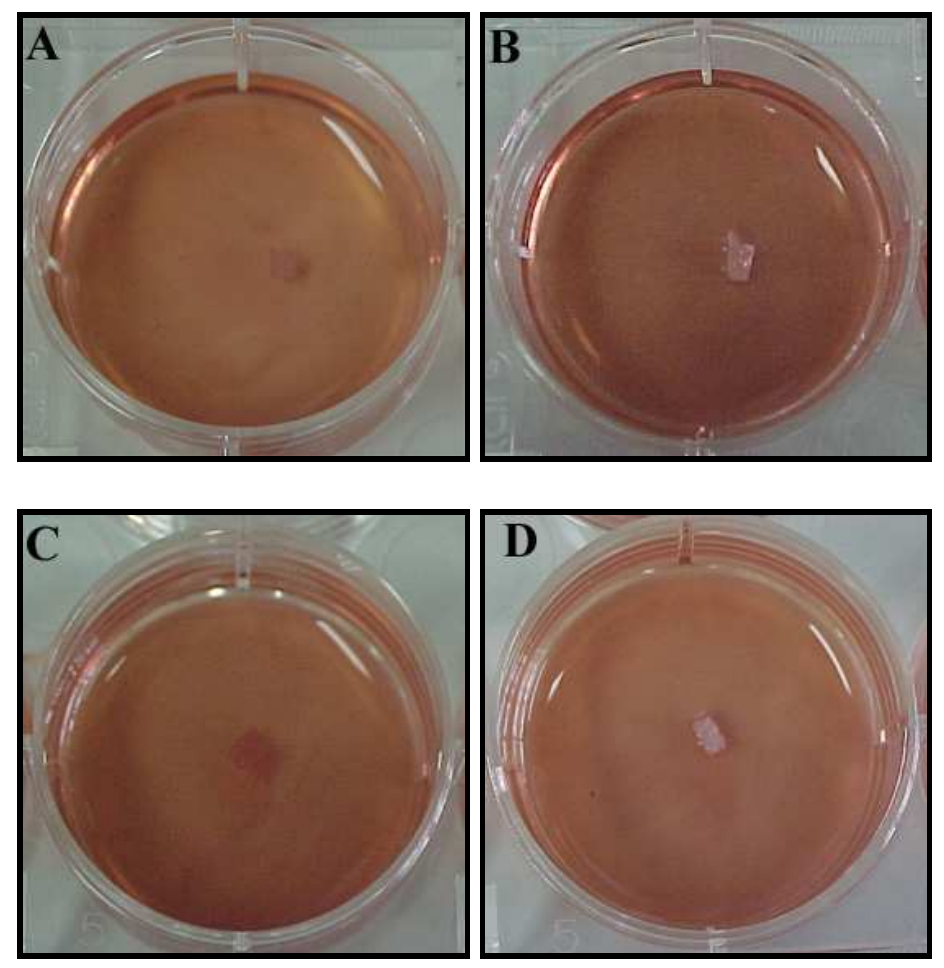

Figura 31. Foto digital das matrizes derivadas de pericárdio bovino PB24 (A), PB24C (B), PB96 (C) e PB96C (D).
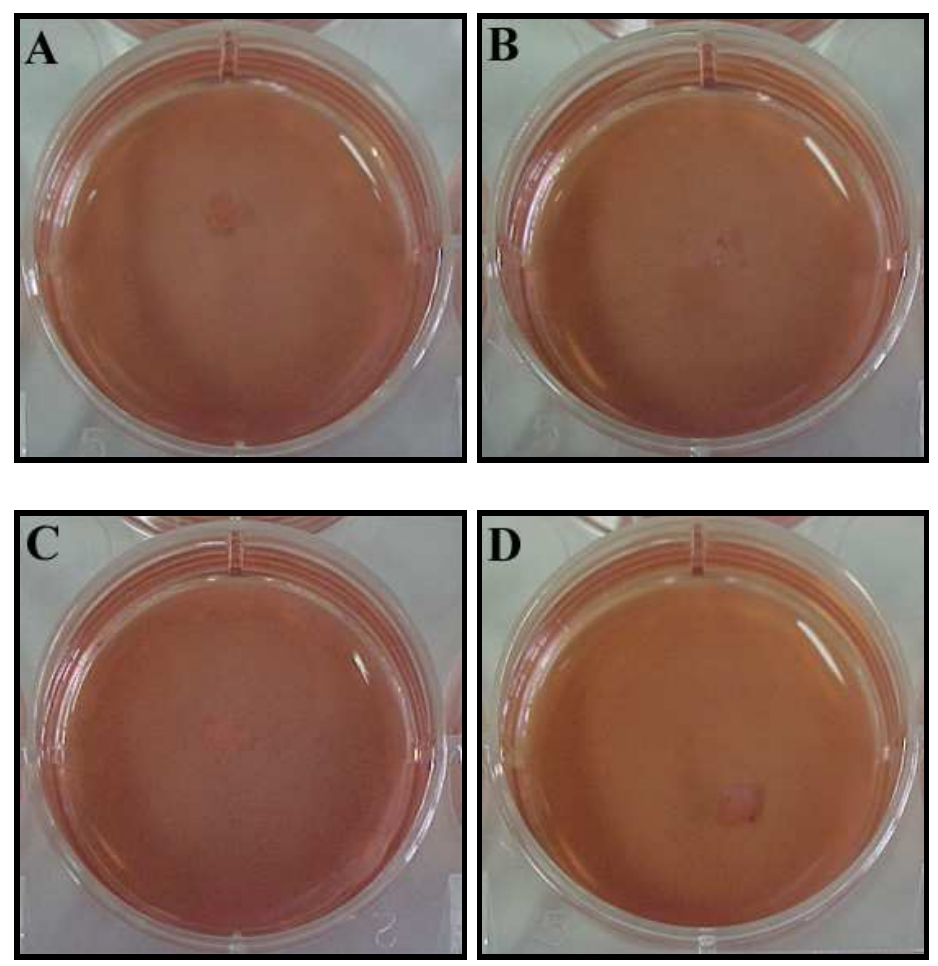

Figura 32. Foto digital das matrizes derivadas de serosa porcina SP24 (A) e SP24C (B), SP96 (C) e SP96C (D). 
Os primeiros resultados obtidos para as matrizes derivadas de pele porcina hidrolisadas por 96 h e 24 h (não tratadas com solvente orgânico) apresentaram citotoxicidade. Isso pode ser observado pela presença de halo de cerca de 27,0 \pm 0,5 mm.ao redor das matrizes (Fig. 33). As matrizes mineralizadas também apresentaram o efeito citotóxico.
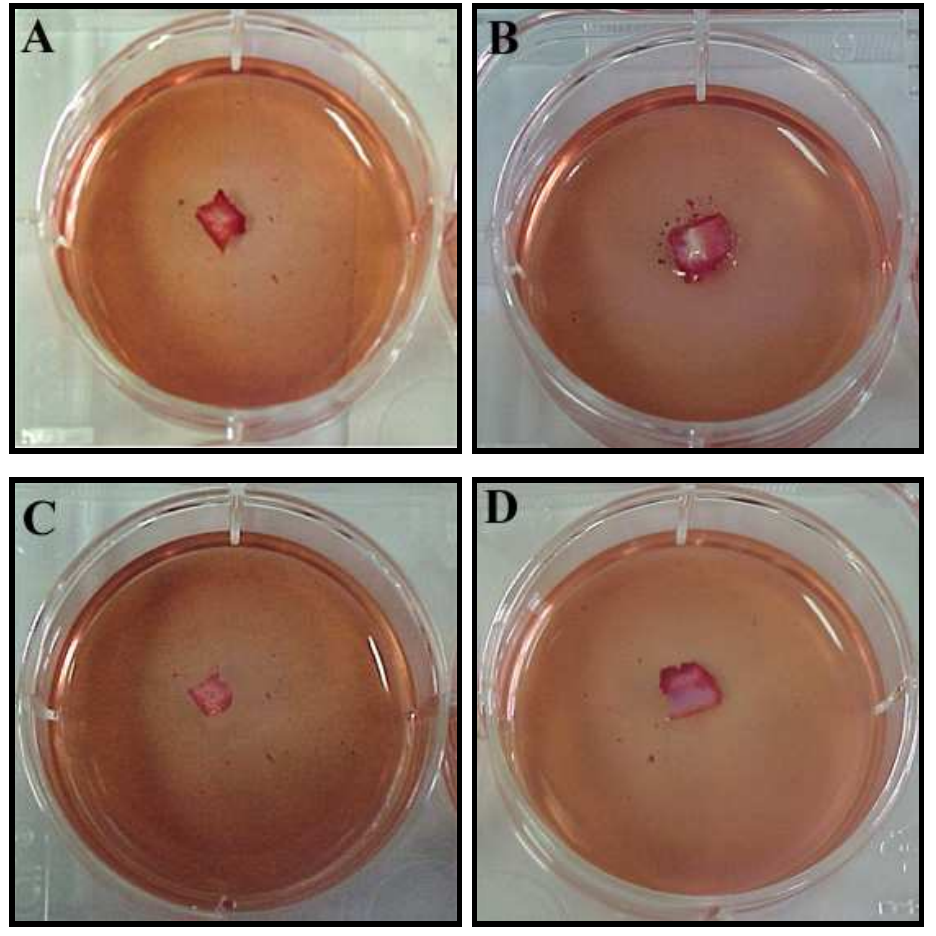

Figura 33. Foto digital das matrizes derivadas de pele porcina PP24S (A), PP24SC (B), PP96S (C) e PP96SC (D).

Em uma avaliação microscópica da amostra PP24S (Fig. 34) pode-se observar claramente a interface do halo em que se tem a morte celular (região mais escura). 


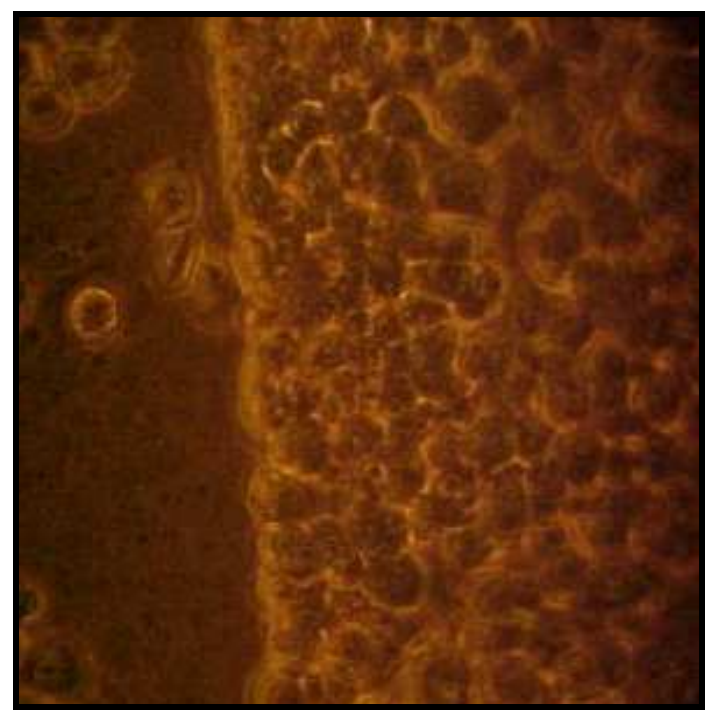

Figura 34. Foto digital da avaliação microscópica da matriz PP24S.

Segundo Rodrigues (2006), esta toxidade está relacionada com a presença de gordura não removida durante a hidrólise alcalina. Optou-se então em fazer um prétratamento antes da hidrólise com a finalidade da retirada desta gordura em que as matrizes são lavadas com uma mistura clorofórmio:metanol.

Repetiram-se os testes de citotoxicidade com as matrizes tratadas previamente com clorofórmio:metanol e estas não apresentaram mais o efeito citotóxico, confirmado pela ausência de halo ao redor das matrizes (Fig. 35), tanto para 24 como 96 h de tratamento alcalino.

Os resultados indicaram que a pele porcina é muito mais gordurosa que o pericárdio bovino e a serosa porcina e que é necessário um pré-tratamento dessa matriz antes da hidrólise alcalina. 

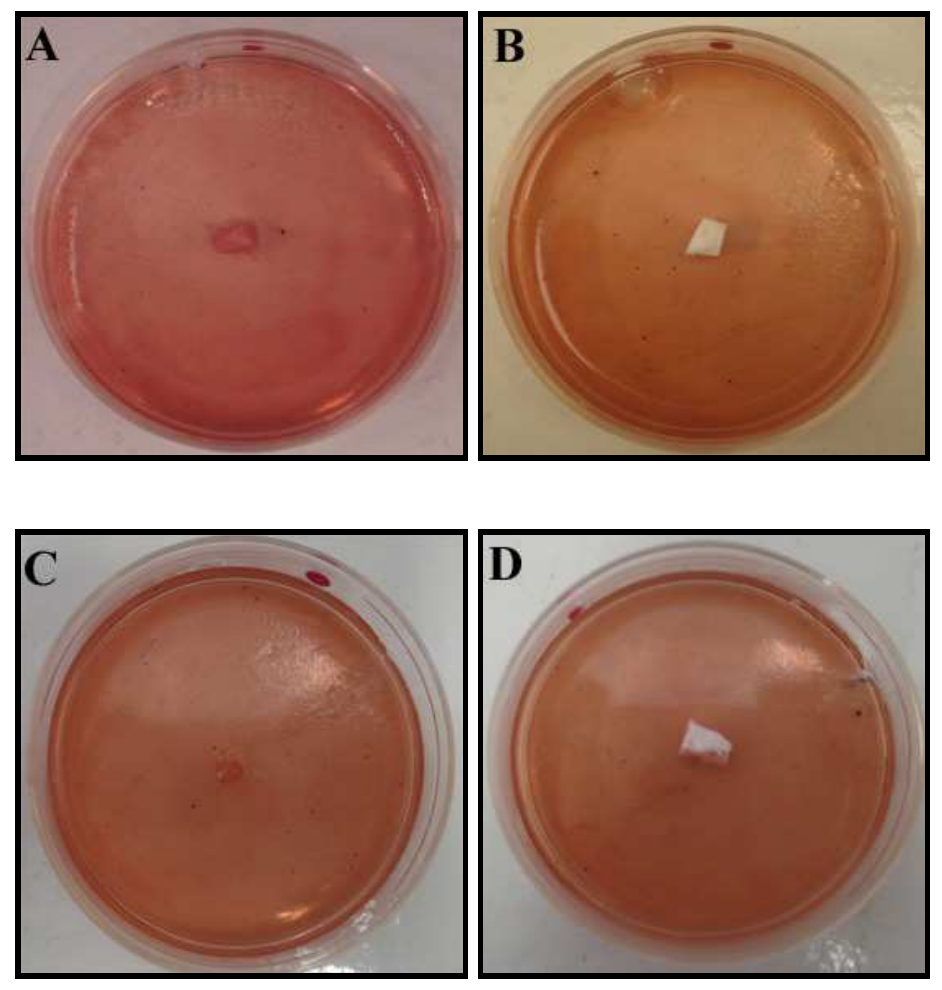

Figura 35. Foto digital da avaliação macroscópica das matrizes derivadas de pele porcina PP24 (A), PP24C (B), PP96 (C) e PP96C (D).

Os tempos intermediários para as matrizes (48 e 72 h) devem seguir a mesma tendência para os resultados das matrizes hidrolisadas por 24 e 96 h, ou seja, não devem apresentar citotoxicidade. Com isso pode-se dizer que não foram detectados efeitos tóxicos das matrizes mineralizadas e não mineralizadas, pelo contato direto dos materiais com a linhagem das células HEp-2 e McCoy B.

\subsubsection{Calorimetria Exploratória Diferencial}

As curvas DSC fornecem um modo sensível de entendimento dos eventos de desnaturação térmica quando o colágeno é aquecido. A desnaturação (Fig. 36) pode ser definida como a transição da hélice tripla para uma forma com distribuição desordenada 
devido a muitos fatores tais como aquecimento, ácidos, álcoois e outros agentes (BADEA et al., 2008).

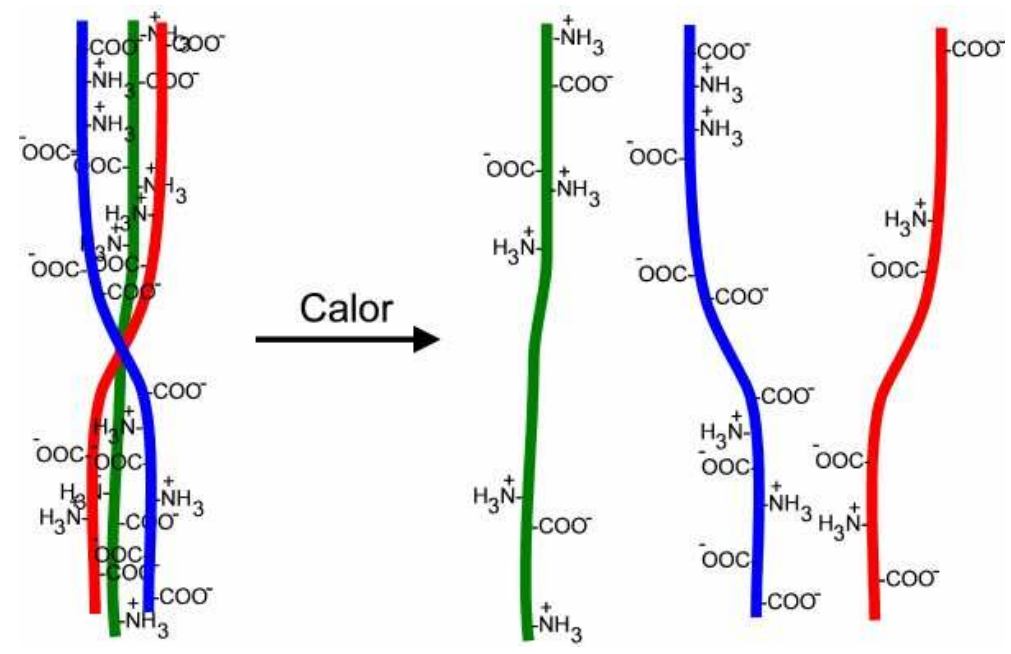

Figura 36. Desnaturação do colágeno.

Quando o colágeno é submetido a altas temperaturas, as ligações intramoleculares são quebradas e a proteína passa de uma estrutura cristalina altamente organizada a um estado aleatório, denominado de gelatina (ARNOCZKY; AKSAN, 2000).

Acredita-se que esta transição é composta por duas etapas: a primeira etapa envolve a ruptura de ligação de hidrogênio entre as três cadeias polipeptídicas da molécula tropocolágeno, a segunda etapa envolve a ruptura intramolecular da ligação hidrogênio da cadeia $\alpha$ (BERNAL; STANLEY, 1987).

Nas curvas DSC a transição aparece como uma descontinuidade na linha de base, que é proporcional à diferença na capacidade de calor antes e depois da desnaturação. Neste trabalho o valor da temperatura de desnaturação (Td) foi obtido pela inflexão nas curvas DSC, como mostrado na Figura 37. 


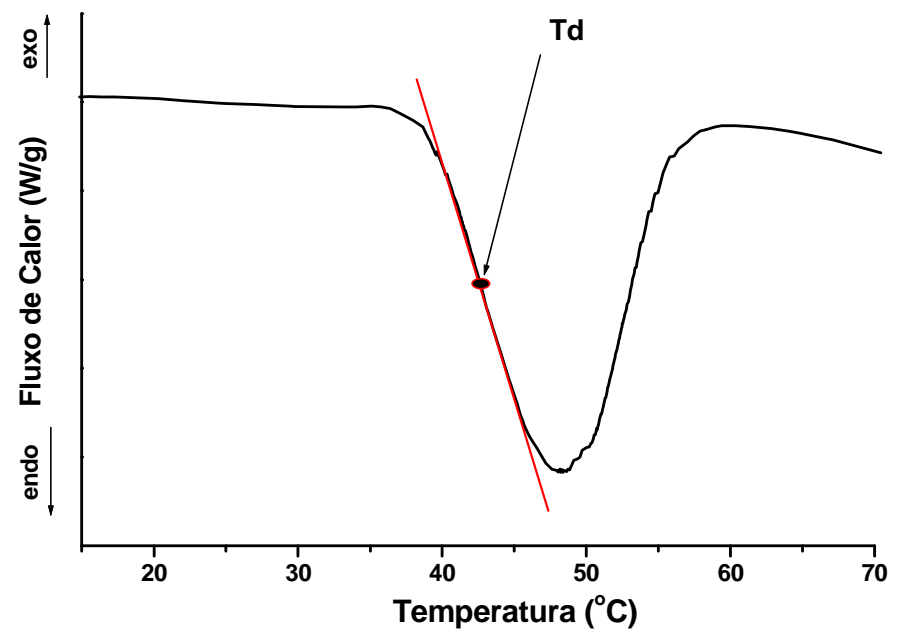

Figura 37. Curva representativa da determinação de Td por DSC.

As curvas DSC permitiram a determinação da temperatura de desnaturação (Td) das matrizes. A Figura 38 mostra as curvas das matrizes nativas, hidrolisadas por $96 \mathrm{~h}$ e as mineralizadas. As curvas para os demais tempos estão apresentados no Apêndice 1.

As matrizes de colágeno hidrolisadas apresentaram uma diminuição da Td após a hidrólise alcalina quando comparadas com o tecido biológico nativo (Tabela 6). Este fato é resultante da quebra das ligações cruzadas (reticulação) pela hidrólise alcalina utilizada para hidrolisar os grupos carboxílicos dos resíduos de amionácidos Asn e Gln. Além disso, a hidrólise altera a distribuição de cargas no tropocolágeno causando uma desorganização das fibras diminuindo assim a sua estabilidade (LACERDA; PLEPIS; GOISSIS, 1998). Esta estabilidade é inversamente proporcional ao tempo de hidrólise. Embora haja esta diminuição da temperatura de desnaturação, a hélice tripla do colágeno permanece íntegra, uma vez que para colágeno desnaturado, ou seja, gelatina, não há transição térmica na faixa de temperatura estudada (FLANDIN; BUFFEVANT; HERBAGE, 1984). 

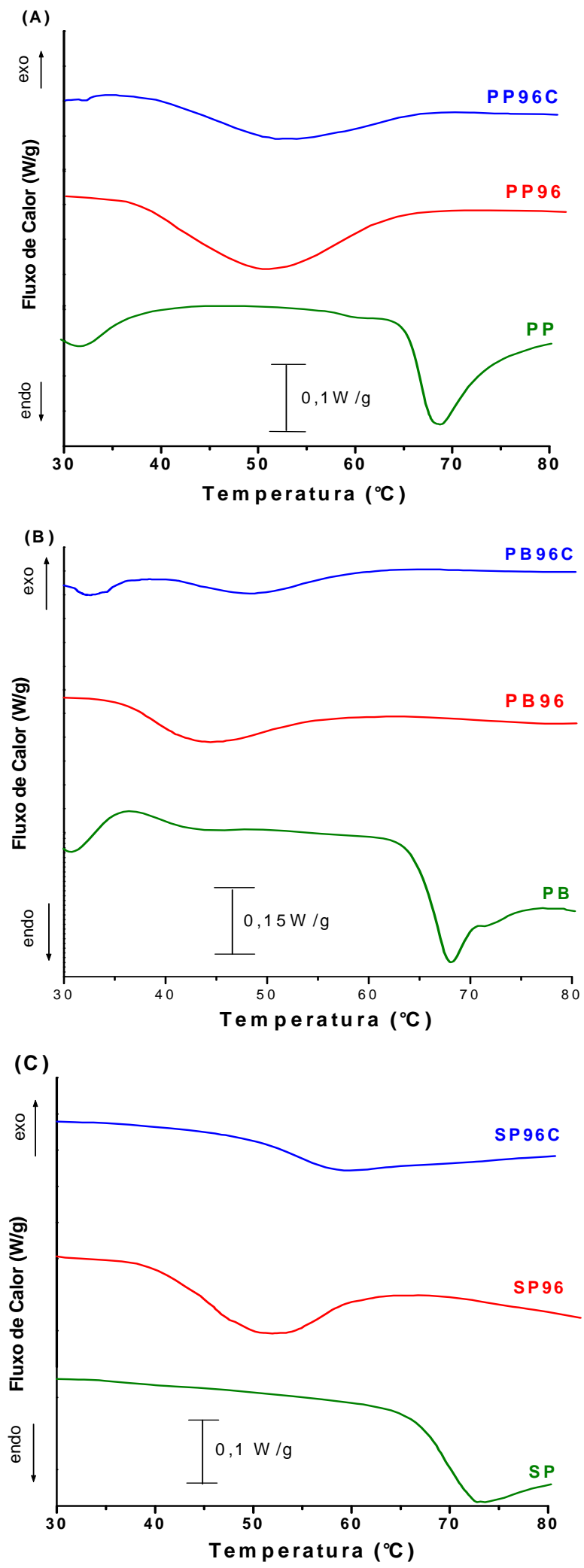

Figura 38. Curvas DSC dos tecidos com ou sem hidrólise alcalina (96h) e mineralizados, (A) Pele Porcina, (B) Pericárdio Bovino e (C) Serosa Porcina. 
A Figura 39 mostra a variação de Td com o aumento do tempo de hidrólise para as matrizes. Observa-se que a Td para as matrizes obtidas de pele porcina é bem menor que pericárdio e serosa porcina, fato este que pode ser devido à diferença na disposição das fibras dos tecidos e na composição dos aminoácidos. Quando as matrizes são submetidas à hidrólise alcalina a pele porcina é a menos afetada tendendo a uma $\mathrm{Td}$ constante. A serosa e o pericárdio bovino são mais afetados com este tratamento.
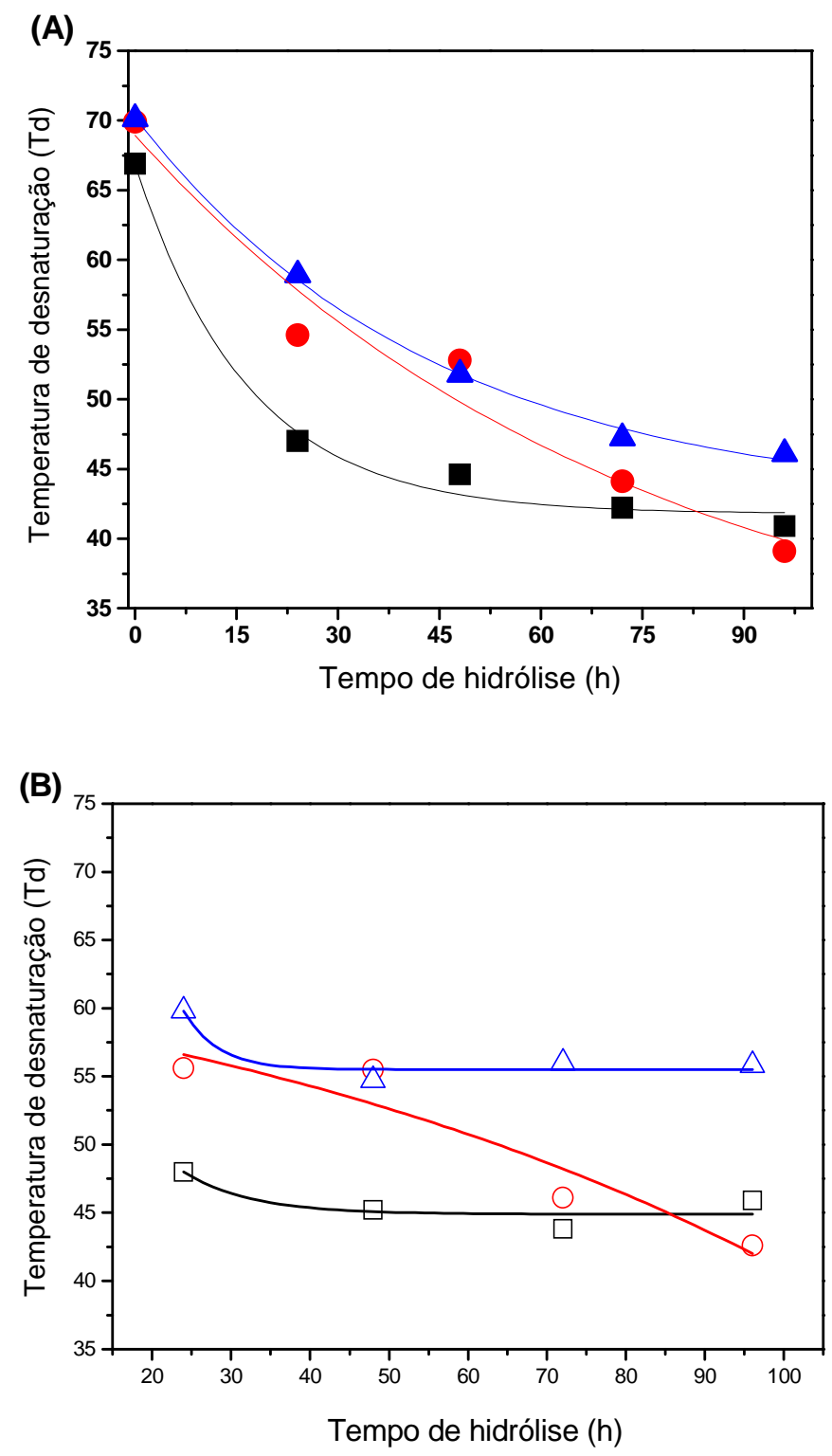

Figura 39. Variação da Td de acordo com o tempo de hidrólise das matrizes (A) não mineralizadas e (B) mineralizadas; derivadas de PP (-), PB (-) e SP (-). 
Quando as matrizes pele e serosa porcina são mineralizadas tendem a um valor constante na Td para maiores tempos de hidrólise, exceto para pericárdio bovino que tem valores decrescentes para maiores tempos de tratamento alcalino.

A Tabela 6 mostra que houve um aumento da Td para todas as matrizes após a mineralização, indicando que a deposição de sais aumenta a estabilidade da hélice tripla (BATISTA; MARTINS; PLEPIS, 2008, GELINSKY et al., 2008). Este comportamento pode ser explicado pela interação dos íons cálcio com os grupos carboxílicos do colágeno, que dificulta a desestruturação da hélice tripla. Tal comportamento foi observado em estudos de desmineralização, ou seja, remoção de fosfato de cálcio da matriz óssea que mostra uma diminuição na temperatura de desnaturação do colágeno, sugerindo que a presença de fosfato de cálcio estabiliza a hélice tripla (KRONICK; COOKE, 1996; TREBACZ; WÓJTOWICZ, 2005). 
Tabela 6. Temperatura de desnaturação do colágeno presente nos tecidos e nas matrizes

\begin{tabular}{|c|c|c|}
\hline \multicolumn{2}{|c|}{ Matrizes } & $\operatorname{Td}\left({ }^{\circ} \mathrm{C}\right)$ \\
\hline \multirow{9}{*}{ Pele Porcina } & PPn & 66,8 \\
\hline & PP24 & 47,0 \\
\hline & PP24C & 48,0 \\
\hline & PP48 & 44,6 \\
\hline & PP48C & 45,2 \\
\hline & PP72 & 42,2 \\
\hline & PP72C & 43,8 \\
\hline & PP96 & 40,9 \\
\hline & PP96C & 45,9 \\
\hline \multirow{9}{*}{ Pericárdio Bovino } & $\mathrm{PBn}$ & 69,9 \\
\hline & PB24 & 54,6 \\
\hline & PB24C & 55,6 \\
\hline & PB48 & 52,8 \\
\hline & PB48C & 55,5 \\
\hline & PB72 & 44,1 \\
\hline & PB72C & 46,4 \\
\hline & PB96 & 39,1 \\
\hline & PB96C & 42,6 \\
\hline \multirow{9}{*}{ Serosa Porcina } & SPn & 70,1 \\
\hline & SP24 & 58,9 \\
\hline & SP24C & 59,8 \\
\hline & SP48 & 51,8 \\
\hline & SP48C & 54,7 \\
\hline & SP72 & 47,2 \\
\hline & SP72C & 56,0 \\
\hline & SP96 & 46,1 \\
\hline & SP96C & 55,8 \\
\hline
\end{tabular}




\subsubsection{Termogravimetria}

Para a determinação da estabilidade térmica das matrizes (mineralizadas ou não) e para a obtenção da quantidade de material inorgânico presente, foram feitas curvas termogravimétricas em atmosfera de ar sintético. Vários trabalhos em literatura mostram a mineralização de matrizes de colágeno, no entanto poucos demonstram a quantificação de sais de fosfato por termogravimetria.

A Figura 40 mostra as curvas TG/DTG das matrizes sem tratamento, hidrolisadas (96 h) e hidrolisadas mineralizadas. As curvas para os demais tempos de hidrólise estão no Apêndice 2. Todas as curvas apresentaram três eventos aos quais são relacionados à perda de água, a degradação e a carbonização. O primeiro entre 25 e $200{ }^{\circ} \mathrm{C}$ é relacionado ao conteúdo de água presente nas matrizes. O segundo na faixa de $200-400{ }^{\circ} \mathrm{C}$ é devido à degradação da estrutura da molécula de colágeno e o terceiro estágio ocorre na faixa de $400-650{ }^{\circ} \mathrm{C}$, relacionado à decomposição dos compostos e carbonização (BATISTA; MARTINS; PLEPIS, 2008).

No segundo estágio, em que ocorre a degradação do colágeno, pode ser observado um decréscimo na estabilidade térmica depois da hidrólise alcalina e um aumento quando ocorre a mineralização (Tabela 7), sugerindo que a mineralização estabiliza a estrutura colagênica. Os valores de temperatura de degradação foram obtidos considerando-se o "onset point" nas curvas termogravimétricas. Para determinar o conteúdo de material inorgânico, ou seja, a quantidade de fosfato de cálcio depositada na matriz durante o processo de mineralização, os resíduos foram obtidos a $750^{\circ} \mathrm{C}$ (Tabela 7), uma vez que a hidroxiapatita (produto mais desejável durante a mineralização) é estável até $1200{ }^{\circ} \mathrm{C}$ (MARKOVIC; FOWLER; TUNG, 2004) e que todo o material orgânico presente já se decompôs. 

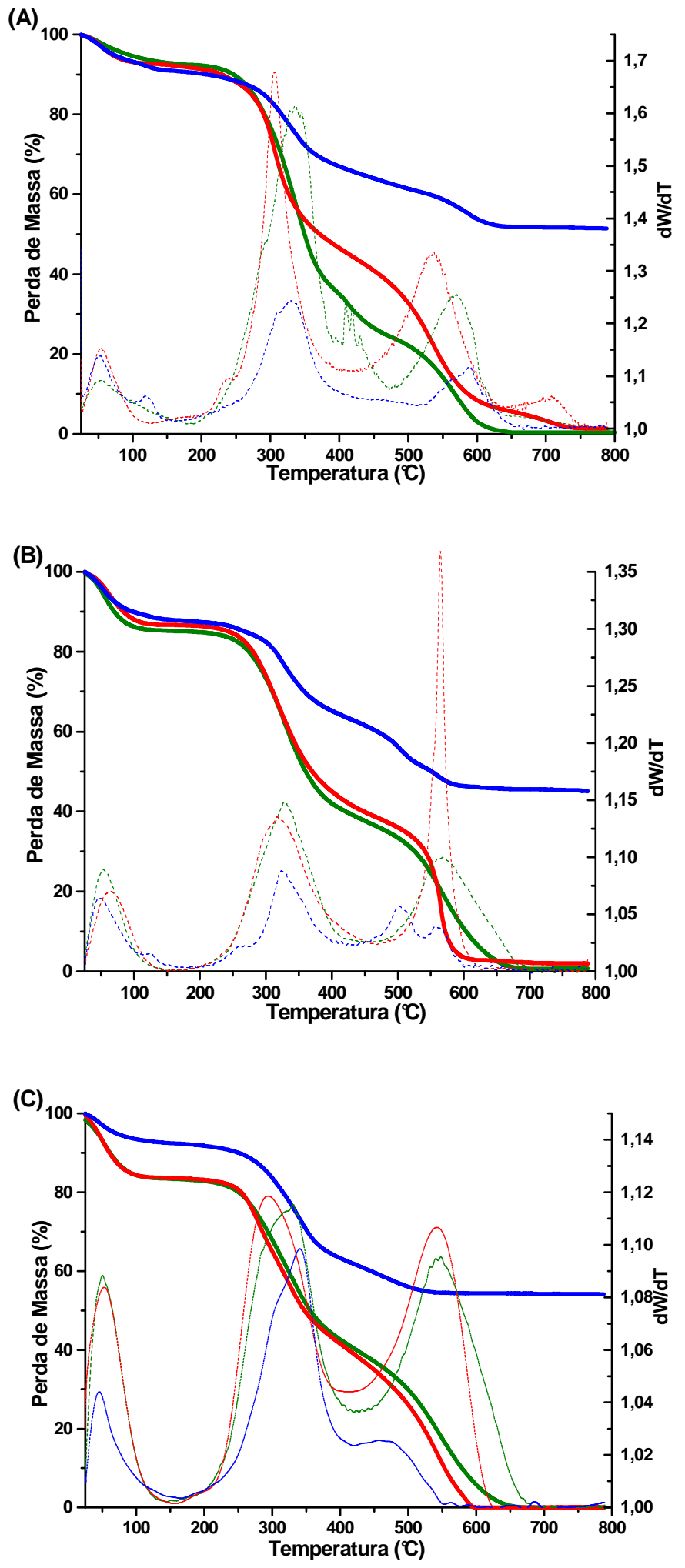

Figura 40. Curva TG/DTG das matrizes $(-)$ sem tratamento, $(-)$ hidrolisadas por $96 \mathrm{~h}$ e $(-)$ mineralizadas, - TG; … DTG.

Tabela 7. Porcentagens de perda de massa das matrizes obtidas através de TG/DTG 


\begin{tabular}{|c|c|c|c|c|c|}
\hline \multirow{2}{*}{ Matrizes } & \multicolumn{3}{|c|}{ Perda de massa $(\%)$} & \multirow{2}{*}{$\begin{array}{c}\text { Resíduo } \\
(\%) \text { em } \\
750^{\circ} \mathrm{C}\end{array}$} & \multirow{2}{*}{$\begin{array}{l}\text { Temperatura de } \\
\text { degradação do } \\
\text { colágeno }\left({ }^{\circ} \mathrm{C}\right)\end{array}$} \\
\hline & $25-200^{\circ} \mathrm{C}$ & $200-400^{\circ} \mathrm{C}$ & $400-650^{\circ} \mathrm{C}$ & & \\
\hline PPn & 7,7 & 57,3 & 34,6 & 0,4 & 280,7 \\
\hline PP24 & 9,7 & 43,2 & 45,6 & 1,5 & 276,5 \\
\hline PP24C & 9,8 & 33,8 & 32,0 & 24,4 & 288,4 \\
\hline PP48 & 9,1 & 42,9 & 46,4 & 1,6 & 274,7 \\
\hline PP48C & 11,4 & 31,5 & 27,0 & 30,1 & 286,1 \\
\hline PP72 & 8,3 & 46,4 & 43,8 & 1,5 & 269,1 \\
\hline PP72C & 9,7 & 27,3 & 24,8 & 38,2 & 289,5 \\
\hline PP96 & 8,8 & 44,8 & 44,9 & 1,4 & 275,5 \\
\hline PP96C & 9,9 & 23,4 & 15,5 & 51,2 & 280,6 \\
\hline $\mathrm{PBn}$ & 15,1 & 42,8 & 39,9 & 0,7 & 273,4 \\
\hline PB24 & 13,0 & 42,9 & 42,2 & 1,6 & 261,8 \\
\hline PB24C & 14,1 & 29,2 & 22,0 & 34,7 & 279,9 \\
\hline PB48 & 12,0 & 43,7 & 42,3 & 1,8 & 270,1 \\
\hline PB48C & 9,4 & 28,7 & 24,9 & 36,7 & 290,5 \\
\hline PB72 & 10,3 & 44,7 & 43,2 & 1,8 & 269,1 \\
\hline PB72C & 13,4 & 25,5 & 22,8 & 37,5 & 288,8 \\
\hline PB96 & 13,6 & 41,6 & 42,8 & 2,0 & 270,7 \\
\hline PB96C & 12,5 & 22,3 & 19,4 & 45,8 & 290,4 \\
\hline SPn & 15,9 & 40,8 & 42,8 & 0 & 261,9 \\
\hline SP24 & 17,6 & 39,1 & 41,9 & 0,8 & 256,6 \\
\hline SP24C & 10,4 & 32,85 & 10,3 & 46,4 & 271,5 \\
\hline SP48 & 14,7 & 40,5 & 41,9 & 1,7 & 256,2 \\
\hline SP48C & 12,1 & 28,9 & 9,6 & 49,1 & 274,9 \\
\hline SP72 & 17,6 & 39,7 & 39,8 & 0,8 & 258,5 \\
\hline SP72C & 10,2 & 27,9 & 9,4 & 52,5 & 282,9 \\
\hline SP96 & 16,7 & 41,6 & 41,5 & 0,1 & 248,2 \\
\hline SP96C & 8,2 & 28,5 & 8,9 & 54,2 & 277,2 \\
\hline
\end{tabular}


Pode-se observar que a mineralização é maior nas matrizes derivadas de serosa porcina, o que pode ser explicado pela menor espessura da matriz e/ou ainda no diferente arranjo estrutural dos tecidos, ou seja, a disposição das fibras que é diferente em cada tecido.

As matrizes hidrolisadas e não mineralizadas tiveram resíduos menores que $2 \%$. A quantidade de resíduo provavelmente foi em decorrência de sais residuais ainda presentes nas matrizes após hidrólise alcalina.

Pôde-se verificar que a quantidade de colágeno é praticamente a mesma em todas as matrizes tanto nativas quanto hidrolisadas exceto para a matriz PPn que apresentou uma quantidade superior relacionado ao colágeno e a gordura presente $\left(200\right.$ à $\left.400^{\circ} \mathrm{C}\right)$.

As matrizes mineralizadas mostraram valores de resíduo que variaram de 20 a 50\%, atribuídos à deposição de fosfato de cálcio nas matrizes. Foi observado que quanto maior o tempo de hidrólise alcalina, maior a quantidade de sal depositada na matriz, independente do tecido biológico utilizado. Além disso, observou-se que a temperatura de degradação das matrizes mineralizadas é maior em relação às não mineralizadas, devido à interação dos íons cálcio com o colágeno.

Estudos mostram que grupos carboxílicos das matrizes são importantes no processo de mineralização óssea (SATO, 2007). Os grupos carregados negativamente dos aminoácidos nas moléculas de tropocolágeno provavelmente têm uma função importante em regular a distribuição de HA, devido à boa afinidade destes por íons cálcio produzindo assim uma distribuição uniforme de partículas na superfície do colágeno (ZHANG et al, 2004; GÓES et al., 2007). 
Em trabalhos anteriores do grupo, o estudo do número de incrementos de grupos carboxilatos após a hidrólise alcalina forneceu cerca de 131, 106, 78, 38 cargas adicionadas quando a matriz é submetida por 96, 72, 48 e 24h de hidrólise, respectivamente (BET, 2000). Este resultado está de acordo com aumento do teor de mineralização com o aumento do tempo de hidrólise alcalina.

\subsubsection{1. $m_{\text {resíduo }} / m_{\text {orgânica }}$}

As matrizes obtidas de pericárdio, pele e serosa porcina possuem espessuras diferentes, o que pode provocar uma mineralização não completa, ou seja, apenas em sua superfície, pela dificuldade de penetração das soluções. Para a análise termogravimétrica é necessária apenas uma pequena quantidade de material, a qual representará a quantidade de mineralização da matriz total. Como a matriz obtida de pele porcina é mais grossa foi necessário um corte transversal da matriz mineralizada, ou seja, pegou-se apenas uma pequena região da superfície enquanto para pericárdio e serosa foi utilizada uma região maior da superfície. A fim de comparar e verificar qual a matriz efetivamente foi mais mineralizada, fez-se uma normalização pela relação $\mathrm{m}_{\text {resíduo }} / \mathrm{m}_{\text {orgânica }}$ (Tabela 8 ), obtida na curva termogravimétrica $\left(\mathrm{M}_{\text {total }}=\mathrm{m}_{\text {resíduo }}+\mathrm{m}_{\text {orgânica }}+\mathrm{m}_{\text {água }}\right)$, considerando a $\mathrm{m}_{\text {orgânica }}$ a massa decomposta no intervalo $200-650{ }^{\circ} \mathrm{C}$.

A partir dos dados da Tabela 8 é possível observar que a quantidade da deposição de sais de fosfato é maior nas matrizes derivadas de serosa porcina, seguida por pericárdio e pele porcina, independente do tempo de hidrólise. 
Tabela 8. Relação massa inorgânica por massa orgânica das matrizes mineralizadas

\begin{tabular}{c|c}
\hline Matrizes & massa $_{\text {resíduo }}(\mathrm{mg}) /$ massa orgânica $(\mathrm{mg})$ \\
\hline PP24C & 0,37 \\
\hline PP48C & 0,51 \\
\hline PP72C & 0,73 \\
\hline PP96C & 1,31 \\
\hline PB24C & 0,67 \\
\hline PB48C & 0,68 \\
\hline PB72C & 0,78 \\
\hline PB96C & 1,09 \\
\hline SP24C & 1,11 \\
\hline SP48C & 1,27 \\
\hline SP72C & 1,41 \\
\hline SP96C & 1,45 \\
\hline
\end{tabular}

\subsubsection{Dispersão de Raios X (EDS)}

Para se verificar a relação cálcio e fósforo $(\mathrm{Ca} / \mathrm{P})$ nas matrizes mineralizadas foi feita a análise por dispersão de raios X, sendo o espectro da amostra PP96C mostrado na Figura 41. Os principais elementos do sal depositados na matriz foram o carbono $(0,2 \mathrm{keV})$, o oxigênio $(0,5 \mathrm{keV})$, o cálcio $(3,7 \mathrm{keV}$ e $4,0 \mathrm{keV})$ e o fósforo $(2,0 \mathrm{keV})$. As demais matrizes hidrolisadas e mineralizadas tiveram espectros similares e não serão mostrados. 


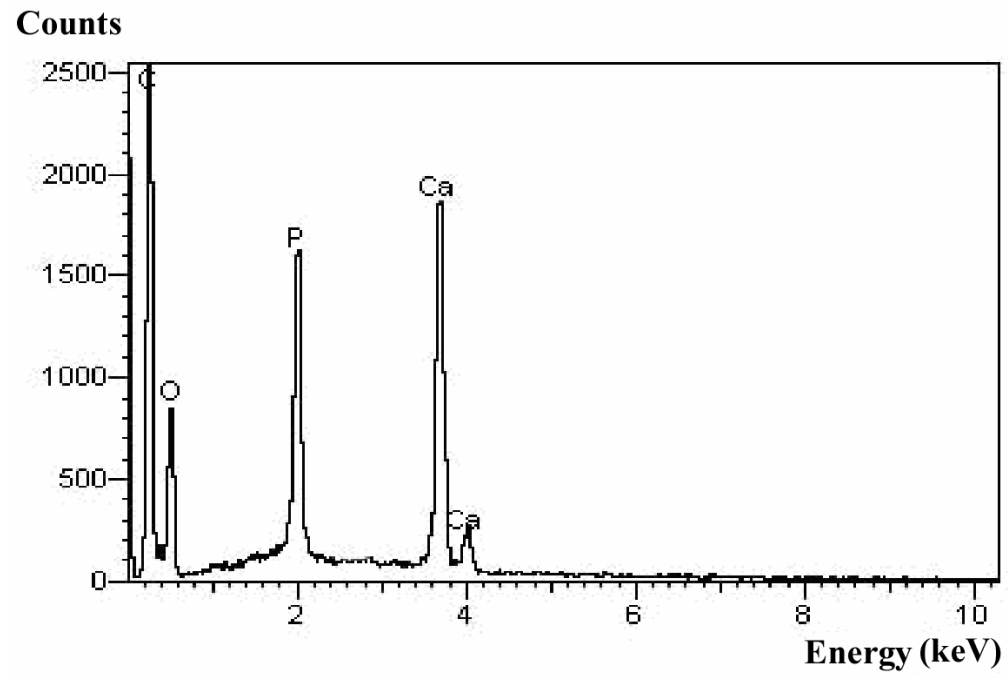

Figura 41. Espectro de dispersão de raios X obtido da superfície da matriz PP96C.

Foram feitas análises semi-quantitativas das matrizes mineralizadas e obtiveramse como resultados para a razão $\mathrm{Ca} / \mathrm{P}$ (Tabela 9) uma variação de 1,54 a 1,67. Esta relação foi obtida pela média dos teores dos elementos cálcio e fósforo presentes nas matrizes em três áreas distintas.

Tabela 9. Razão $\mathrm{Ca} / \mathrm{P}$ dos sais depositados nas matrizes mineralizadas e hidrolisadas

\begin{tabular}{c|c}
\hline Matrizes & $\mathrm{Ca} / \mathrm{P}$ \\
\hline PP24C & $1,59 \pm 0,04$ \\
\hline PP48C & $1,67 \pm 0,07$ \\
\hline PP72C & $1,66 \pm 0,06$ \\
\hline PP96C & $1,66 \pm 0,12$ \\
\hline PB24C & $1,65 \pm 0,06$ \\
\hline PB48C & $1,55 \pm 0,03$ \\
\hline PB72C & $1,65 \pm 0,03$ \\
\hline PB96C & $1,65 \pm 0,02$ \\
\hline SP24C & $1,57 \pm 0,11$ \\
\hline SP48C & $1,64 \pm 0,02$ \\
\hline SP72C & $1,54 \pm 0,13$ \\
\hline SP96C & $1,57 \pm 0,02$ \\
\hline
\end{tabular}

* média de 3 determinações 
As relações $\mathrm{Ca} / \mathrm{P}$ obtidas para as matrizes são próximas ao valor teórico para hidroxiapatita que é de 1,67, quando comparado com os diversos valores encontrados em literatura para os diversos fosfatos de cálcio (Tabela 10).

Tabela 10. Relação Ca/P dos principais tipos de fosfato de cálcio (HABRAKEN; WOLKE; JANSEN, 2007)

\begin{tabular}{|c|c|c|}
\hline Tipos de Fosfato de Cálcio & Fórmula & $\mathrm{Ca} / \mathrm{P}$ \\
\hline Apatita carbonatada & $\mathrm{Ca}_{5}\left(\mathrm{PO}_{4}, \mathrm{CO}_{3}\right)_{3}$ & 1,67 \\
\hline HA deficiente em cálcio & $\mathrm{Ca}_{10-\mathrm{x}}\left(\mathrm{HPO}_{4}\right)_{\mathrm{x}}\left(\mathrm{PO}_{4}\right)_{6-\mathrm{x}}(\mathrm{OH})_{2-\mathrm{x}}$ & $1,50<\mathrm{x}<1,67$ \\
\hline Monolita & $\mathrm{CaHPO}_{4}$ & 1,00 \\
\hline Brushita & $\mathrm{CaHPO}_{4} \cdot \mathrm{H}_{2} \mathrm{O}$ & 1,00 \\
\hline Hidroxiapatita & $\mathrm{Ca}_{10}\left(\mathrm{PO}_{4}\right)_{6}(\mathrm{OH})_{2}$ & 1,67 \\
\hline Fosfato $\beta$ tri cálcio & $\beta-\mathrm{Ca}_{3}\left(\mathrm{PO}_{4}\right)_{2}$ & 1,50 \\
\hline Octafosfato de cálcio & $\mathrm{Ca}_{8} \mathrm{H}_{2}\left(\mathrm{PO}_{4}\right)_{6} \cdot 5 \mathrm{H}_{2} \mathrm{O}$ & 1,33 \\
\hline
\end{tabular}

\subsubsection{Raios $X$}

A estrutura cristalográfica do sal de fosfato de cálcio obtido na mineralização foi estudada por difração de raios $\mathrm{X}$. Como os valores da relação $\mathrm{Ca} / \mathrm{P}$ obtidos por EDS para todas as matrizes foram próximos aos da hidroxiapatita, optou-se em realizar as análises por raios $\mathrm{X}$ apenas das matrizes mineralizadas hidrolisadas por 96h, que apresentaram uma porcentagem maior de resíduo inorgânico. Os resultados (Fig. 42, Tabela 11) para as matrizes PP96C, PB96C e SP96C são similares aos da HA sintética de acordo com o difratograma padrão da JCPDS (9-0432). 
Tabela 11. Principais valores de d para as matrizes mineralizadas

\begin{tabular}{c|c|c|c|c}
\hline Matrizes & \multicolumn{4}{|c}{ Principais valores de d $(\AA)$} \\
\hline PP96C & 2,84 & 2,68 & 3,44 & 1,81 \\
\hline PB96C & 2,79 & 2,63 & 3,40 & 1,80 \\
\hline SP96C & 2,77 & 2,62 & 3,43 & 1,80 \\
\hline JCPDS (9-0432) & 2,81 & 2,72 & 3,43 & 1,84 \\
\hline
\end{tabular}
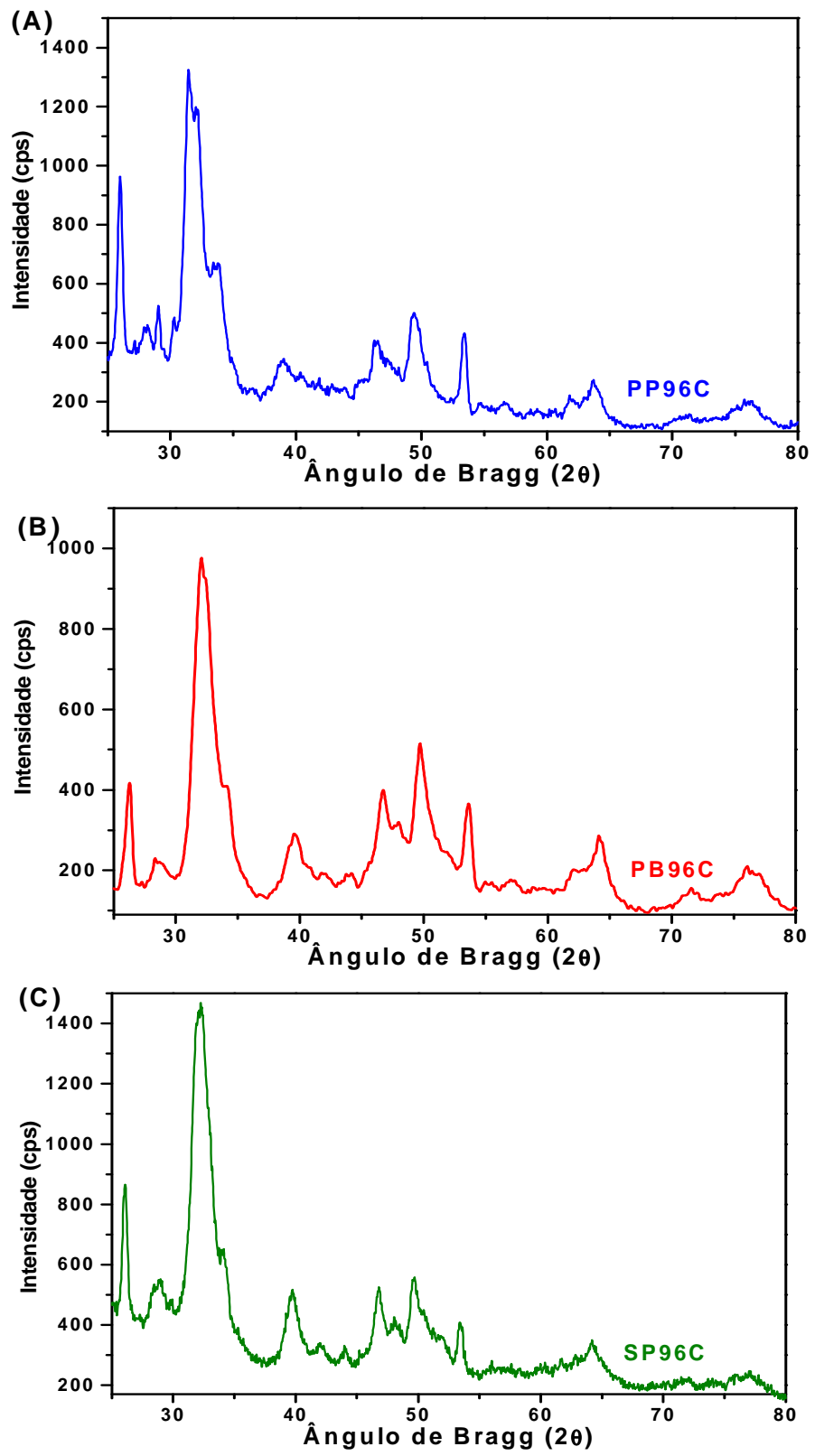

Figura 42. Difratograma de raios X das matrizes (A) PP96C, (B) PB96C, (C) SP96C. 
Os difratogramas das matrizes hidrolisadas por $96 \mathrm{~h}$ e mineralizadas são mostradas na Figura 42. As curvas são similares e mostram um pico intenso e largo em torno de $31{ }^{\circ} \mathrm{C}(2 \theta)$, mostrando que foi formada HA nas matrizes de colágeno. Este alargamento e baixa resolução mostrados nos difratogramas, resulta da baixa cristalinidade da HA formada na superfície das matrizes mineralizadas.

Os difratogramas obtidos para a fase inorgânica nas matrizes mineralizadas foram comparáveis àqueles da HA não cristalina (Figura 43) obtida por Martins et al. (1998) com picos mais largos em comparação com os padrões de difração da HA sintética.

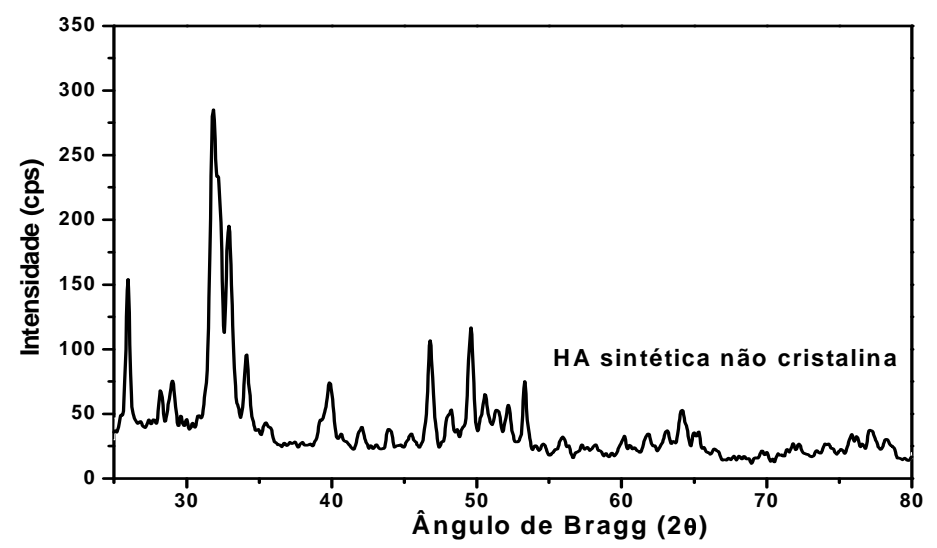

Figura 43. Difratograma de raios X de HA sintética não cristalina (MARTINS et al, 1998).

\subsubsection{FTIR}

As regiões de amida I, II e III presentes no espectro estão diretamente relacionadas com a conformação das cadeias peptídicas do colágeno. A banda de amida I tem freqüência característica na faixa de 1600 a $1660 \mathrm{~cm}^{-1}$ e é associada com a deformação axial da ligação $\mathrm{C}=\mathrm{O}$. A banda de amida II $\left(1500-1550 \mathrm{~cm}^{-1}\right)$ está relacionada à deformação angular N-H e ao estiramento C-N, enquanto a banda de amida III (1320-1220 $\left.\mathrm{cm}^{-1}\right)$ é devida aos modos de estiramento C-N e deformação N-H. A banda de amida A do colágeno (associada 

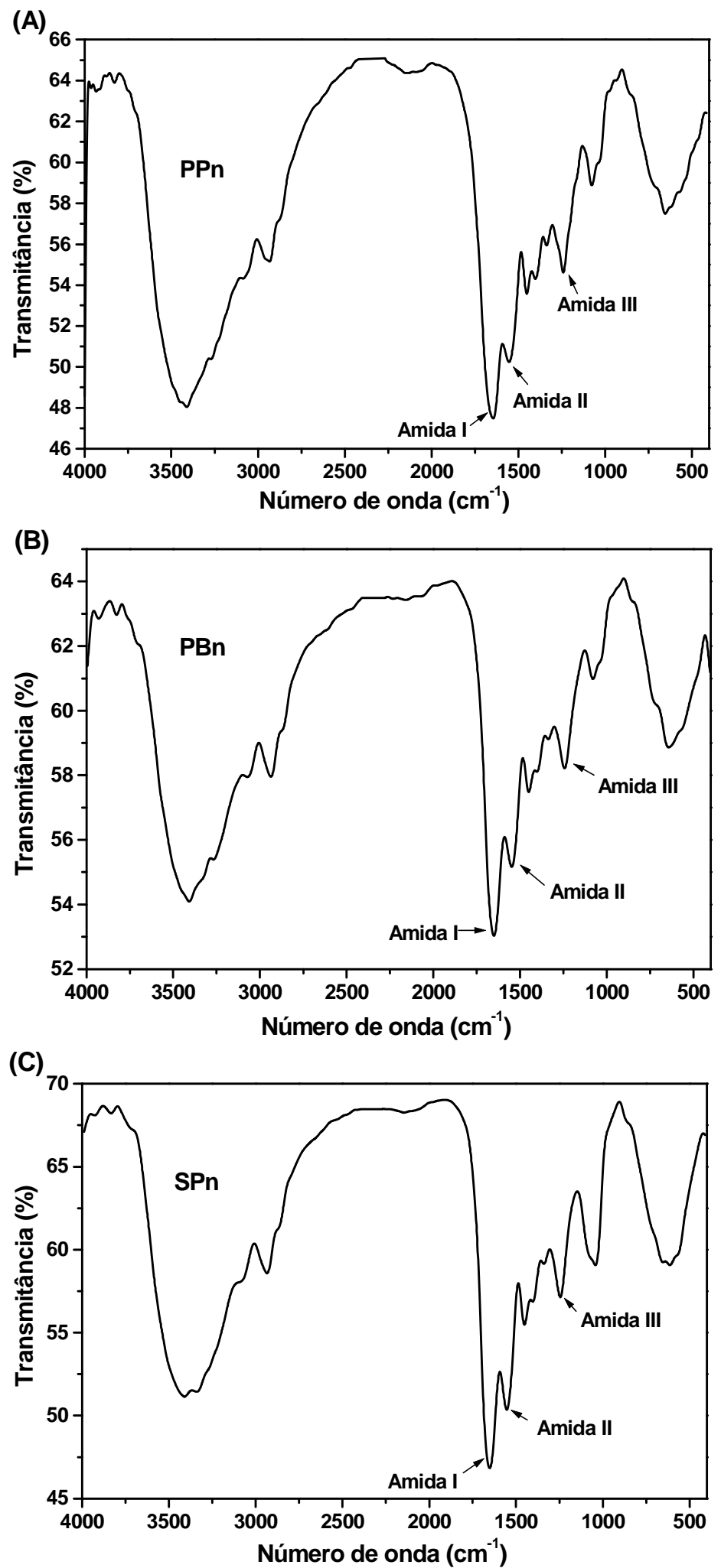

Figura 44. Espectros no FTIR das matrizes PPn (A), PBn (B) e SPn (C). 
com a freqüência de estiramento - $\mathrm{NH}$ e grupos - $\mathrm{OH}$ ) é encontrada frequentemente em 3315$3330 \mathrm{~cm}^{-1}$ (PLEPIS; GOISSIS, DAS-GUPTA, 1996).

As principais bandas associadas ao colágeno estão listadas na Tabela 12 e os espectros de absorção na região do infravermelho das matrizes nativas são mostrados na Figura 44.

Tabela 12. Principais freqüências das bandas para o colágeno presente nas matrizes

\begin{tabular}{c|c|c|c}
\hline Matrizes & Amida I & Amida II & Amida III \\
\hline PPn & 1645 & 1560 & 1239 \\
\hline PP24 & 1632 & 1560 & 1238 \\
\hline PP48 & 1632 & 1564 & 1244 \\
\hline PP72 & 1634 & 1564 & 1244 \\
\hline PP96 & 1632 & 1564 & 1240 \\
\hline PBn & 1651 & 1551 & 1238 \\
\hline PB24 & 1637 & 1562 & 1236 \\
\hline PB48 & 1637 & 1560 & 1238 \\
\hline PB72 & 1637 & 1559 & 1238 \\
\hline PB96 & 1636 & 1561 & 1237 \\
\hline SPn & 1651 & 1553 & 1239 \\
\hline SP24 & 1634 & 1554 & 1242 \\
\hline SP48 & 1632 & 1554 & 1240 \\
\hline SP72 & 1632 & 1554 & 1240 \\
\hline SP96 & 1634 & 1556 & 1242 \\
\hline & & &
\end{tabular}

Com os dados da Tabela 12 pôde-se notar que após a hidrolise alcalina houve um deslocamento da banda de amida I para frequiências menores, que é independente do tempo de hidrólise e do tecido usado. 
A Figura 45 mostra o espectro FTIR para as matrizes hidrolisadas por $96 \mathrm{~h}$ mineralizadas.
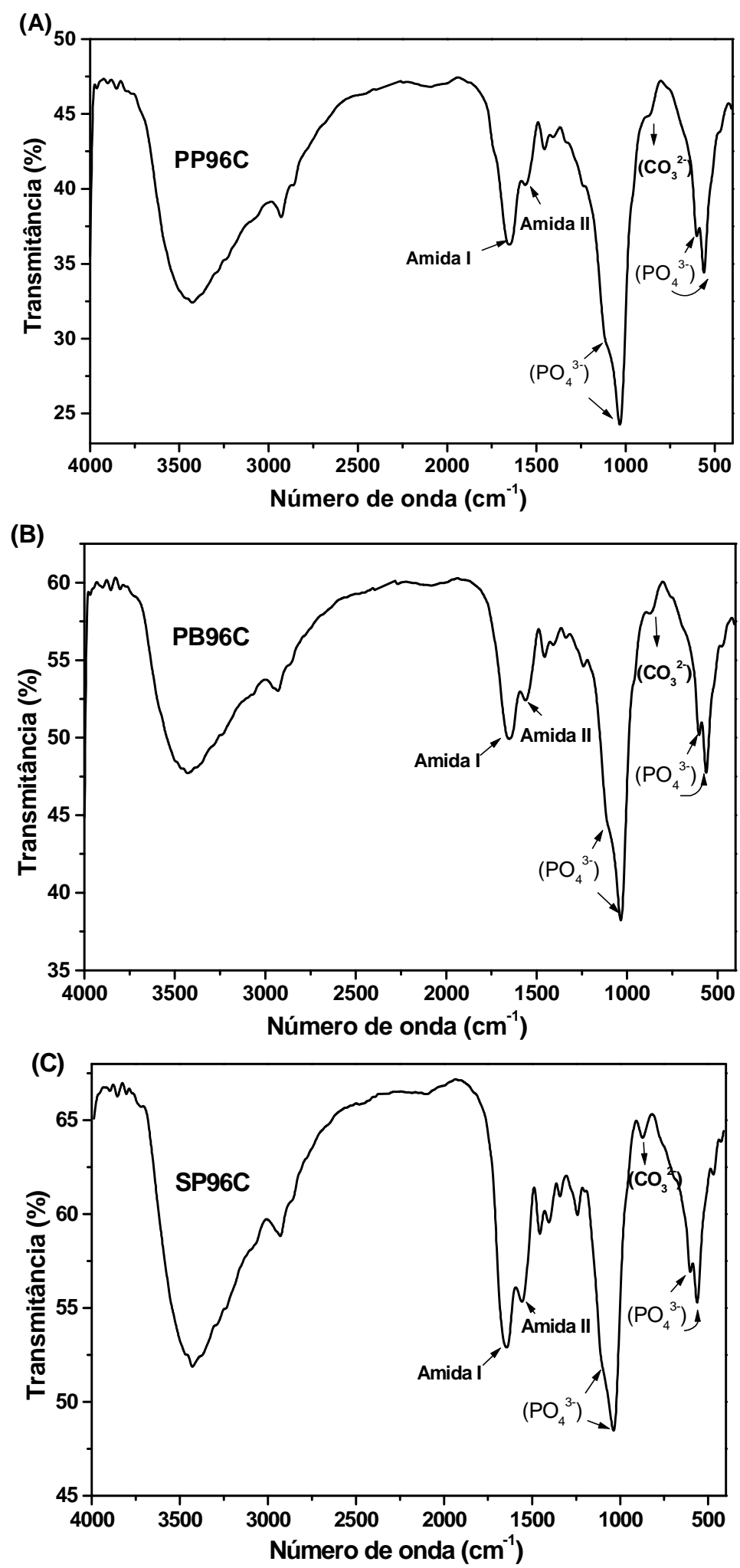

Figura 45. Espectros no FTIR das matrizes PP96C (A), PB96C (B) e SP96C (C). 
Os resultados mostram que independente do tecido usado há a formação de fosfato de cálcio, com a presença de bandas características de íons $\mathrm{PO}_{4}{ }^{3-}, \mathrm{V}_{3}-1036 \mathrm{e}$ $1095 \mathrm{~cm}^{-1}, v_{4}-563$ e $600 \mathrm{~cm}^{-1}$ e na região de $870 \mathrm{~cm}^{-1}$ que podem ser atribuídos aos íons $\mathrm{CO}_{3}{ }^{2-}$. Os espectros para as demais matrizes mineralizadas são mostrados no Apêndice III.

A Tabela 13 mostra as principais regiões de absorção para as matrizes mineralizadas.

Tabela 13. Principais frequências das bandas para o colágeno mineralizado

\begin{tabular}{c|c|c|c|c|c|c}
\hline Matrizes & Amida I & Amida II & $\mathbf{v}_{\mathbf{3}} \mathbf{P O}_{\mathbf{4}}{ }^{\mathbf{}}$ & \multicolumn{2}{|c|}{$\mathbf{v}_{\mathbf{4}} \mathbf{P O}_{\mathbf{4}}{ }^{3-}$} & $\mathbf{C O}_{\mathbf{3}}{ }^{\mathbf{}}$ \\
\hline PP24C & 1643 & 1560 & 1038 & 602 & 562 & 869 \\
\hline PP48C & 1647 & 1556 & 1036 & 602 & 562 & 870 \\
\hline PP72C & 1652 & 1560 & 1034 & 602 & 561 & 870 \\
\hline PP96C & 1653 & 1562 & 1034 & 602 & 562 & 868 \\
\hline PB24C & 1647 & 1560 & 1035 & 602 & 562 & 870 \\
\hline PB48C & 1643 & 1560 & 1037 & 602 & 562 & 869 \\
\hline PB72C & 1645 & 1556 & 1036 & 602 & 563 & 870 \\
\hline PB96C & 1653 & 1556 & 1034 & 602 & 562 & 868 \\
\hline SP24C & 1649 & 1557 & 1038 & 604 & 562 & 870 \\
\hline SP48C & 1655 & 1556 & 1038 & 604 & 565 & 872 \\
\hline SP72C & 1654 & 1554 & 1037 & 602 & 565 & 872 \\
\hline SP96C & 1651 & 1556 & 1038 & 602 & 563 & 873 \\
\hline
\end{tabular}

Pôde-se verificar a partir dos dados da Tabela 13, relativo às matrizes mineralizadas, que houve um deslocamento da banda de amida I para maiores valores sugerindo assim a interação química dos íons cálcio com os grupos carboxilatos presentes no colágeno. Este mesmo deslocamento já foi observado para membranas de colágeno mineralizadas (ZHANG et al.; 2004). As bandas de amida II e III não foram modificadas. 


\subsubsection{Microscopia Eletrônica de Varredura}

As microestruturas das matrizes hidrolisadas e liofilizadas observadas por MEV são mostradas nas Figuras 46-48. As matrizes de pele porcina (Fig.46) mostram uma estrutura mais porosa na superfície quando comparada com os outros tecidos. As matrizes de pericárdio e serosa têm uma estrutura mais compacta.
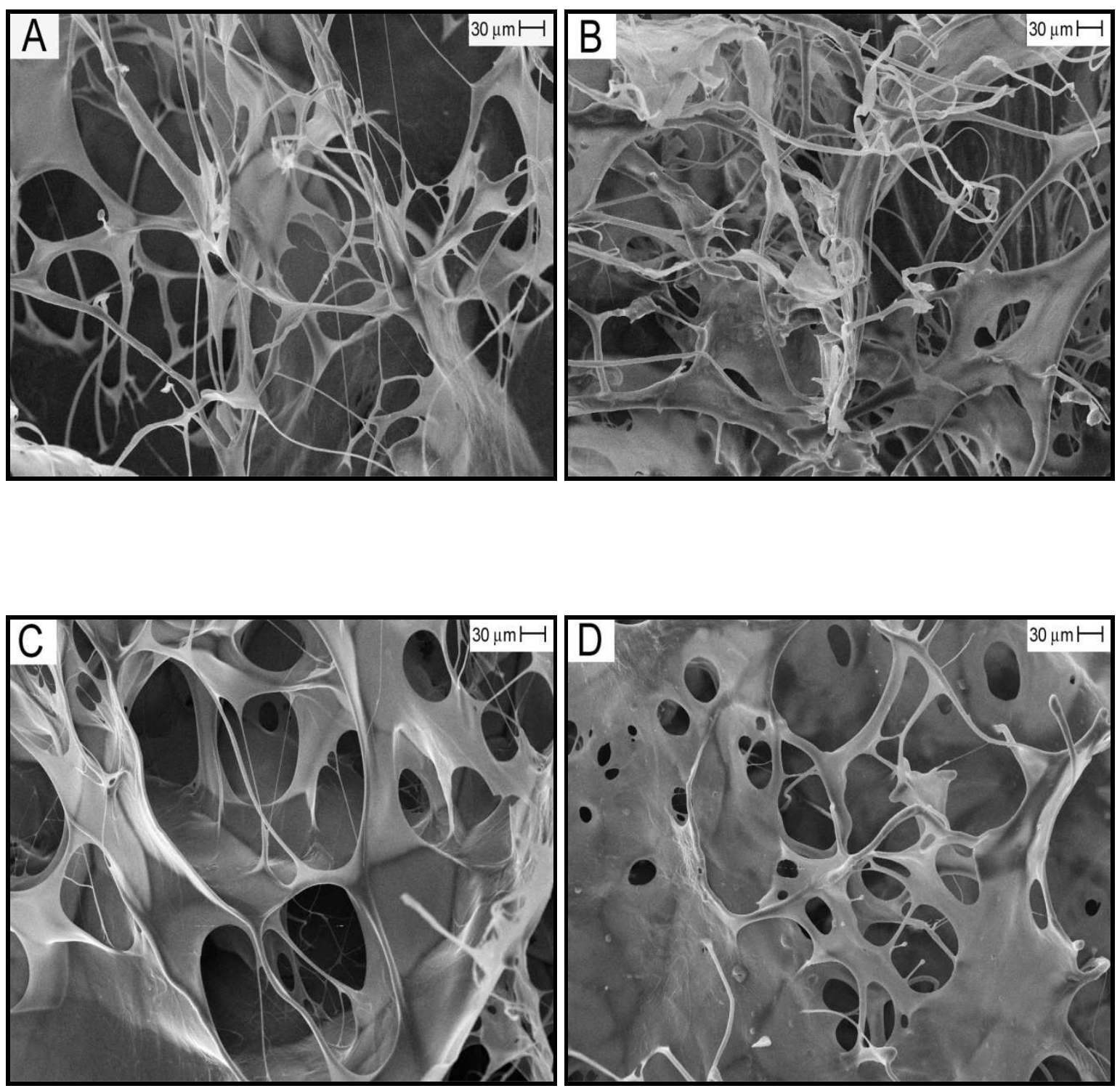

Figura 46. Fotomicrografias das matrizes PP24 (A), PP48(B), PP72 (C) e PP96 (D), aumento de 500 vezes. 

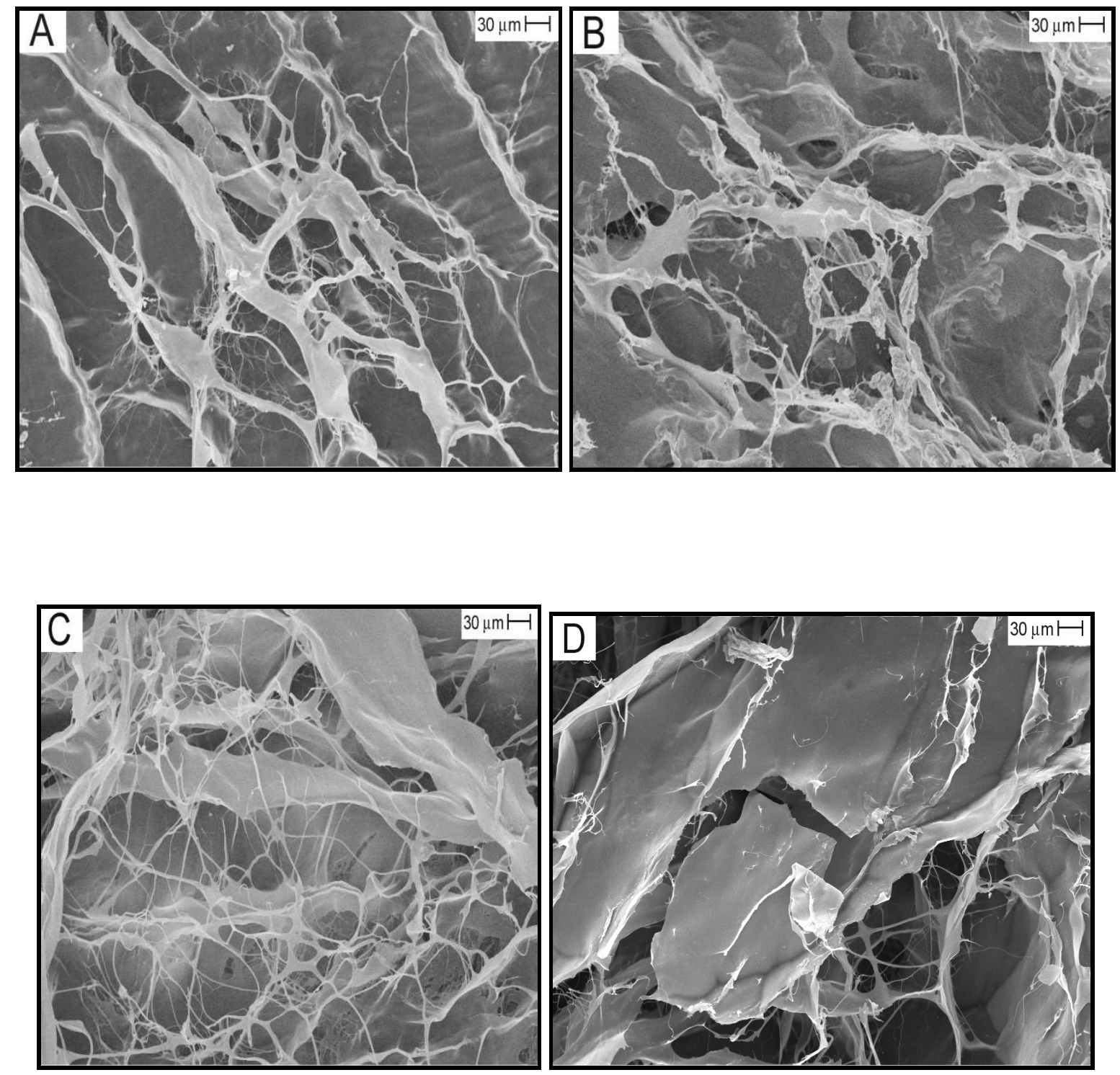

Figura 47. Fotomicrografias das matrizes PB24 (A), PB48(B), PB72 (C) e PB96 (D), aumento de 500 vezes. 

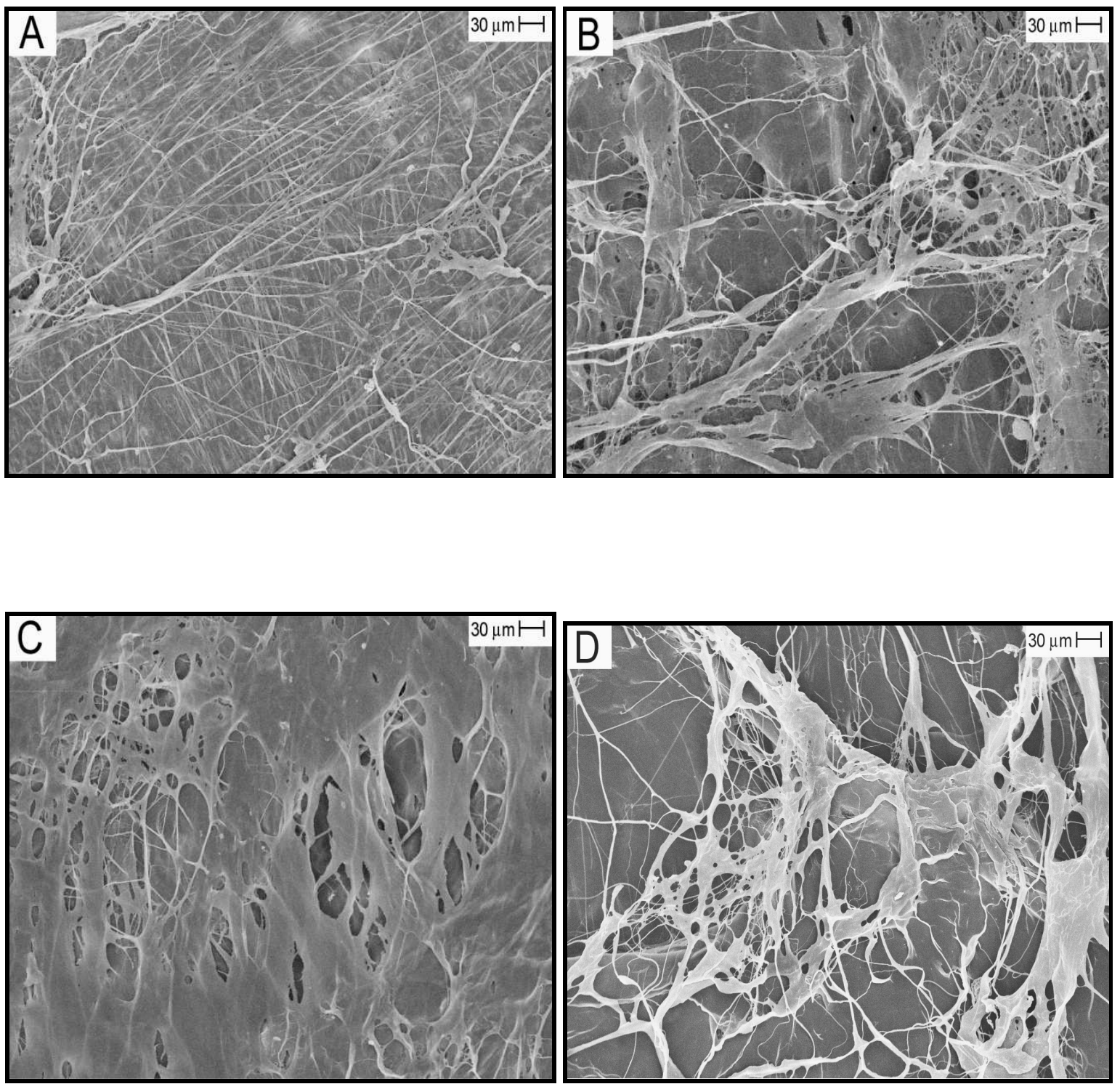

Figura 48. Fotomicrografias das matrizes SP24 (A), SP48(B), SP72 (C) e SP96 (D), aumento de 500 vezes.

O aumento do tempo de hidrolise alcalina provoca uma desestruturação das fibras das matrizes tornando-as mais "amorfas", ou seja, mais desestruturadas. Este mesmo comportamento foi verificado por Bet (2003) para as matrizes de pericárdio bovino em $\mathrm{pH} 3,0$. 
As matrizes de serosa e pericárdio são mais afetadas pela hidrólise, observando-se que a estrutura vai se rompendo com o aumento do tempo de tratamento alcalino, assim o tratamento é mais agressivo para as matrizes mais finas.

A Figura 49 mostra um corte transversal das matrizes PP96 e PB96, em que se observa uma microestrutura de poros interconectados. O tamanho médio dos poros está na faixa de $60 \mu \mathrm{m}$ para PP96 e $74 \mu \mathrm{m}$ para PB96.
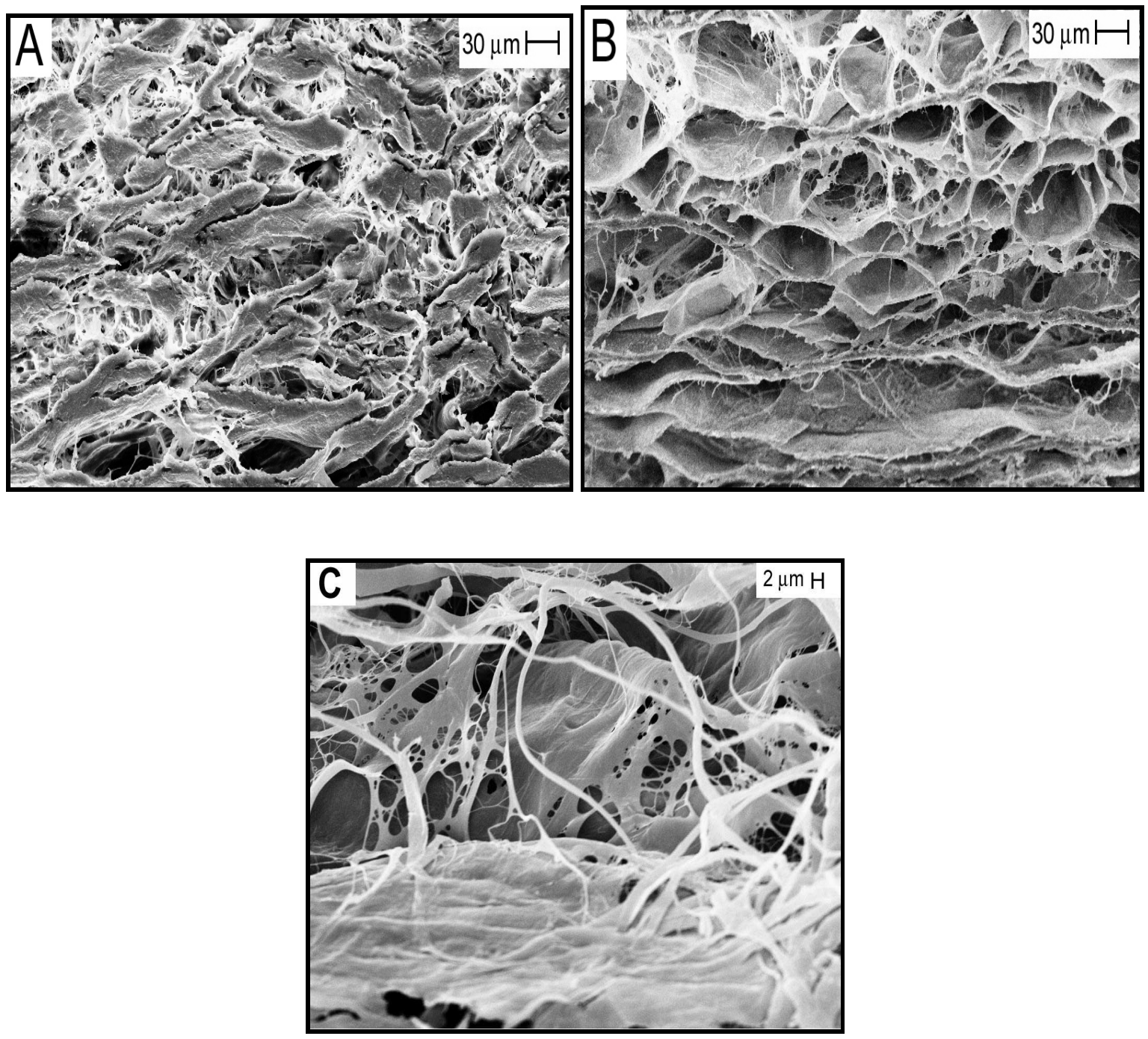

Figura 49. Fotomicrografia da secção transversal de PP96 (A), PB96(B), aumento de 500 vezes e SP24, aumento de (C) 3500 vezes (MENDES, 2003). 
A matriz SP24 não possui uma estrutura de poros e sim uma estrutura constituída de arranjos de fibras randomicamente dispostos com regiões compactas em que as fibras parecem "fundidas" entre si nos locais mais compactos (Fig. 49C).

Após a mineralização, a morfologia das matrizes é mostrada nas Figuras 50, 51 e 52. As matrizes estão recobertas por uma camada mineral que foi analisada por EDS e difração de raios X como sendo fosfato de cálcio na forma de hidroxiapatita.
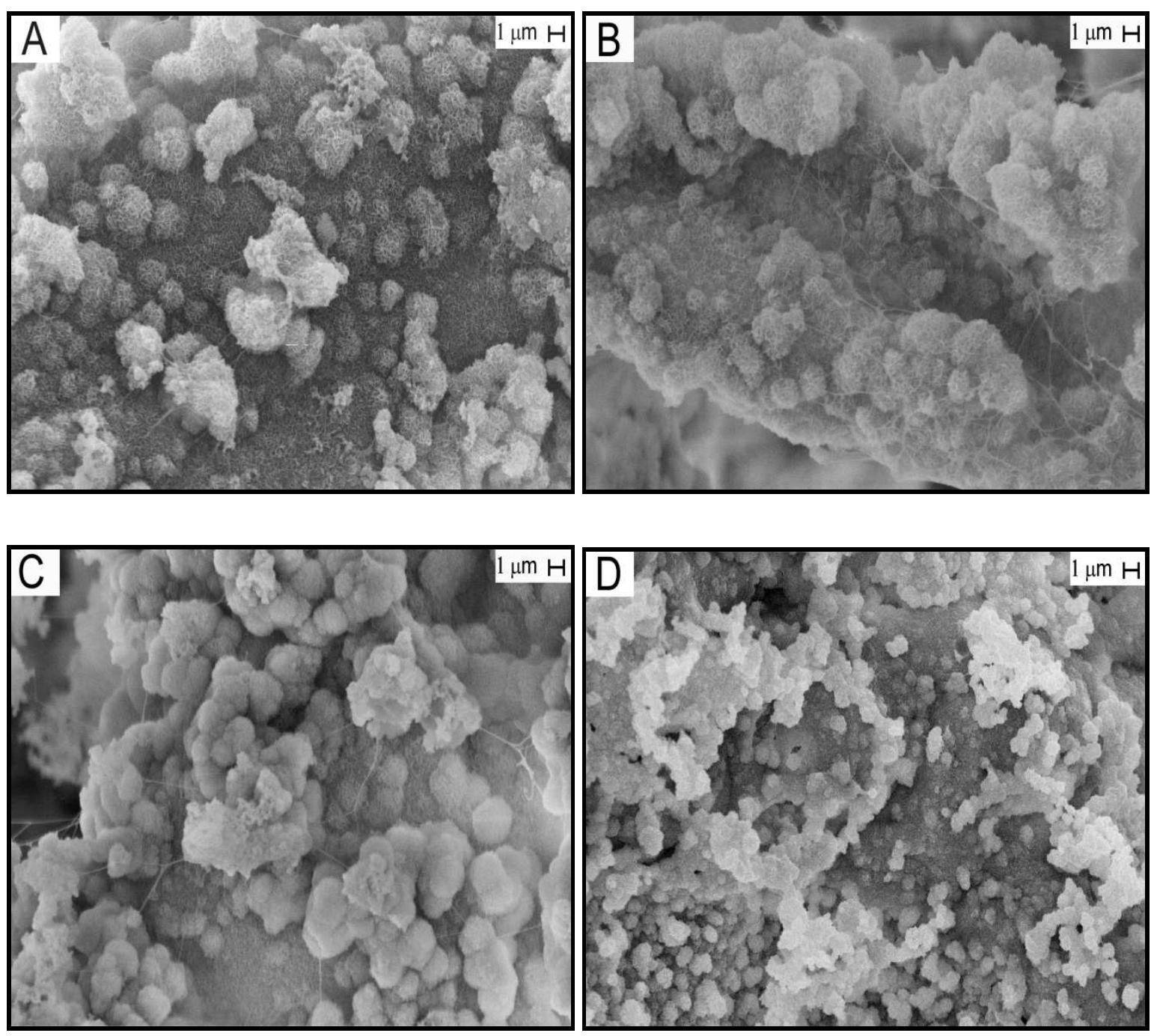

Figura 50. Fotomicrografia da matriz PP24C (A), PP48C (B), PP72C (C) e PP96C (D) aumento de 5.000x. 
A deposição não foi uniforme (Fig. 50), já que foi observado em alguns locais maiores aglomerados esféricos de sais. O tamanho destes aglomerados foi de 3,18 $\pm 0,2 \mu \mathrm{m}$ (PP24C), 3,11 $\pm 0,19 \mu \mathrm{m}$ (PP48C), 3,20 \pm 0,13 (PP72C) $\mu \mathrm{m}$ e 1,99 $\pm 0,09 \mu \mathrm{m}$ (PP96C).

As fotomicrografias das matrizes de pericárdio bovino mineralizadas estão apresentadas nas Figuras 51. Observou-se a deposição de sais por toda a superfície com a formação de aglomerados de tamanhos diferentes sendo de 1,46 $\pm 0,05 \mu \mathrm{m}$ (PB24C), 1,42 \pm 0,11 $\mu \mathrm{m}$ (PB48C), 1,23 $\pm 0,05 \mu \mathrm{m}$ (PB72C) e 1,49 $\pm 0,06 \mu \mathrm{m}$ (PB96C).
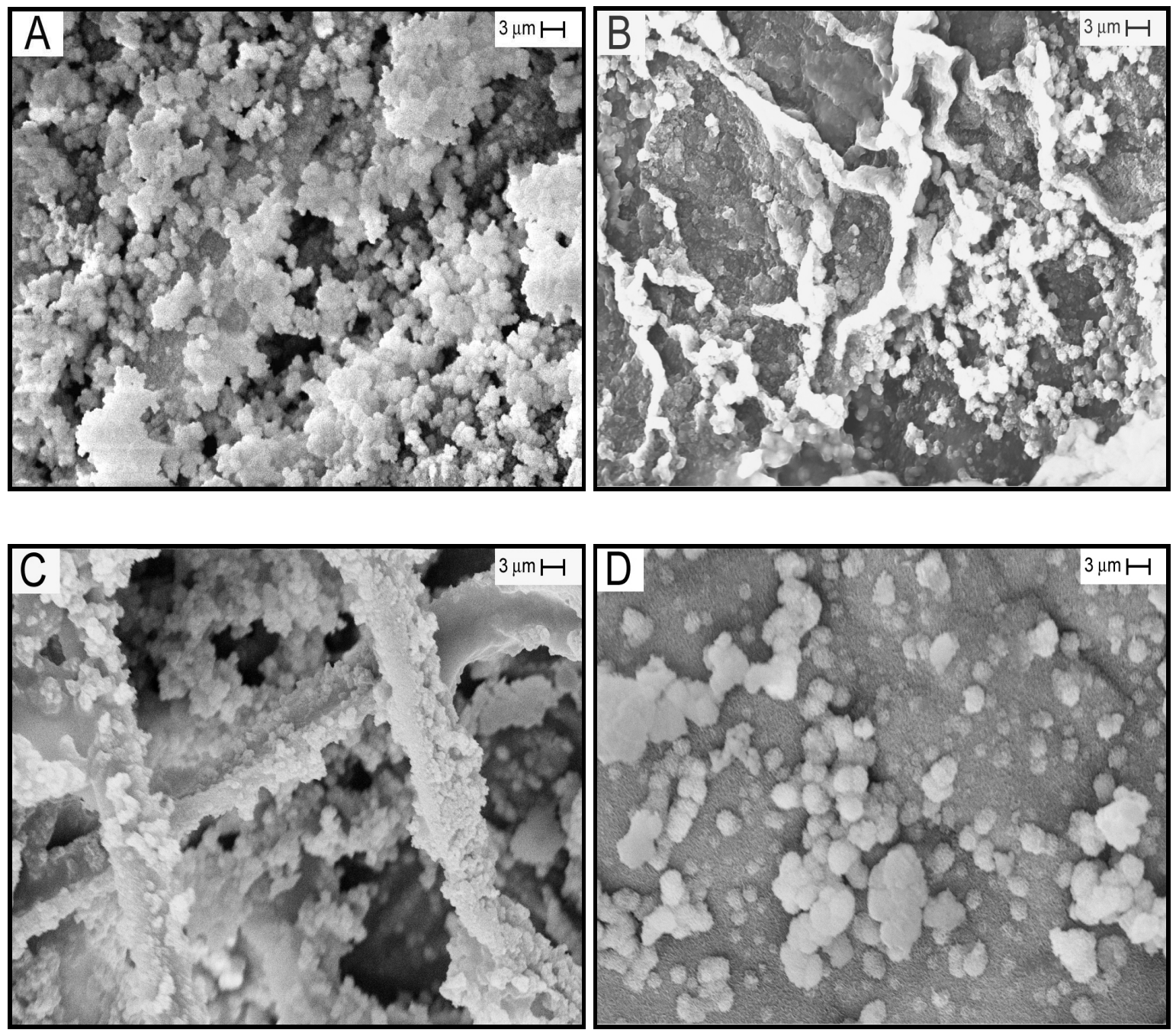

Figura 51. Fotomicrografia da matriz PB24C (A), PB48C (B), PB72C (C) e PB96C (D) aumento de 5.000x. 
As fotomicrografias das matrizes de serosa porcina mineralizadas estão apresentadas nas Figuras 52. Observou-se a deposição de sais por toda a superfície com maiores aglomerados em algumas regiões. Estes aglomerados foram medidos e formam de $1,36 \pm 0,12 \mu \mathrm{m}$ (SP24C), 0,89 $\pm 0,06 \mu \mathrm{m}$ (SP48C), 1,39 $\pm 0,06 \mu \mathrm{m}(\mathrm{SP} 72 \mathrm{C})$ e $1,17 \pm 0,06 \mu \mathrm{m}$ (SP96C).
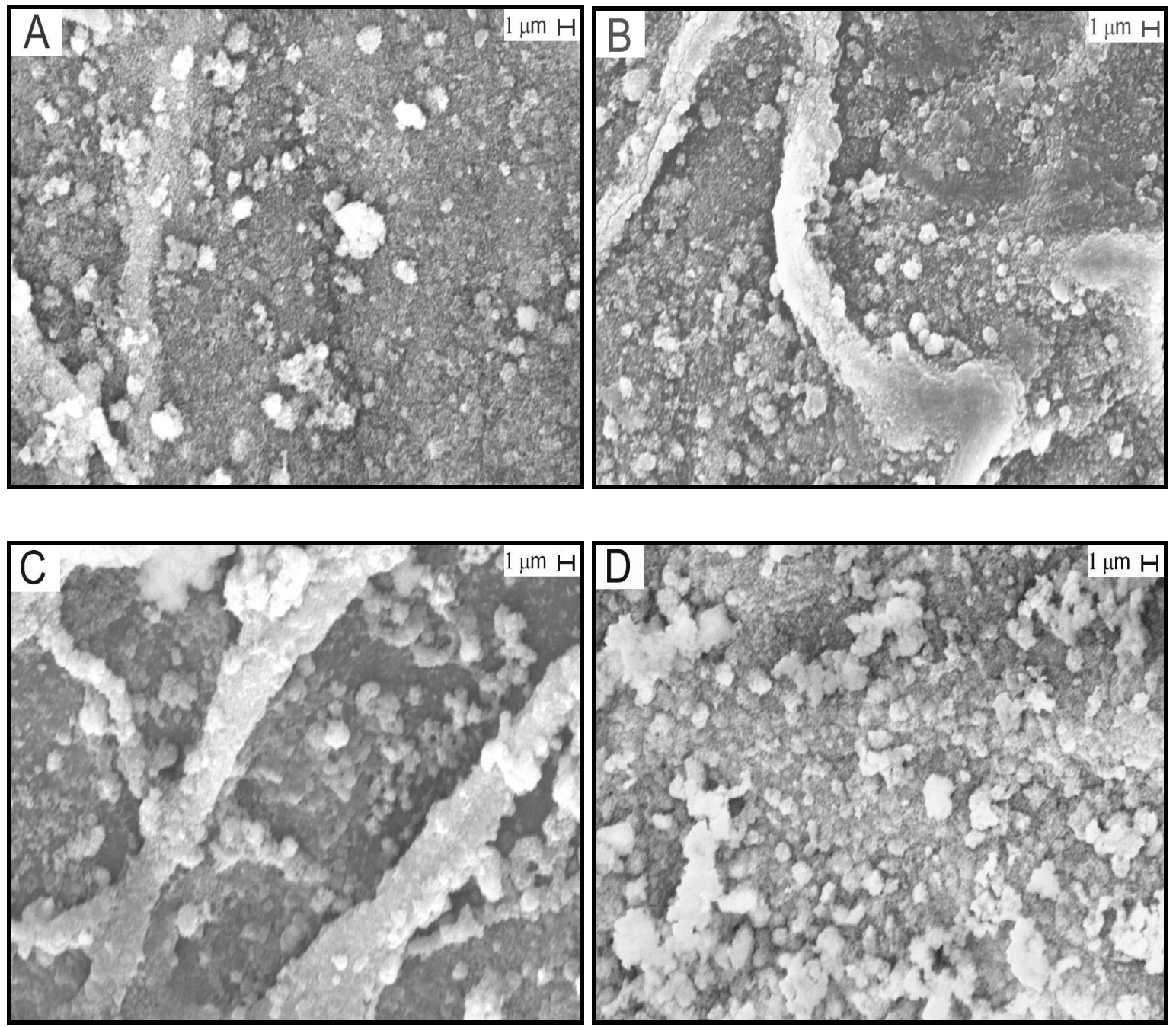

Figura 52. Fotomicrografia da matriz SP24C (A), SP48C (B), SP72C (C) e SP96C (D) aumento de 10.000x. 
Em um aumento maior (Fig.53) pôde-se observar que a morfologia dos cristais de fosfato de cálcio é no formato de placas que estão agrupadas em agregados esféricos. Esta morfologia é semelhante à deposição dos cristais já encontrados em literatura (WANG et al, 2006), reportados como sendo característicos de HA carbonatada.
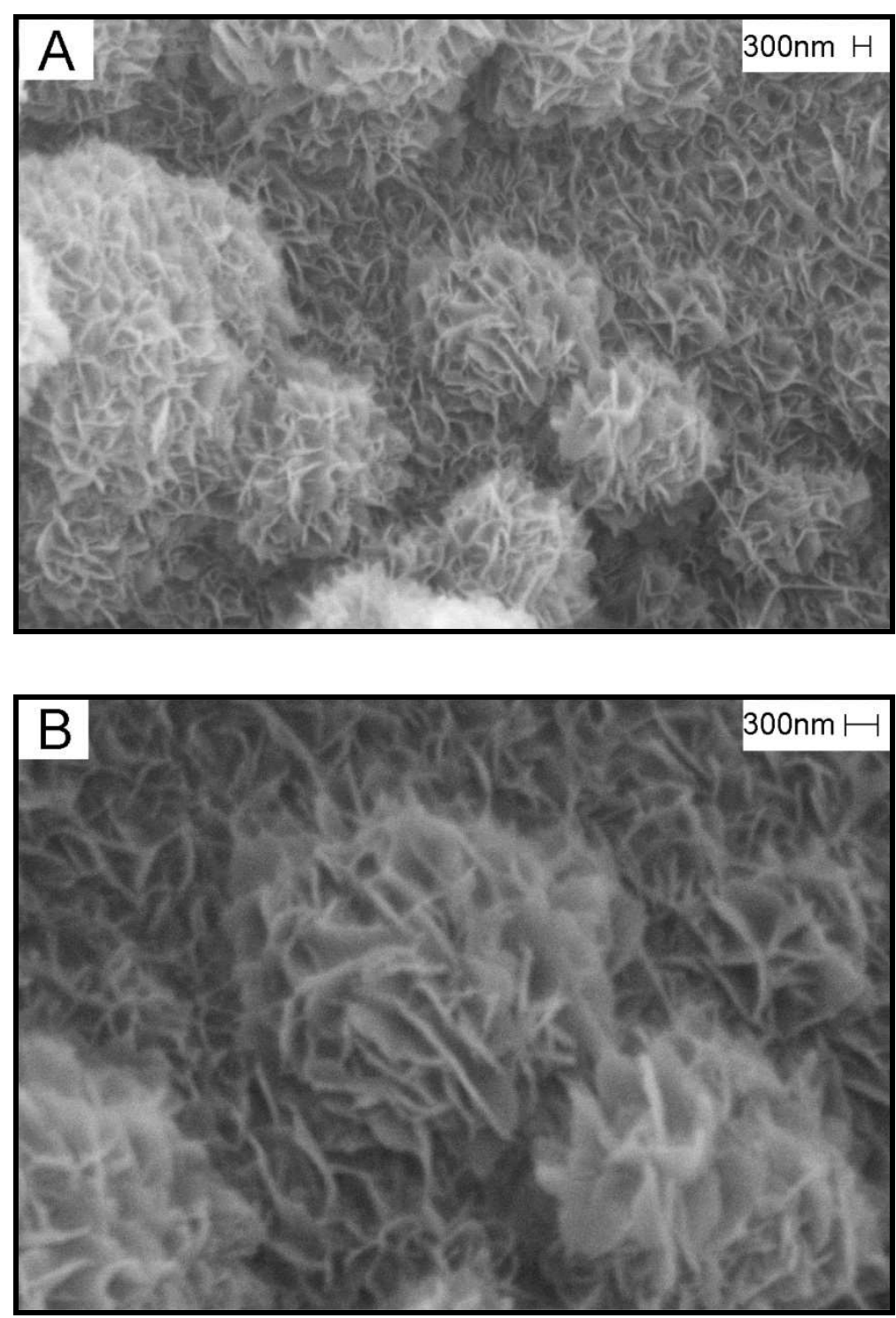

Figura 53. Fotomicrografia da matriz PP24C, aumento de: (A) 20.000x e (B) 40.000X.

Foram feitos cortes transversais nas matrizes mineralizadas que tiveram maior resíduo inorgânico, valor obtido por TG, a fim de verificar se havia deposição de sais na parte 
interna. A deposição de sais na matriz PP96C ocorre em sua superfície como mostrado anteriormente e na região interior próxima da superfície, como mostrado na Figura 54. Para as matrizes PB96C e SP96C, além de ocorrer na superfície também ocorre em seu interior, em toda a extensão. (Fig. 55 e 56).

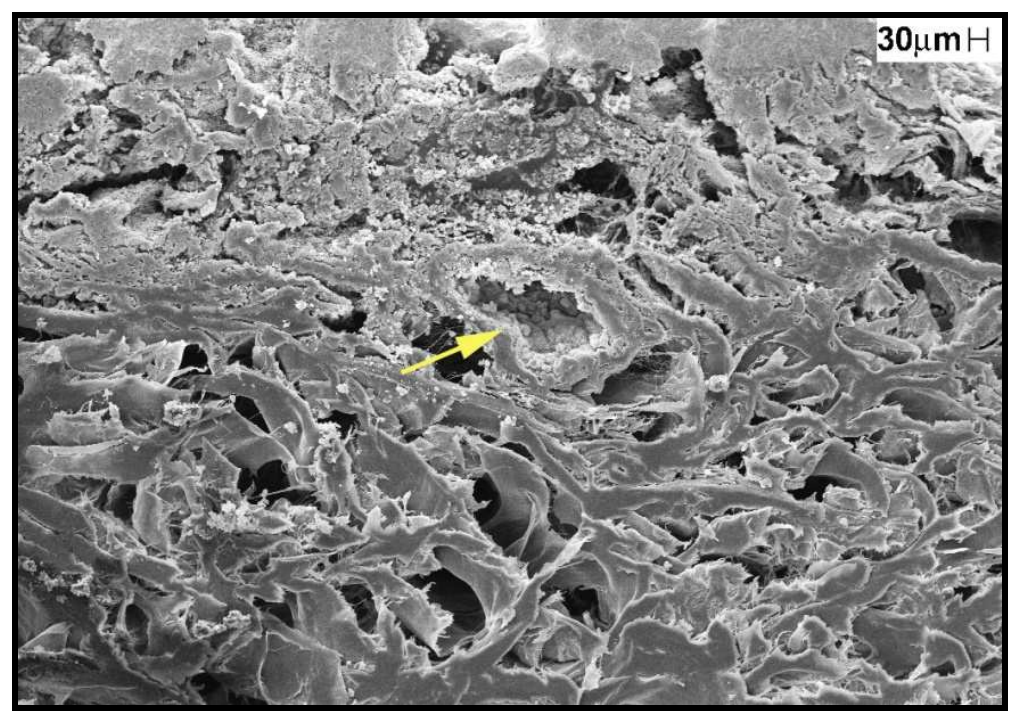

Figura 54. Fotomicrografia do interior da matriz PP96C, aumento de: 200x.

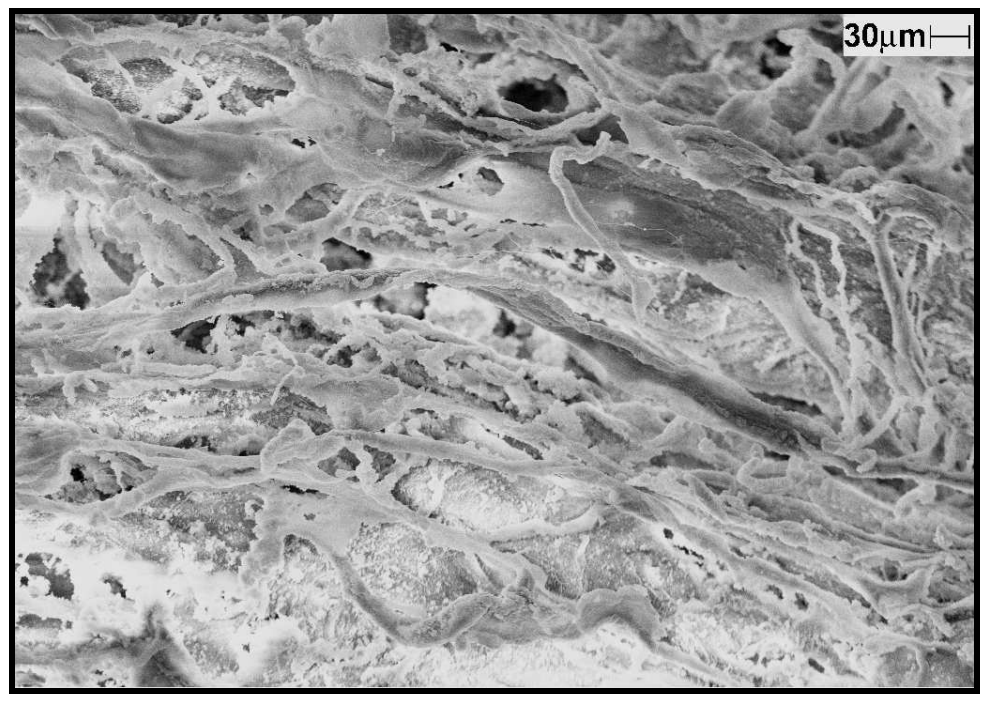

Figura 55. Fotomicrografia do interior da matriz PB96C, aumento de 500x. 


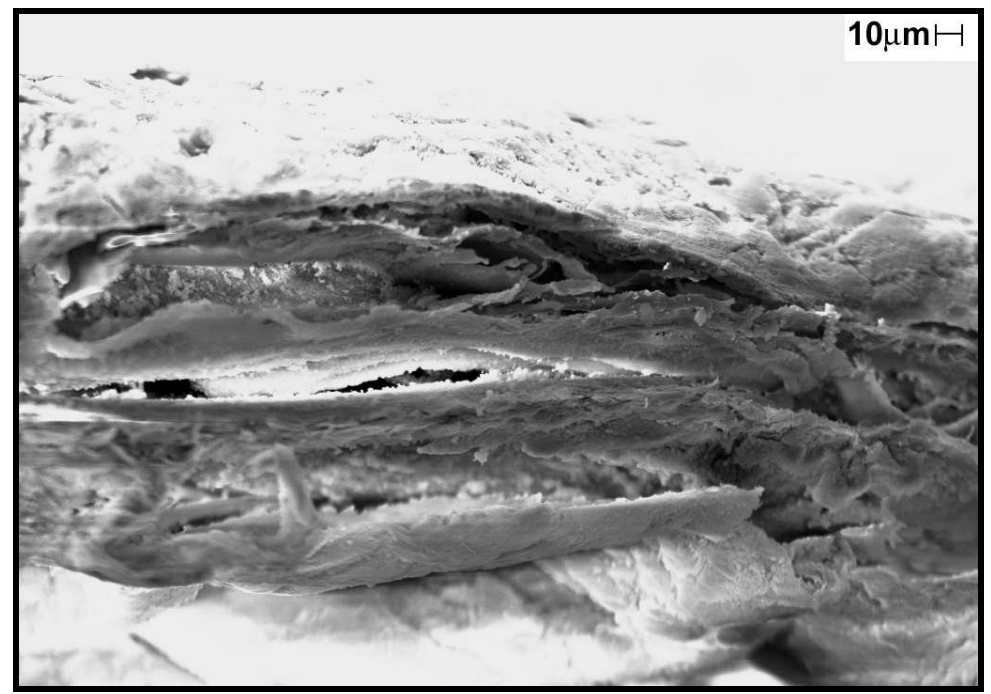

Figura 56. Fotomicrografia do interior da matriz SP96C, aumento de 1000x.

Nas fotomicrografias por MEV observou-se que a mineralização no interior dos tecidos pode ser afetada pela espessura dos mesmos, pois quanto mais fino o material, mais fácil é a entrada das soluções e a precipitação do sal pelo método de mineralização usado. Além disso, o arranjo estrutural dos tecidos é diferente permitindo ou não a deposição de sais em seu interior. 


\section{CONCLUSÕES}

Os três métodos de mineralização permitiram a obtenção de matrizes de colágeno mineralizadas. Contudo, o método de imersão alternada foi o de maior repetitibilidade.

O colágeno presente nas matrizes derivadas de pericárdio bovino, pele e serosa porcina não sofre desnaturação da hélice tripla após a hidrólise alcalina, apenas ocorre uma diminuição desta temperatura com o aumento do tempo de hidrólise.

As matrizes mineralizadas tornam-se termicamente mais estáveis quando comparadas com as matrizes hidrolisadas, ou seja, a presença de fosfato de cálcio estabiliza a hélice tripla do colágeno.

O tempo de hidrólise alcalina influencia na quantidade de deposição de sais, pois quanto maior o tempo de hidrólise maior a quantidade de grupos carboxilatos obtidos e consequentemente maior o número de sítios para deposição de sais de fosfato depositados nas matrizes.

O sal depositado nas matrizes é hidroxiapatita carbonatada e amorfa, com a relação $\mathrm{Ca} / \mathrm{P}$ variando entre $1,54-1,67$.

A deposição de hidroxiapatita, nas condições deste trabalho, é maior nas matrizes de serosa porcina, seguida pelas matrizes derivadas de pericárdio bovino e pele porcina, sendo a matriz derivada de pele porcina mineralizada apenas na superfície.

As matrizes hidrolisadas e mineralizadas não apresentaram citotoxicidade para as duas linhagens de células utilizadas, HEp-2 e McCoy.

Assim, há a possibilidade da preparação de matrizes com diferentes tempos de hidrólise e quantidades diferentes de deposição de hidroxiapatita não cristalina. 


\section{REFERÊNCIAS BIBLIOGRÁFICAS}

ARNOCZKY, S. P.; AKSAN, A. Thermal modification of connective tissues: basic science considerations and clinical implications. Journal of the American Academy of Orthopaedic Surgeons, v. 8, p. 305-313, 2000.

BADEA, E.; MIU, L.; BUDRUGEAC, P.; GIURGINCA, M.; MASIC, A.; BADEA, N.; GATTA, G. D. Study of deterioration of historical parchments by various thermal analysis techniques complemented by SEM, FTIR, UV-VIS-NIR and unilateral RMN investigations. Journal of Thermal Analysis and Calorimetry, v. 91, p. 17-27, 2008.

BADYLAK, S.; LIANG, A.; RECORD, R.; TULLIUS, R.; HODDE, J. Endothelial cell adherence to small intestinal submucosa: an acellular bioscaffold. Biomaterials, v. 20, p. 2257-2263, 1999.

BAHARUDDIN, A.; GOB, B.T.; FIRDAUS, M.N.A.R.; ABDULLAH, J. Bovine pericardium for dural graft: clinical results in 22 patients. Clinical Neurology and Neurosurgery, v. 104, p. 342-344, 2002.

BARRINGTON, J.W.; EDWARDS, G.; ARUNKALAIVANAN, A.S.; SWART, M. The use of porcine dermal implant in a minimally invasive pubovaginal sling procedure for genuine stress incontinence. BJU International, v. 90, p. 224-227, 2002.

BATISTA, T. M.; MARTINS, V. C. A.; PLEPIS, A. M. G. Thermal behavior of in vitro mineralized anionic collagen matrices. Journal of Thermal Analysis and Calorimetry, 2008. No prelo.

BATISTA, T. M.; MARTINS, V. C. A.; PLEPIS, A. M. G. Efeito do pH na calcificação in vitro de pele porcina. Polímeros, v. 17, p. 289-293, 2007.

BERNAL, V.M.; STANLEY, D.W. Stability of bovine muscle connective tissue. Journal of Food Science, v. 52, p. 876-878, 1987.

BERTRAN, C.A; ALLEGRETTI, L. J. M.; BERTAZZO, S. Synthesis of calcium phosphate nanoparticles in collagen medium. Macromolecular Symposia, v. 253, p. 77-81, 2007.

BET, M.; GOISSIS, G.; VARGAS, S.; SELISTRE-de-ARAUJO, H. S. Cell adhesion and cytotoxicity studies over polyanionic collagen surfaces with variable negative charge and wettability. Biomaterials, v. 24, p. 131-137, 2003.

BET, Marcos Roberto. Colágeno aniônico: propriedades físico-químicas, estruturais e comportamento biológico. 2000. 107f. Tese (Doutorado em Química Analítica) -Instituto de Química de São Carlos, Universidade de São Paulo, São Carlos, 2000. 
BRAILE, D. M.; BILAQUI, A.; ARDITO, R. V.; GRECO, O. T.; GARZON, S. A.; NICOLAU, J. C.; JACOB, J. L.; AYOUB, J. C.; FEDOZZI, N. M.; ANGELONI, M. A.; LORGA, A. M. Bovine pericardium cardiac prosthesis. Arquivos Brasileiros de Cardiologia, v. 39, p. 247-257, 1982.

BROMBERG, B. E.; SONG, I. C.; MOHN, M. P. The use of pigskin as a temporary biological dressing. Plastic and Reconstructive Surgery, v. 36, p. 80-90, 1965.

BROWN-ETRIS, M.; CUTSHALL, W. D.; HILES, M. C. A new biomaterial derived from small intestine submucosa and developed into a wound matrix device. Wounds, v. 14, p. 150$166,2002$.

CAIONE, P.; CAPOZZA, N.; ZAVAGLIA, D.; PALOMBARO, G.; BOLDRINI, R. In vivo bladder regeneration using small intestinal submucosa: experimental study. Pediatric Surgery International, v. 22, p. 593-599, 2006.

CARVALHO, Valéria Cardoso de Melo. Estudo dos efeitos de duas porfirinas hidrofílicas em células tumorais HEp-2 visando aplicação em terapia fotodinâmica do câncer. 2001 . 100f. Dissertação (Mestrado em Química Analítica) - Instituto de Química de São Carlos, Universidade de São Paulo, São Carlos, 2001.

CHAPMAN, J.A.; TZAPHLIDOU, M.; MEEK, K.M.; KADLER, K.E. The collagen fibril - a model system for studying the staining and fixation of a protein. Electron Microscopy Reviews, v. 3, p. 143-82, 1990.

CHIU, T.; BURD, A. Xenograft dressing in the treatment of burns. Clinics in Dermatology, v. 23, p. 419-423, 2005.

CUNHA, M. R.; SANTOS JUNIOR, A.R.; GENARI, S. C. Cultura de osteoblastos sobre membranas de colágeno polianiônico: avaliação preliminar do potencial de indução da formação de tecido ósseo visando reparação tecidual. Boletim Médico Veterinário, v. 1, p. 73-85, 2005.

CUNHA, M. R.; SANTOS JUNIOR, A.R.; GOISSIS, G.; GENARI, S. C. Implants of polyanionic collagen matrix in bone defects of ovariectomized rats. Journal of Materials Science: Materials Medicine, v. 19, p. 1341-1348, 2008.

FENG, X.; TAN, J.; PAN, Y.; WU, Q.; RUAN, S.; SHEN, R.; CHEN, X.; DU, Y. Control of hypertrophic scar from inception by using xenogenic (porcine) acellular dermal matrix (ADM) to cover deep second degree burn. Burns, v. 32, p. 293-298, 2006.

FLANDIN, F.; BUFFEVANT, C.; HERBAGE, D. Differential scanning calorimetry analysis of the age-related changes in the thermal stability of rate skin collagen. Biochimica

Biophysica Acta, v. 791, p. 205-211, 1984. 
FURTH, M. E.; ATALA, A.; DYKE, M. E. V. Smart biomaterials design for tissue engineering and regenerative medicine. Biomaterials, v. 28, p. 5068-5073, 2007.

GAERTNER, W. B.; BONSACK, M. E.; DELANEY, J. P. Experimental evaluation of four biologic prostheses for ventral hernia repair. Journal of Gastrointestinal Surgery, v. 11, p. 1275-1285, 2007.

GALLO, J.I.; ARTIÑANO, E.; VAL, F.;DURAN, C. G. Glutaraldehyde-preserved heterologous pericardium for the repair of diaphragmatic defects. The Journal of Thoracic and Cardiovascular Surgery, v.83, p.905-908, 1982.

GAYRE, G. S.; DEBACKER, C.; LIPHAM, W.; TAWFIK, H. A.; HOLCK, D.; DUTTON, J.J. Bovine pericardium as a wrapping for orbital implants. Ophthalmic Plastic

Reconstructive Surgery, v.17, p.381-387, 2001.

GELINSKY, M.; WELZEL, P. B.; SIMON, P.; BERNHARDT, A.; KÖNIG,U. Porous threedimensional scaffolds made of mineralized collagen: Preparation and properties of a biomimetic nanocomposite material for tissue engineering of bone. Chemical Engineering Journal, v. 137, p. 84-96, 2008.

GIGLIOTI, A. F. Matrizes acelulares de colágeno:elastina a partir da desvitalização do pericárdio bovino: caracterização química, físico-química e estrutural. 2005. 80 f. Tese (Doutorado em Físico-Química) - Instituto de Química de São Carlos, Universidade de São Paulo, São Carlos, 2005.

GIRARDI, Raquel Cecília. Eficácia do colágeno na cicatrização de feridas. 2005. 101f. Dissertação (Mestrado em Bioengenharia) - Programa de Pós-Graduação Interunidades em Bioengenharia, Universidade de São Paulo, São Carlos, 2005.

GIRIJA, E. K.; YOKOGAWA, Y.; NAGATA, F. Bone-like apatite formation on collagen fibrils by biomimetic method. Chemistry Letters, v. 31, p. 702-703, 2002.

GÓES, J. C.; FIGUEIRÓ, S. D.; OLIVEIRA, A. M.; MACEDO, A. A. M. SILVA, C. C.; RICARDO, N. M. P. S.; SOMBRA, A. S. B. Apatite coating on anionic and native collagen films by an alternate soaking process. Acta Biomaterialia, v. 3, p. 773-778, 2007.

GOISSIS, G.; MAGINADOR, S.V.S.; MARTINS, V.C.A. Biomimetic mineralization of charged collagen matrices: in vitro and in vivo study. Artificial Organs, v. 27, p. 437-443, 2003.

HABRAKEN, W. J. E. M.; WOLKE, J. G. C.; JANSEN, J. A. Ceramic composites as matrices and scaffolds for drug delivery in tissue engineering. Advanced Drug Delivery Reviews, v. 59, p. 234-248, 2007. 
HARTGERINK, J. D.; BENIASH, E.; STUPP, S. I. Self-assembly and mineralization of peptide-amphiphile nanofibers. Science, v. 294, p. 1684, 2001.

HOYAMA,E.; SCHELLINI, S. A.; PELLIZON, C. H.; MARQUES, M. E. A.; PADOVANI, C. R.; ROSSA, R. Porcine acellular dermal graft with and without impermeable dressing to treat extensive wounds. Anais Brasileiros de Dermatologia, v. 80, p. 369-374, 2005.

INTERNATIONAL CENTRE FOR DIFFRACTION DATA. Powder diffraction file 1994: PDF-2 Database Sets 1-44. Newtown Square : ICDD, 1994. 9-0432.

JONES, J. R.; LEE, P. D.; HENCH, L. L. Hierarchical porous materials for tissue engineering. Philosophical Transactions of the Royal Society A, v. 364, p. 263-281, 2006.

KAWASHI, Elizabete Yoshie. Síntese de Nanopartículas de Fosfatos de Cálcio em Ambientes Confinados no Sistema Renex-100® /Cicloexano/"brine". 2002. 107f. Tese (Doutorado em Química) -Instituto de Química, UNICAMP, Campinas, 2002.

KENNEDY, C. J.; WESS, T. J. The Structure of collagen within parchment - a review. Restaurator, v. 24, p. 61-80, 2003.

KIKUCHI, M.; IKOMA, T.; ITOH, S.; MATSUMOTO, H. N.; KOYAMA, Y.; TAKAKUDA, K.; SHIZUKO I., SHINOMIYA K., TANAKA J. Biomimetic synthesis of bone-like nanocomposites using the self-organization mechanism of hydroxyapatite and collagen. Composites Science and Technology, v. 64, p. 819-825, 2004.

KIM B. S.; MOONEY, D. J. Development of biocompatible synthetic extracellular matrices for tissue engineering. TIBTECH, v. 16, p. 224-230, 1998.

KNESER, U.; SCHAEFER, D. J.; POLYKANDRIOTIS, E.; HORCH, R. E. Tissue engineering of bone: the reconstructive surgeon's point of view. Journal of Cellular and Molecular Medicine, v. 10, p. 7-19, 2006.

KOKUBO, T.; TAKADAMA, H. How useful is SBF in predicting in vivo bone bioactivity? Biomaterials, v. 27, p. 2907-2915, 2006.

KOTCH, F. W.; RAINES, R. T. Self-assembly of synthetic collagen triple helices. PNAS, v. 103, p. 3028-3033, 2006.

KRONICK, P. L.; COOKE, P. Thermal Stabilization of collagen fibers by calcification. Connective Tissue Research, v. 33, p. 275-82, 1996.

LACERDA, C.; PLEPIS, A. M. G.; GOISSIS, G. Hidrólise seletiva de carboxiamidas de resíduos de Asparagina e Glutamina em colágeno: preparação e caracterização de matrizes aniônicas para uso como biomateriais. Quimica Nova, v. 21, p. 267-271, 1998. 
LEE, C. H.; SINGLA, A.; LEE, Y. Biomedical applications of collagen. International Journal of Pharmaceutics, v. 220, p. 1-22, 2001.

LEE, M.; CHANG, P. C. Y.; DUNN, J. C. Y. Evaluation of small intestinal submucosa as scaffolds for intestinal tissue engineering. Journal of Surgical Research, v. 147, p. 168-171, 2008.

LICKORISH, D.; RAMSHAW, J. A. M.; WERKMEISTER, J. A.; GLATTAUER, V.; HOWLETT, C. R. Collagen-hydroxyapatite composite prepared by biomimetic process. Journal of Biomedical Materials Research, Part A, v. 68, p. 20-27, 2004.

LINDBERG, K.; BADYLAK, S. F. Porcine small intestinal submucosa (SIS): a bioscaffold supporting in vitro primary human epidermal cell differentiation and synthesis of basement membrane proteins. Burns, v. 27, p. 254-266, 2001.

MACLEOD, T. M.; WILLIAMS, G.; SANDERS, R.; GREEN, C. J. Histological evaluation of permacol as a subcutaneous implant over a 20-week period in the rat model. British Journal of Plastic Surgery, v. 58, p. 518-532, 2005.

MAIZATO, Marina Junko Shiotsu. Avaliação das propriedades do pericárdio bovino liofilizado. 2003. 120f. Tese (Doutorado em Engenharia Mecânica) - Faculdade de Engenharia Mecânica, UNICAMP, Campinas, 2003.

MARKOVIC, M.; FOWLER, B. O.; TUNG, M. S. J. Preparation and comprehensive characterization of a calcium hydroxyapatite reference material. Journal of Research of the National Institute of Standards and Technology, v. 109, p. 553-568, 2004.

MARTINS, V. C. A.; GOISSIS, G.; RIBEIRO, A. C.; MARCANTÔNIO JÚNIOR., E.; BET, $\mathrm{M}$. The controlled release of an antibiotic by hydroxyapatite: anionic collagen composites. Artificial Organs, v. 22, p. 215-221, 1998.

MAYNE, R.; BURGESON, R. E. Structure and function of collagen types, London: Academic Pres, 1987. 317p.

MENDES, Isequiel dos Santos. Preparação e caracterização de matriz colagênica derivada de serosa. 2003. 47f. Monografia - Instituto de Química de são Carlos, Universidade de São Paulo, São Carlos, 2003.

METCALFE, A. D.; FERGUSON, M. W. J. Tissue engineering of replacement skin: the crossroads of biomaterials, wound healing, embryonic development, stem cells and regeneration. Journal of the Royal Society Interface, v. 4, p. 413-437, 2007.

MEYERS, M. A.; CHEN, P. Y.; LIN, A. Y. M.; SEKI, Y. Biological materials: Structure and mechanical properties. Progress in Materials Science, v. 53, p. 1-206, 2008. 
MIRNAJAFI, A.; RAYMER, J.; SCOTT, M. J.; SACKS, M. S. The effects of collagen fiber orientation on the flexural properties of pericardial heterograft biomaterials. Biomaterials, $\mathrm{v}$. 26, p. 795-804, 2005.

MOORE, R. D.; MIKLOS, J. R.; KOHLI, N. Rectovaginal fistula repair using a porcine dermal graft. Obstretics \& Gynecology, v. 104, p. 1165-1167, 2004.

MURUGAN, R.; RAMAKRISHNA, S. Crystallographic study of hydroxyapatite bioceramics derived from various sources. Crystal Growth \& Design, v. 5, p. 111-112, 2005.

NIMNI, M.E.; HARKNESS, R.D. Molecular structure and function of collagen. In: NIMNI, M.E. (Ed.). Collagen: biochemistry. Boca Raton: CRC Press, 1988. v. 1, p. 1-77.

PARK, J. B.; BRONZINO, J. D. Biomaterials - principles and applications. Boca Raton: CRC Press, 2003, 250p.

PLEPIS, A. M. D.; GOISSIS, G.; DAS-GUPTA, D. K. Dielectric and pyroelectric characterization of anionic and native collagen. Polymer Engineering and Science, v. 36, p. 2932-2938. 1996.

PRASERTSUNG, I.; KANOKPANONT, S.; BUNAPRASERT, T.; THANAKIT, V.; DAMRONGSAKKUL, S. Development of acellular dermis from porcine skin using periodic pressurized technique. Journal of Biomedical Materials Research Part B, v. 85, p. 210-219, 2007.

REID, G. G.; GORHAM, S. D.; LACKIE, J. M. The attachment, spreading, and growth of baby hamster kidney cells on collagen, chemically modified collagen-composite substrata. J. Materials Science Letter, v. 4, p. 201-209, 1993.

ROCHA, L. B.; ADAM, R. L.; LEITE, N. J.; METZE, K., ROSSI, M. A. Biomineralization of polyanionic collagen-elastin matrices during cavarial bone repair. Journal of Biomedical Materials Research, Part A, v. 79, p. 237-245, 2006.

RODRIGUES, Fabiana Tessari. Pele porcina como fonte de matrizes tridimensionais de colágeno. 2006. 66f. Dissertação (Mestrado em Química Analítica) - Instituto de Química de São Carlos, Universidade de São Paulo, São Carlos, 2006.

ROGERO, S. O.; LUGÃO, A. B.; IKEDA, T. I; CRUZ, A. S. Teste in vitro de citotoxicidade: estudo comparativo entre duas metodologias. Materials Research, v. 6, p. 317-320, 2003.

ROSA, F. P.; LIA, R. C. C.; SOUZA, K. O. F.; GOISSIS, G.; MARCANTONIO JÚNIOR, E. Tissue response to polyanionic collagen: elastin matrices implanted in rat calvaria.

Biomaterials, v. 24, p. 207-212, 2003. 
ROSE, F. A. J.; OREFFO, R. O. C. Bone tissue engineering: hope vs hype. Biochemical and Biophysical Research Communications, v. 292, p. 1-7, 2002.

ROSSOUW, P.; VILLIERS, M. Bovine pericardial ligament and tendon augmentation: a new and revolutionary ligament. Journal of Bone and Joint Surgery, v. 87, p. 277, 2005.

RUSZCZAK, Z. Effect of collagen matrices on dermal wound healing. Advanced Drug Delivery Reviews, v. 55, p. 1595-1611, 2003.

SACKS, M. S.; HAMAMOTO, H.; CONNOLLY, J. M.; GORMAN, R. C.; GORMAN III, J. H.; LEVY, R. J. In vivo biomechanical assessment of triglycidylamine crosslinked pericardium. Biomaterials, v. 28, p. 5390-5398, 2007.

SALGADO, A J.; COUTINHO, O. P.; RUI, L. R. Bone tissue engineering: state of the art and future trends. Macromolecular Bioscience, v. 4, p. 743-765, 2004.

SATO, K. Mechanism of hydroxyapatite mineralization in biological systems. Journal of the Ceramic Society of Japan, v. 115, p. 124-130, 2007.

SHAIKH, F. M.; GIRI, S. K.; DURRANI, S.; WALDRON, D.; GRACE, P. A. Experience with porcine acellular dermal collagen implant in one-stage tension-free reconstruction of acute and chronic abdominal wall defects. World Journal of Surgery, v. 31, p. 1966-1972, 2007.

SHIN, H.; JO, S.; MIKOS, A. G. Biomimetic materials for tissue engineering. Biomaterials v. 24, p. 4353-4364, 2003.

SIGMA-ALDRICH, 2008. Disponível em: <http://www.sigmaaldrich.com/etc/medialib/docs/Sigma/General_Information/imdm.Par.000 1.File.tmp/imdm.pdf >; <http://www.sigmaaldrich.com> Acesso em: 15 set. de 2008.

SILVA, M. H. P. Apostila de biomateriais. Disponível em: $<$ http://mesonpi.cat.cbpf.br/e2006/posgraduacao/pdf_p3/ApostilaBiomateriaias.pdf $>$. Acesso em: 15 jan. 2008.

SMITH, J.W. Molecular pattern in native collagen. Nature, v. 219, p. 157-63, 1968.

SOCCOL, A. T.; BETTEGA, S. B.; NORONHA, L.; SASS, S.; SOCCOL, V. T.; SCHOLZ, M. R.; MOCELLIN, M. Comparação entre os bioenxertos de hidroxiapatitade cálcio e submucosa de intestino delgado porcino no preenchimento de defeitos ósseos criados em mandíbula de ratos. Revista Brasileira de Otorrinolaringologia, v. 72, p. 195-199, 2006.

SÖDERHÄLL, C;MARENHOLZ, I; KERSCHER, T; RÜSCHENDORF, F; ESPARZAGORDILLO, J; WORM, M; GRUBER, C; MAYR, G; ALBRECHT, M; ROHDE, K; 
SCHULZ, H; WAHN, U; HUBNER, N; LEE, Y. Variants in a novel epidermal collagen gene (COL29A1) are associated with atopic dermatitis. PLoS Biology, v. 5, p. 1952-1961, 2007.

SUNG, H. W.; CHANG, Y.; CHIU, C. T.; CHEN, C. N.; LIANG, H. C. Crosslinking characteristics and mechanical properties of a bovine pericardium fixed with a naturally occurring crosslinking agent. Journal of Biomedical Materials Research, Part A, v. 47, p. 116-126, 1999.

TANAHASHI, M.; YAO, T.; KOKUBO, T.; MINODA, M.; MIYAMOTO, T.;

NAKAMURA, T.; YAMAMURO, T. Apatite coating on organic polymers by a biomimetic rocess. Journal of the American Ceramic Society, v.77, p. 2805-2808, 1994.

TREBACZ, H., WÓJTOWICZ, K. Thermal stabilization of collagen molecules in bone tissue. International Journal of Biological Macromolecules, v. 37, p. 257-262, 2005.

VARDAXIS, N. J.; BRANS, T. A.; BOON, M. E.; KREIS, R. W.; MARRES, L. M. Confocal laser scanning microscopy of porcine skin: implications for human wound healing studies. Journal of Anatomy, v. 190, p. 601-611, 1997.

VEIS, A. Collagen fibrilogenesis. Connective Tissue Research, v. 10, p. 11, 1982.

VENUGOPAL, J.; LOW, S.; CHOON, A. T.; KUMAR T. S. S. RAMAKRISHNA, S. Mineralization of osteoblasts with electrospun collagen/hydroxyapatite nanofibers. Journal Materials Science: Materials in Medicine, v. 19, p. 2039-2046, 2008.

WAHL, D. A.; CZERNUSZKA, J. T. Collagen-hydroxyapatite composites for hard tissue repair. European Cells \& Materials Journal, v. 11, p. 43-56, 2006.

WANG, Y.; YANG, C. Biomimetic formation of hydroxyapatite/collagen matrix composite. Advanced Engineering Materials, v. 8, p. 97-100, 2006.

XIE, J.; BAUMANN, M. J.; McCABE, L. R. Osteoblasts respond to hydroxyapatite surfaces with immediate changes in gene expression. Journal of Biomedical Materials Research, Part A, v. 71, p. 108-117, 2004.

YAMAGUSHI, I.; KOGURE, T.; SAKANE, M.; TANAKA, S.; OSAKA, A.; TANAKA, J. Microstructure analysis of calcium phosphate formed in tendon. Journal of Materials Science: Materials in Medicine, v. 14 p. 883-889, 2003.

YOKOYAMA, A.; GELINSKY, M.; KAWASAKI, T.; KOHGO, T.; KONIG, U.; POMPE, W.; Watari, F. Biomimetic porous scaffolds with high elasticity made from mineralized collagen-an animal study. Journal of Biomedical Materials Research Part B, v. 75, p. 464-472, 2005. 
ZHANG, L. J.; FENG, X. S.; LIU, H. G.; QIAN, D. J.; ZHANG, L.; YU, X. L.; CUI, F. Z. Hydroxyapatite/collagen composite materials formation in simulated body fluid environment. Materials Letter, v. 58, p. 719-722, 2004.

ZHANG, Z.; LIU, W.; LI, D.; LI, G. Physicochemical properties of succinylated calfskin pepsin-solubilized collagen. Bioscience Biotechnology Biochemistry, v. 71, p. 2057-2060, 2007.

ZHAO, F.; GRAYSON, W. L.; MA, T.; BUNNELL, B.; LU, W. W. Effects of hydroxyapatite in 3-D chitosan-gelatin polymer network on human mesenchymal stem cell construct development. Biomaterials, v. 27, p. 1859-1867, 2006. 


\section{Apêndice 1- Curvas DSC}
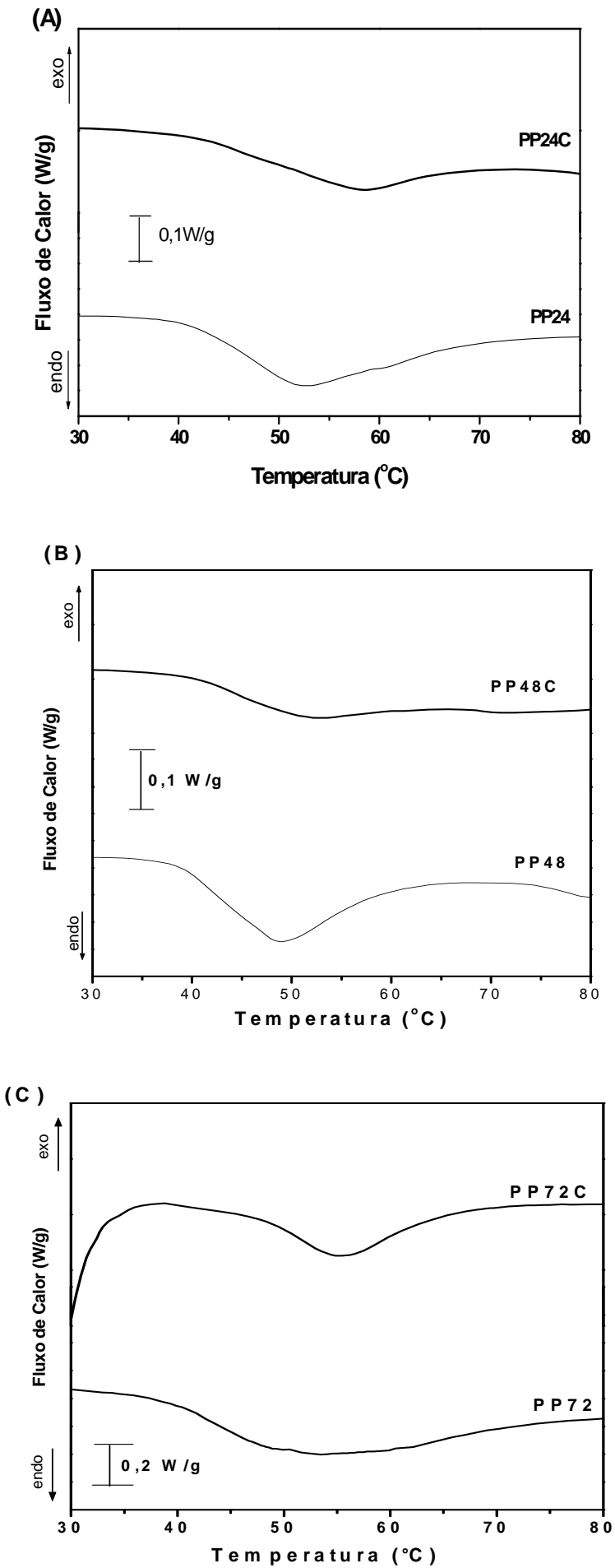

Figura 57. Curvas DSC para as matrizes derivadas de pele porcina hidrolisadas e mineralizadas: (A)24h, (B) 48h e (C) 72h. 

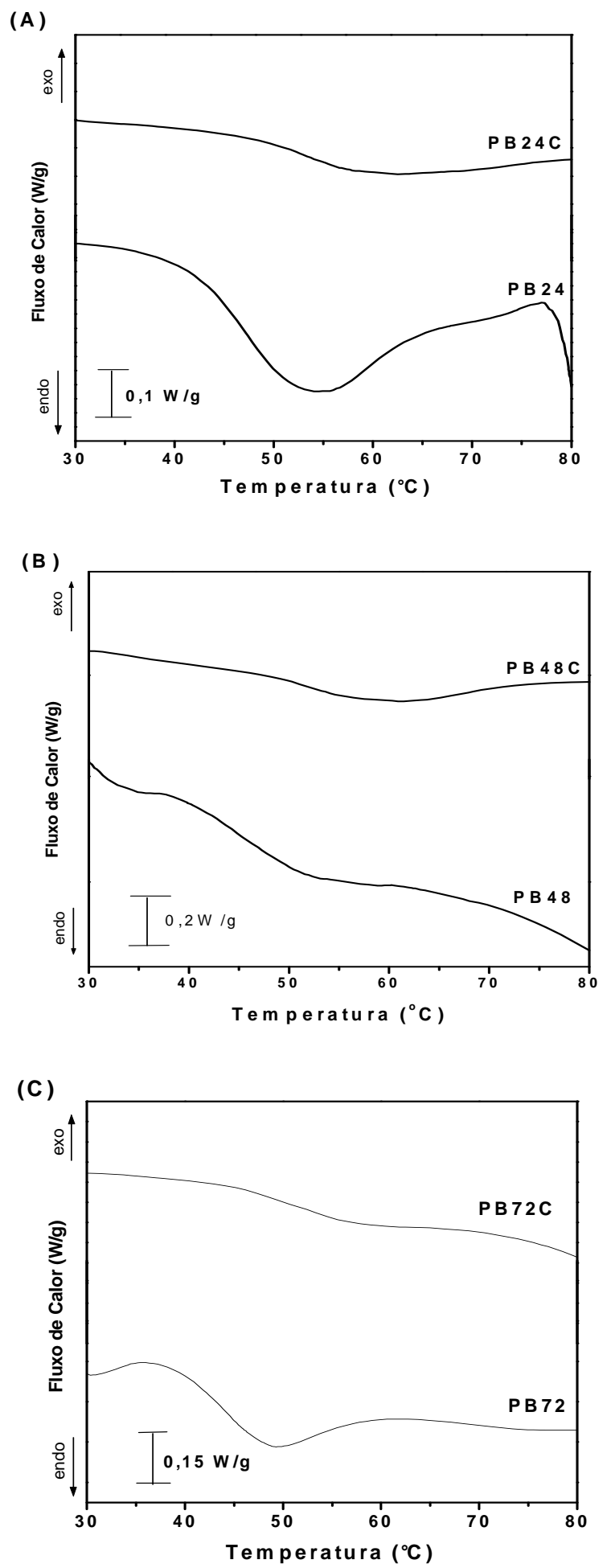

Figura 58. Curvas DSC para as matrizes derivadas de pericárdio bovino hidrolisadas e mineralizadas: (A)24h, (B) 48h e (C) 72h. 


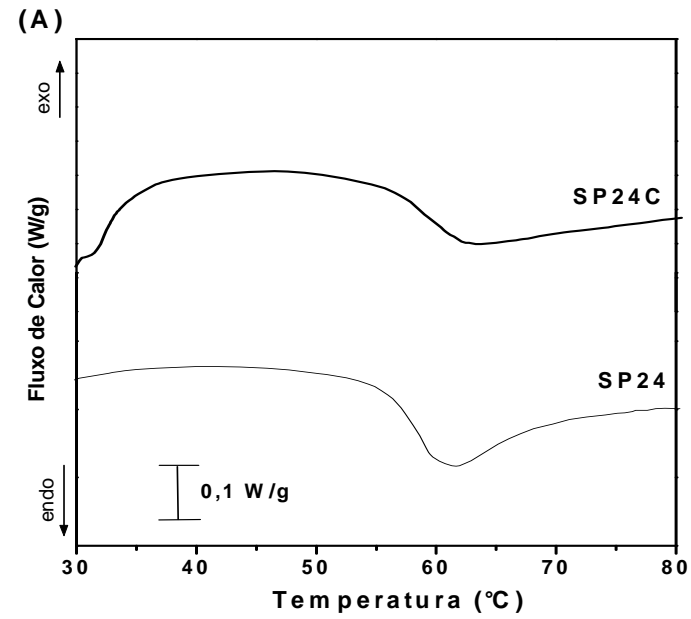

(B)

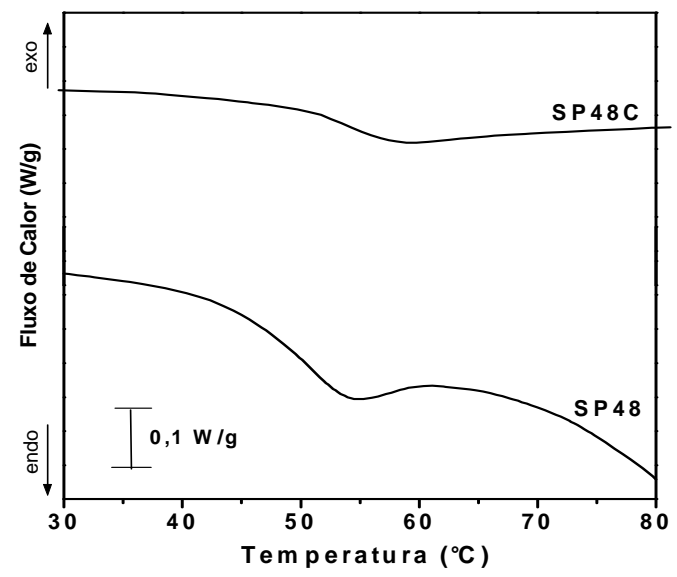

(C)

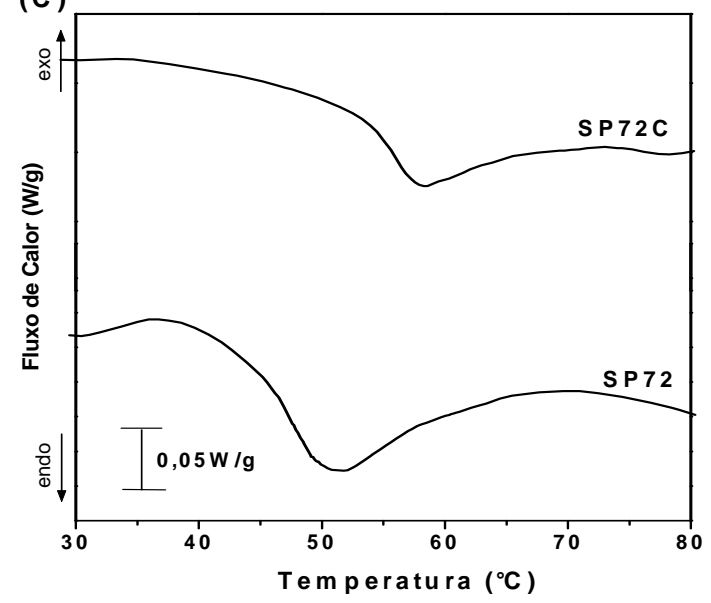

Figura 59. Curvas DSC para as matrizes derivadas de serosa hidrolisadas e mineralizadas:

(A) $24 \mathrm{~h},(B) 48 \mathrm{~h} \mathrm{e} \mathrm{(C)} 72 \mathrm{~h}$. 


\section{Apêndice 2 - Curvas Termogravimétricas}

(A)

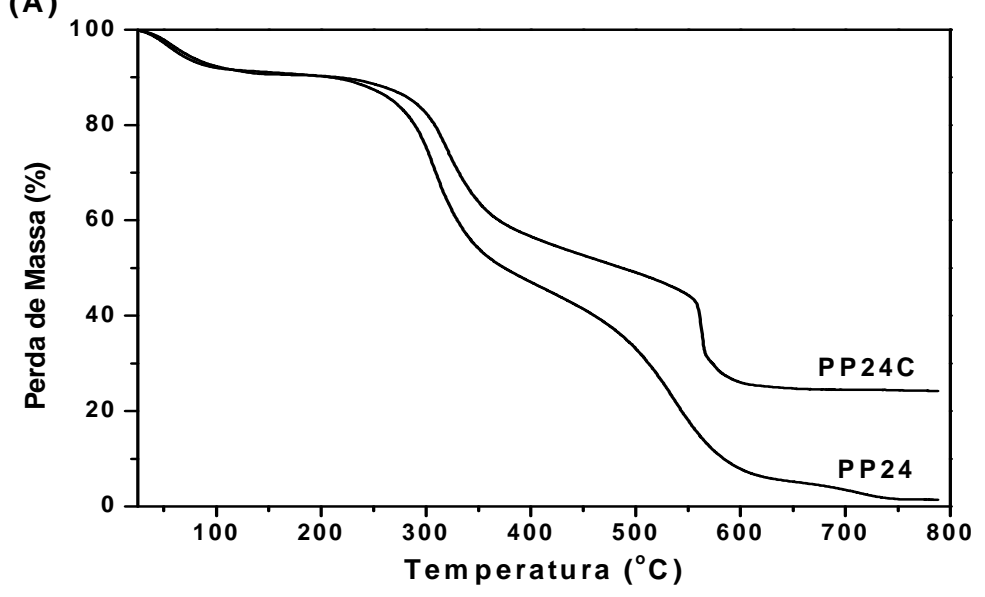

(B)
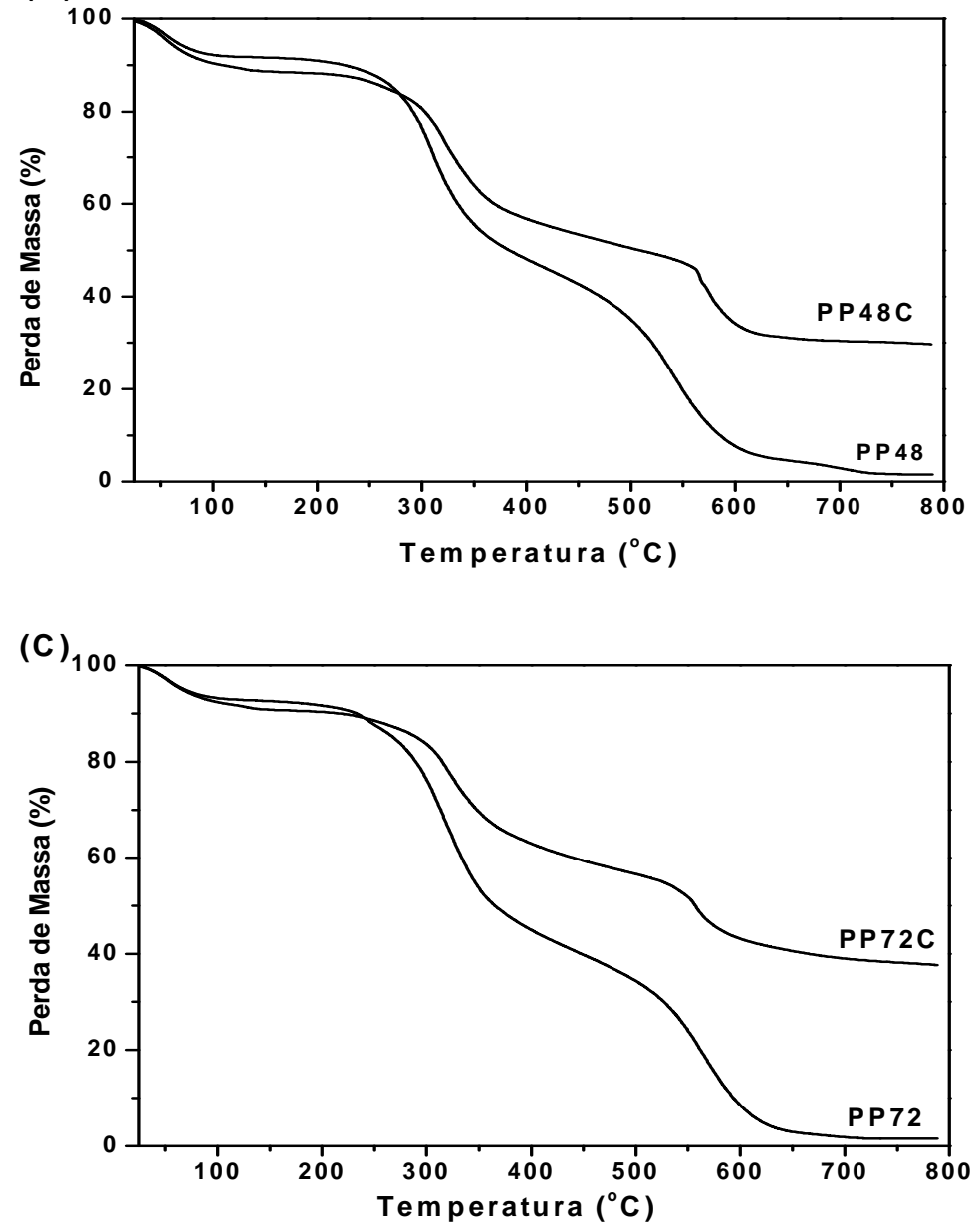

Figura 60. Curvas termogravimétricas das matrizes derivadas de pele porcina hidrolisadas e mineralizadas: (A) 24h, (B) 48h e (C) $72 \mathrm{~h}$. 

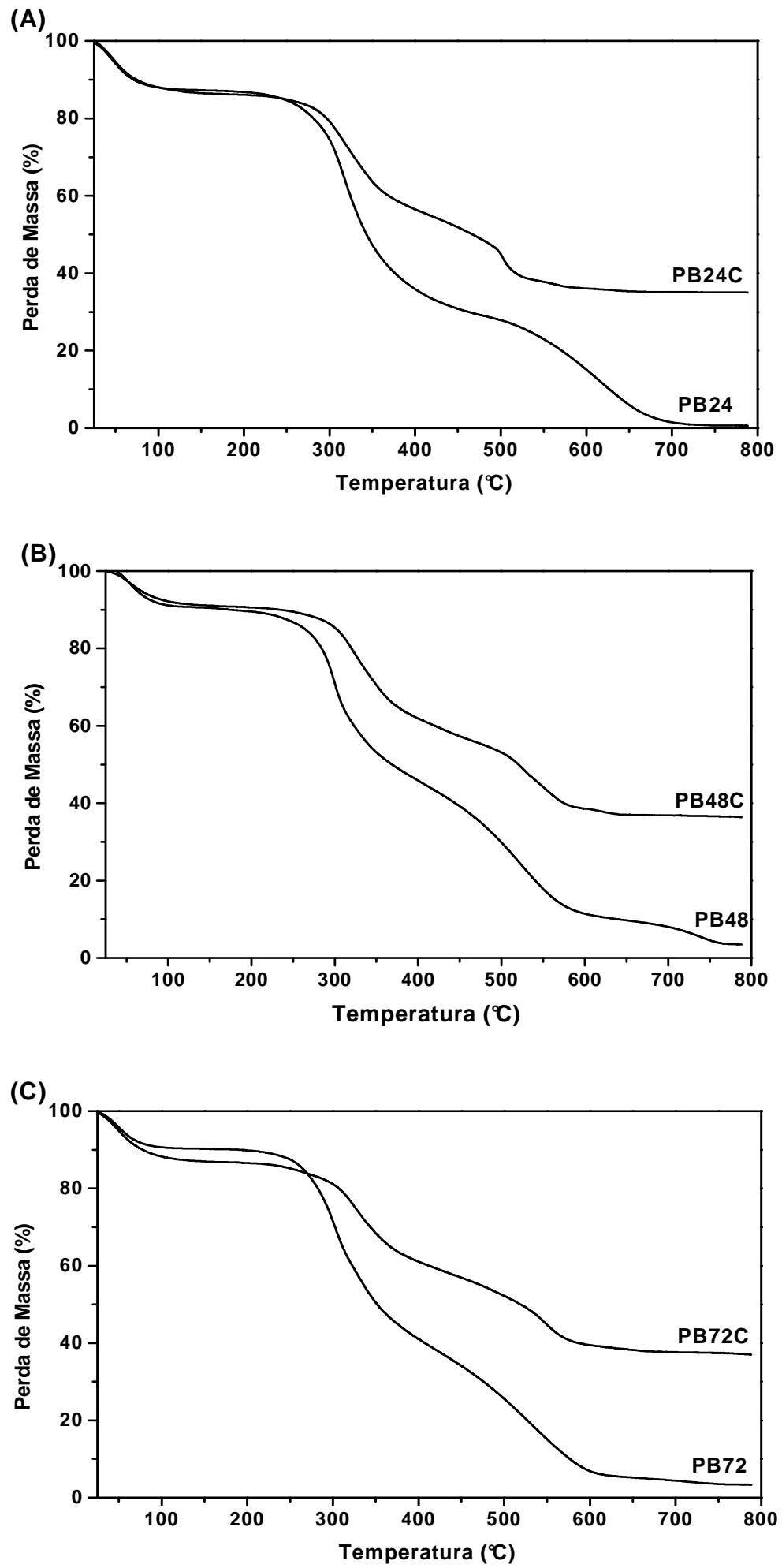

Figura 61. Curvas termogravimétricas das matrizes derivadas de pericárdio bovino hidrolisadas e mineralizadas: (A) 24h, (B) 48h e (C) 72h. 

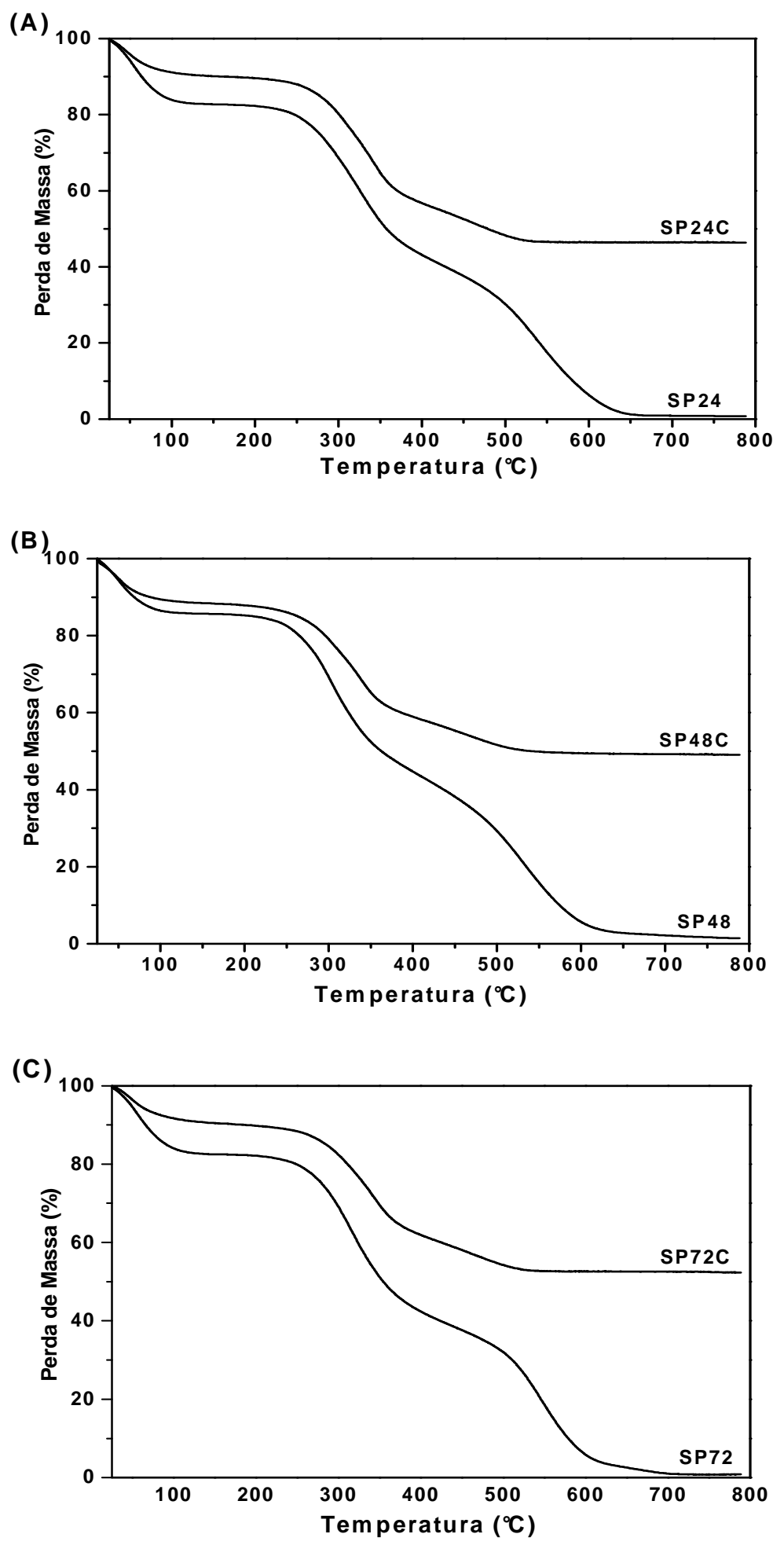

Figura 62. Curvas termogravimétricas das matrizes derivadas de serosa porcina hidrolisadas e mineralizadas: (A) 24h, (B) 48h e (C) $72 \mathrm{~h}$. 


\section{Apêndice 3 - Espectros no infravermelho}

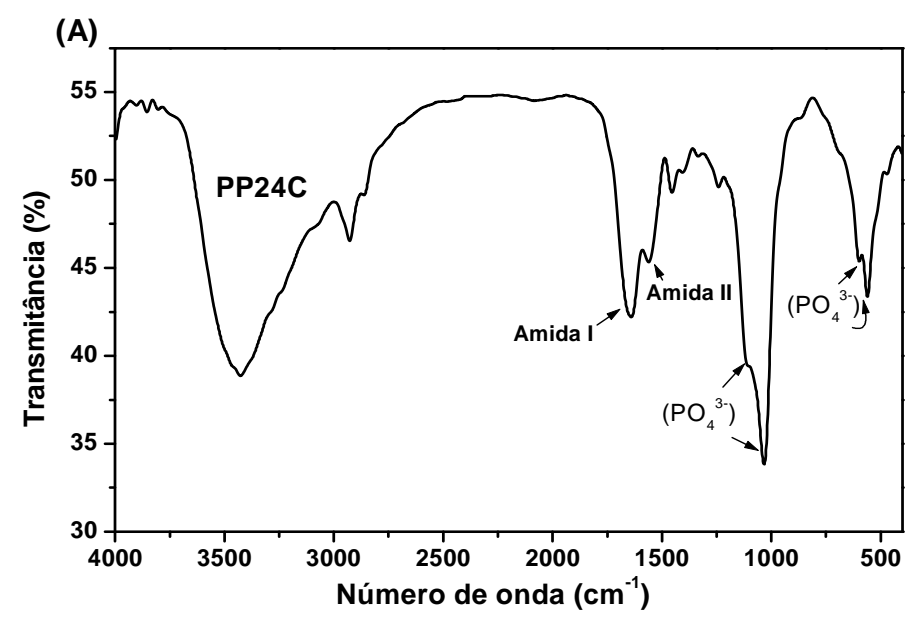

(B)
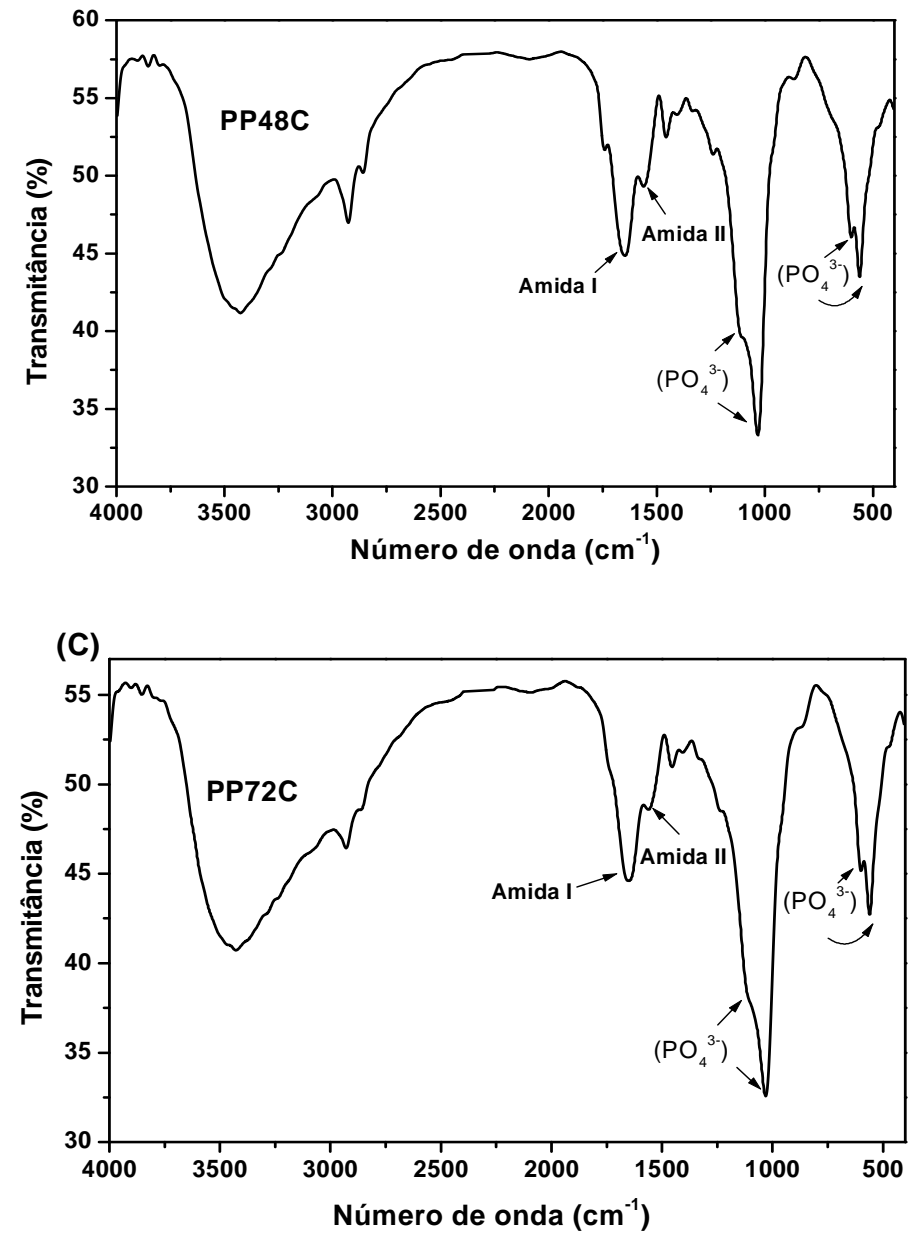

Figura 63. Espectros no infravermelho das matrizes derivadas de pele porcina (A) PP24C, (B) PP48C e (C) PP72C. 


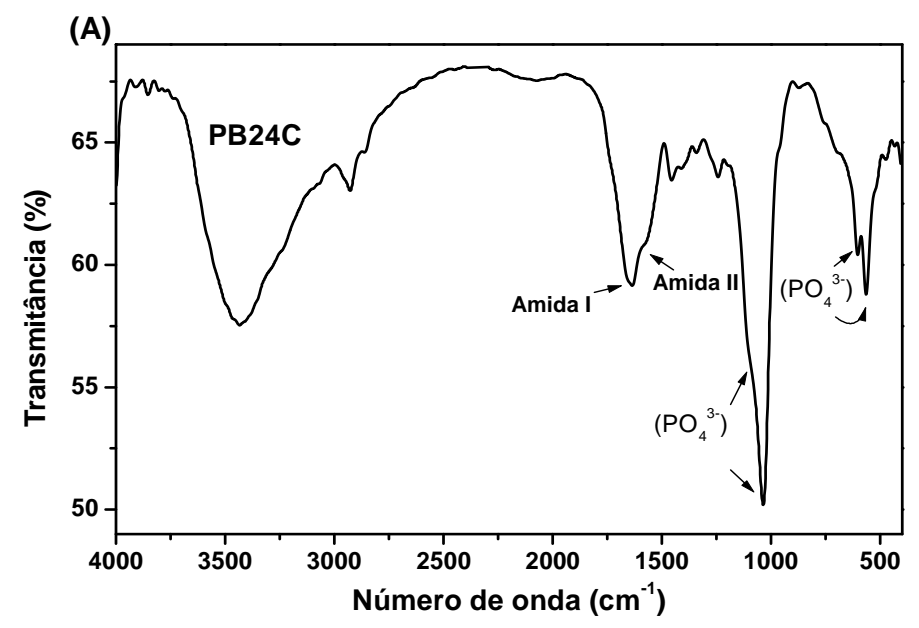

(B)
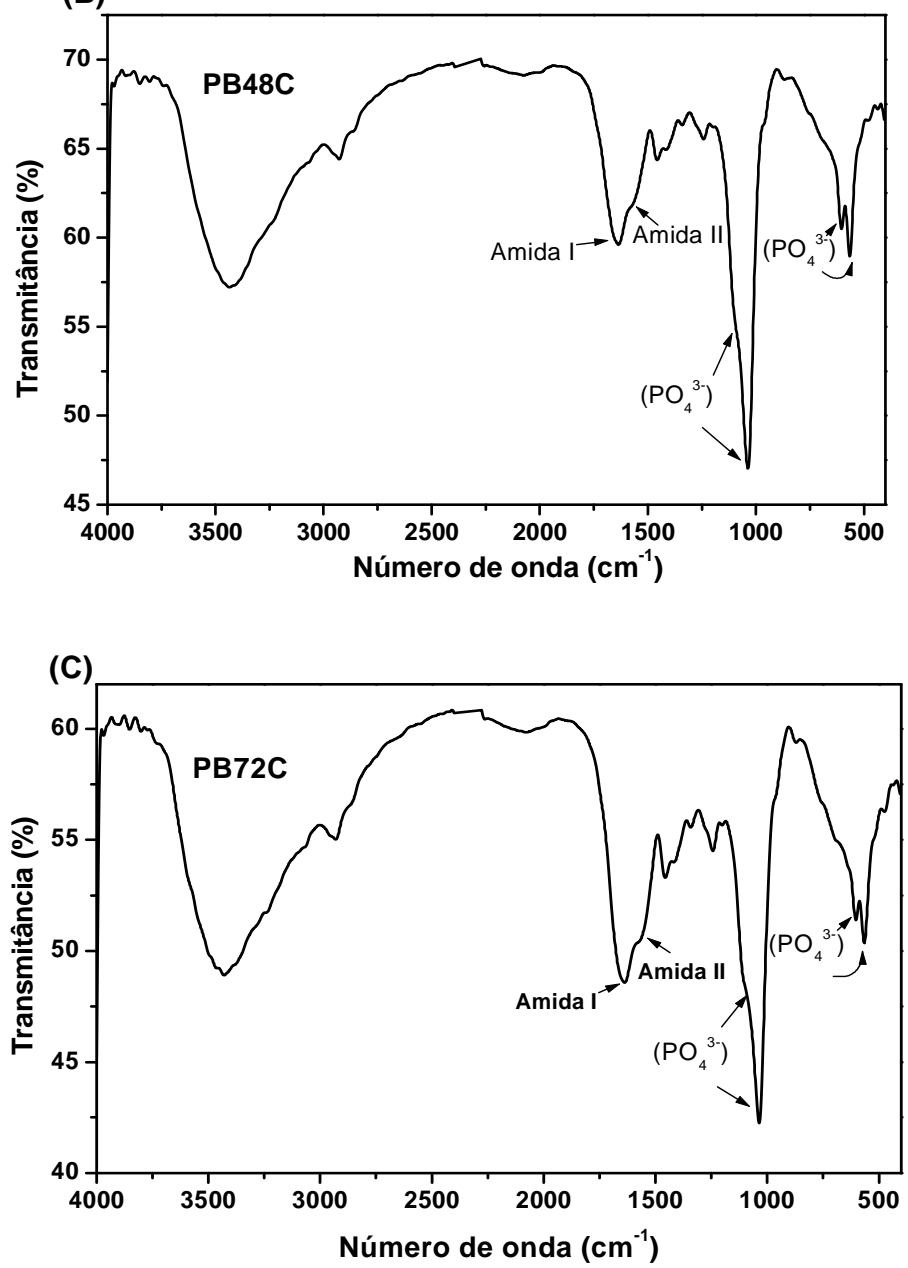

Figura 64. Espectros no infravermelho das matrizes derivadas de pericárdio bovino (A) PB24C, (B) PB48C e (C) PB72C. 


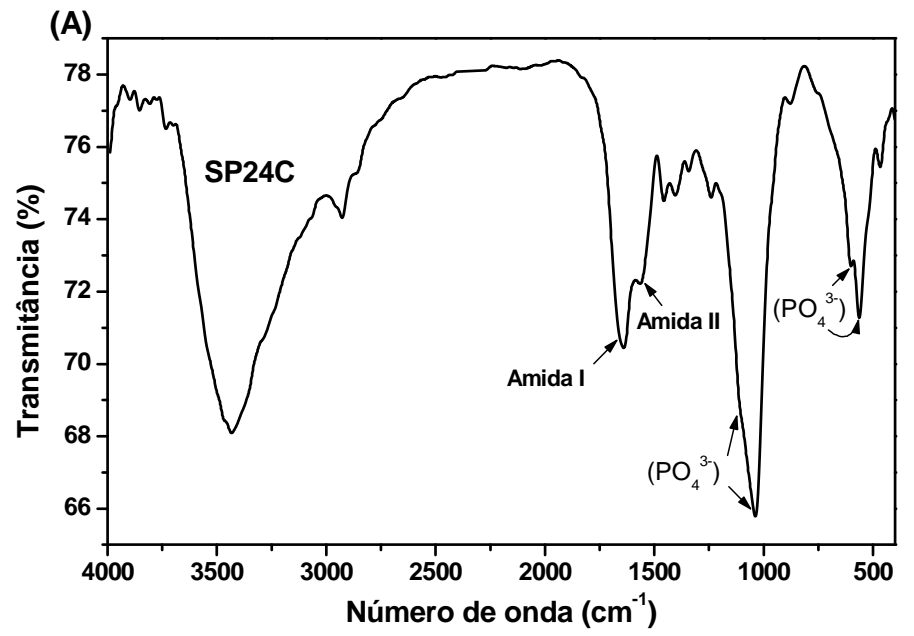

(B)
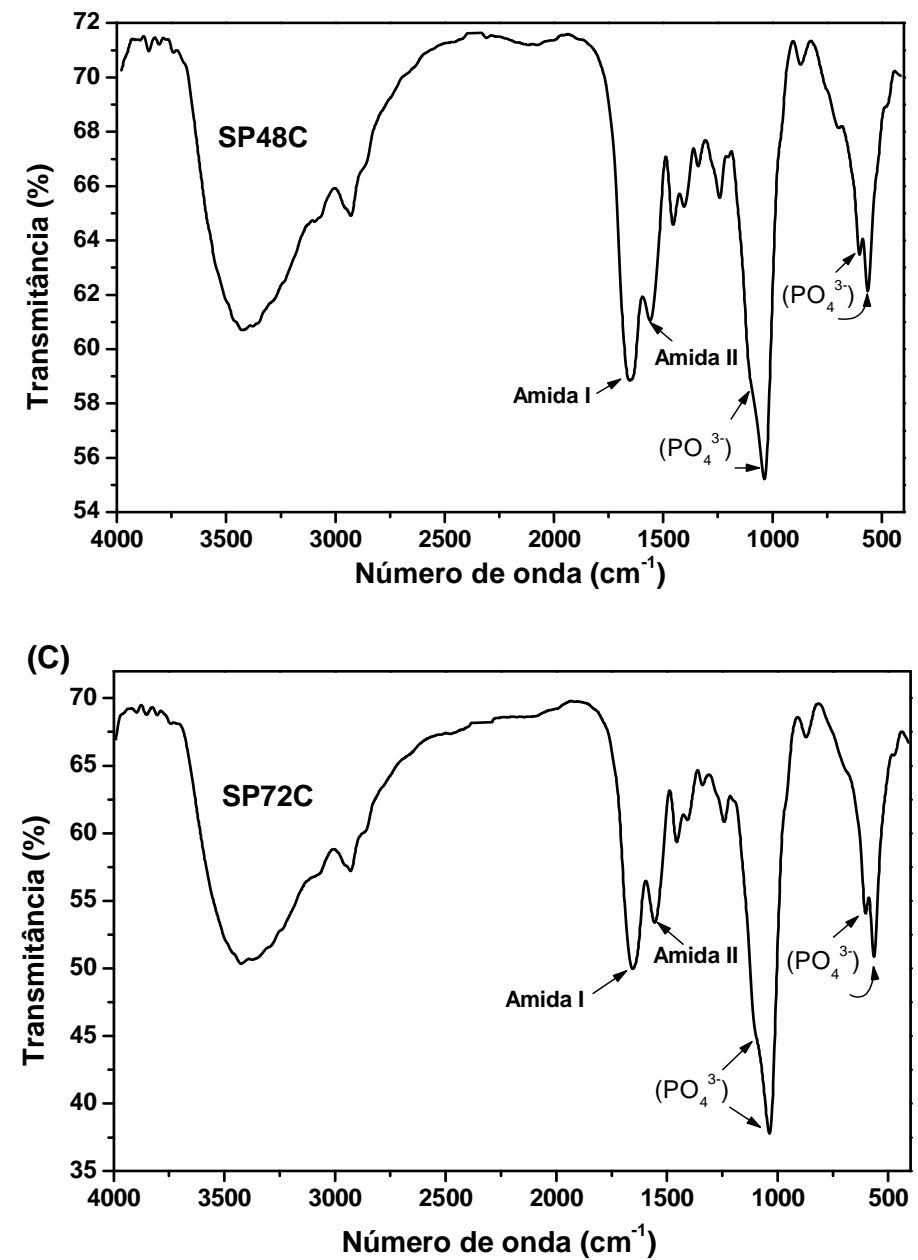

Figura 65. Espectros no infravermelho das matrizes derivadas de serosa porcina (A) SP24C, (B) SP48C e (C) SP72C. 


\section{Anexo I}

Tabela 14 - Composição do meio ISCOVE'S.

\begin{tabular}{|c|c|c|c|}
\hline Componentes & $\mathrm{g} \mathrm{L}^{-1}$ & Componentes & $\mathrm{g} \mathrm{L}^{-1}$ \\
\hline $\mathrm{CaCl} 2$ (anidro) & 0,1653 & L-Fenilalanina & 0,066 \\
\hline MgSO4 (anidro) & 0,09767 & L-Prolina & 0,04 \\
\hline $\mathrm{KCl}$ & 0,33 & L-Serina & 0,042 \\
\hline $\mathrm{KNO}_{3}$ & 0,000076 & L-Treonina & 0,0095 \\
\hline $\mathrm{NaCl}$ & 4,505 & L-Triptofano & 0,016 \\
\hline Selenito de sódio & 0,0000173 & L-Tirosina. $2 \mathrm{Na} .2 \mathrm{H} 2 \mathrm{O}$ & 0,10379 \\
\hline L-Alanina & 0,025 & L-Valina & 0,094 \\
\hline L-Arginina.HCl & 0,084 & D-Biotina & 0,000013 \\
\hline L-Asparagina. $\mathrm{H} 2 \mathrm{O}$ & 0,0284 & Cloreto de Colina & 0,004 \\
\hline L-Ácido Aspártico & 0,03 & Ácido Fólico & 0,004 \\
\hline L-Cisteína.2HCl & 0,09124 & Mio-Inositol & 0,0072 \\
\hline L-Ácido Glutâmico & 0,075 & Niacinamida & 0,004 \\
\hline L-Glutamina & 0,584 & $\begin{array}{l}\text { Ácido D-Pantotenico } \\
\text { (hemicálcio) }\end{array}$ & 0,004 \\
\hline Glicina & 0,03 & Piridoxina. $\mathrm{HCl}$ & 0,004 \\
\hline L-Histidina.HCl.H2O & 0,042 & Riboflavina & 0,0004 \\
\hline L-Isoleucina & 0,105 & Tiamina.HCl & 0,004 \\
\hline L-Leucina & 0,105 & D-Glucose & 4,5 \\
\hline L-Lisina. $\mathrm{HCl}$ & 0,146 & $\begin{array}{l}\text { Sal de Sódio de } \\
\text { Vermelho de Fenol }\end{array}$ & 0,016 \\
\hline L-Metionina & 0,03 & Piruvato de Sódio & 0,11 \\
\hline HEPES & 5,958 & & \\
\hline
\end{tabular}

Fonte: SIGMA-ALDRICH. 